$$
\begin{gathered}
\text { Universidade de São Paulo } \\
\text { Instituto de Química } \\
\text { Programa de Pós-Graduação em Química }
\end{gathered}
$$

Estudo mecanístico da reação de hidrocloração de alquinos não ativados: perspectiva com e sem complexos de ouro(I) 


\section{Estudo mecanístico da reação de hidrocloração de alquinos não ativados: perspectiva com e sem complexos de ouro(I)}

Dissertação apresentada ao Instituto de Química da Universidade de São Paulo para obtenção do Título de Mestre em Ciências (Programa: Química)

Orientador: Prof. Dr. Ataualpa Albert Carmo Braga

São Paulo 
Autorizo a reprodução e divulgação total ou parcial deste trabalho, por qualquer meio convencional ou eletronico, para fins de estudo e pesquisa, desde que citada a fonte.

Ficha Catalográfica elaborada eletronicamente pelo autor, utilizando o programa desenvolvido pela Seção Técnica de Informática do ICMC/USP e adaptado para a Divisão de Biblioteca e Documentação do Conjunto das Químicas da USP

Bibliotecária responsável pela orientação de catalogação da publicação: Marlene Aparecida Vieira - CRB - 8/5562

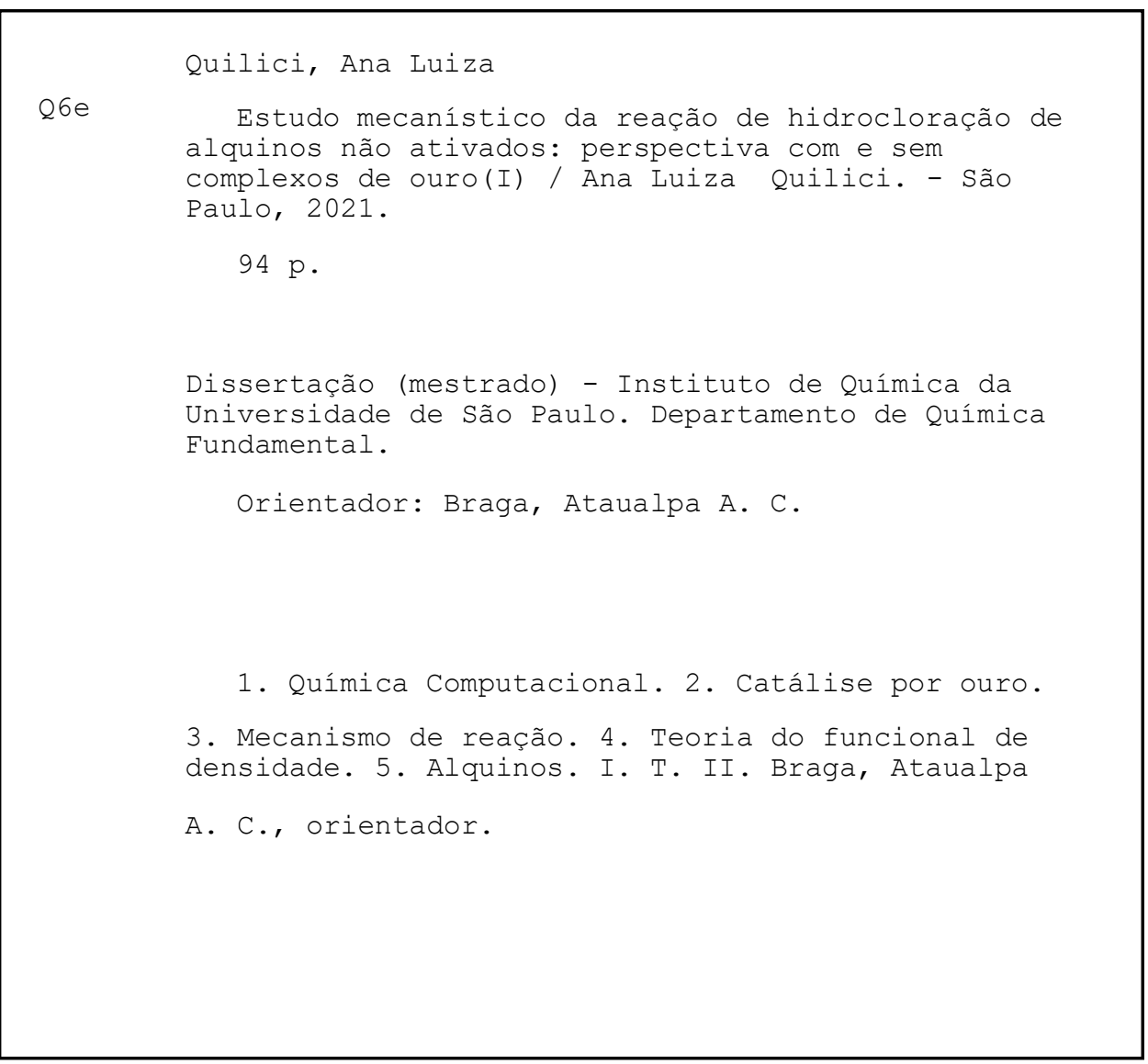




\section{Agradecimentos}

Ser aluna da Universidade de São Paulo foi um sonho que emergiu em mim aos 14 anos. Sendo assim, é uma enorme felicidade fazer parte dessa universidade que se tornou um segundo lar. Sou imensamente grata à USP e ao IQ, pelos anos de ensino, conhecimentos adquiridos, por todas as oportunidades e, sobretudo, pelas excelentes pessoas que conheci ao longo dessa trajetória.

Agradeço ao apoio das agências de fomento: Coordenação de Aperfeiçoamento de Pessoal de Nível Superior (CAPES), Fundação de Amparo à Pesquisa do Estado de São Paulo (FAPESP), e Conselho Nacional de Desenvolvimento Científico e Tecnológico (CNPq), que financiou este trabalho (processo 165633/2018-2).

Agradeço ao prof. Nelson H. Morgon, pela confiança e acolhimento no início do meu mestrado. Agradeço ao prof. Ataualpa, igualmente pela confiança e acolhimento, pelas boas lembranças e bons anos de trabalho. Devo agradecê-lo também por todo o apoio, incentivo, conselhos; por ser essa ótima pessoa, tão compreensiva e que nunca hesitou em ajudar, qualquer que fosse a situação, de todas as formas que estivessem ao seu alcance.

Agradeço a todos os colegas de laboratório, pelos bons momentos e por sempre estarem dispostos a ajudar. Em especial, agradeço a Maurício, por todo o suporte oferecido.

Agradeço a Patrícia e Vandir que, mesmo longe fisicamente, sempre se fizeram presentes; a Célia e Carlos, por todo o carinho e cuidado; a Miguel, pela admirável disposição, dedicação, carinho e apoio.

Agradeço aos que são minhas fortalezas, sempre fontes de muita alegria, amparo e companheirismo: Sinuen, Thaís, Diana, Dafne, Lucas, Martín, Júlia, Thaís Maria, Victor, Henrique, Patrick e Fabiana.

Agradeço à minha família: Rosangela Bacima, Cláudio Roberto, Marco César, Odete, Nadima e Linda. Obrigada por me darem a vida, por sempre terem cuidado tanto de mim e estarem comigo, incondicionalmente. Vocês vivem em mim. 
Para Rosangela e Linda, que me agraciaram com o desejo e amor pelo estudo e pelo conhecimento, possibilitando a concretização deste trabalho. 
Quilici, Ana Luiza. Estudo mecanístico da reação de hidrocloração de alquinos não ativados: perspectiva com e sem complexos de ouro(I), 2021.

\section{Resumo}

A catálise homogênea por complexos de ouro(I) geralmente tem como substrato um alquino e ocorre por meio de uma adição nucleofílica, formando como produto um alqueno de configuração anti. Primeiramente, é feita uma pré-catálise com sais de prata agindo sobre a espécie LAuCl (sendo L um ligante orgânico), que gera o catalisador $\mathrm{LAu}^{+}$ao romper a ligação $\mathrm{Au}-\mathrm{Cl}$. Recentemente, foi reportada a reação de hidrocloração de alquinos por complexos de ouro(I), à temperatura ambiente e recipiente aberto, sem a necessidade da pré-catálise e possivelmente mantendo a ligação $\mathrm{Au}-\mathrm{Cl}$ ao longo de toda a reação, algo que poderia ser viabilizado pela interação entre moléculas de HCl, HFIP (hexafluoroisopropanol) e do catalisador inativo, LAuCl. Posteriormente, um novo estudo, tendo como substrato um bromoalquino, mostrou ser possível a obtenção do alqueno formado como produto na configuração syn, porém sem a presença de catalisadores de ouro (ou qualquer outro metal) no meio reacional. Dessa forma, a presença do centro metálico dirige a regiosseletividade da reação de hidrocloração de alquinos, produzindo apenas os alquenos anti. Com auxílio da Teoria do Funcional de Densidade (Density Functional Theory, DFT), foram estudados neste trabalho os mecanismos de reação, sem ouro e com o catalisador $\mathrm{LAu}^{+}$, de modo a se entender os aspectos principais que dirigem a regiosseletividade da reação de hidrocloração de alquinos, bem como a ativação do catalisador LAuCl. Na frente da regiosseletividade, observou-se como o impedimento estérico proporcionado pelo átomo de bromo determina a formação majoritária do produto syn, cujo estado de transição é $3 \mathrm{kcal} \mathrm{mol}^{-1}$ menos energético que o estado de transição anti. No caso da reação com ouro, é o metal que promove o impedimento estérico à entrada do nucleófilo, direcionando-o à posição anti. Por fim, no que diz respeito à reação catalisada por LAuCl, a molécula de HFIP parece ser decisiva para iniciar a ativação do catalisador, por meio da interação com a ligação tripla.

Palavras-chave: catálise por ouro, DFT, mecanismo de reação, hidrocloração, alquinos, regiosseletividade, impedimento estérico 
Quilici, Ana Luiza. Mechanistic study of hydrochlorination reaction of unactivated alkynes: perspective with and without gold(I) complexes, 2021.

\section{Abstract}

The homogeneous catalysis by gold $(I)$ complexes generally acts in an alkyne as substrate and occurs under a nucleophilic addition, forming the antialkene as the product. First, a pre-catalysis step with silver salts is done, acting on LAuCl specie (where $\mathrm{L}$ is an organic ligand), which generates LAu catalyst when breaking $\mathrm{Au}-\mathrm{Cl}$ bond. Recently, the hydrochlorination reaction of alkynes catalyzed by gold(I) complexes was reported, under room temperature and open air, without the pre-catalysis step and possibly maintaining the $\mathrm{Au}-\mathrm{Cl}$ bond all over the reaction course. This could be feasible by hydrogen bonds between HCl, HFIP (hexafluoroisopropanol) molecules and the inactive catalyst, LAuCl. Later, a new study, using a bromoalkyne as substrate, showed to be possible the alkene obtainment as a syn product, but without the presence of gold catalyst (or any other one). So, the gold presence leads the regioselectivity of the hydrochlorination of alkynes, resulting only the anti product. With Density Functional Theory (DFT), the reaction pathways were studied, with gold (LAu') and without it, aiming to understand the main aspects that drive the regioselectivity in the alkynes hydrochlorination reaction. The activation of $\mathrm{LAuCl}$ catalyst was studied either. In the regioselectivity case, the steric hindrance promoted by bromine atom guides the major formation of syn product, which transition state is $3 \mathrm{kcal}^{\mathrm{mol}}{ }^{-1}$ more stable than the antione. In the gold reaction, the metal is the responsible one for steric hindrance to the nucleophile, directing it to the antiposition. Finally, in the LAuCl catalyzed reaction, HFIP molecule seems to be decisive to initiate the catalyst activation, by its interaction with the triple bond.

Keywords: gold catalysis, DFT, reaction mechanism, hydrochlorination, alkynes, regioselectivity, steric hindrance 


\section{Sumário}

1. Introdução

.11

1.1 Breve história e atualidade da catálise envolvendo ouro...................................................................11

1.2 Mecanismo da catálise homogênea por complexos de ouro(I): adição nucleofílica....................16

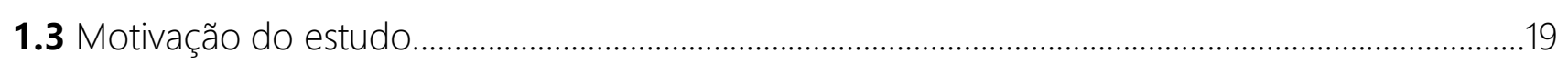

2. Metodologia

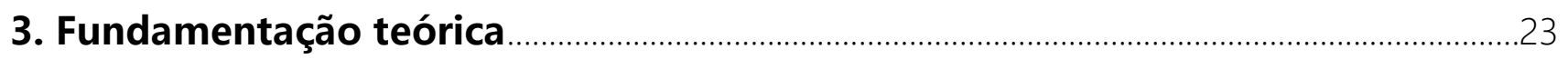

3.1 $\bigcirc$ nascimento da Mecânica Quântica e a equação de Schrödinger................................................23

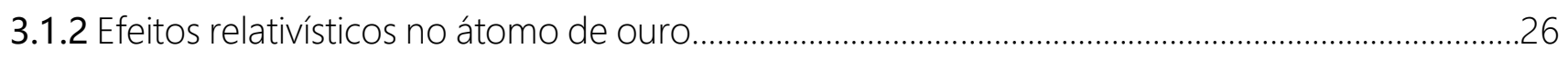

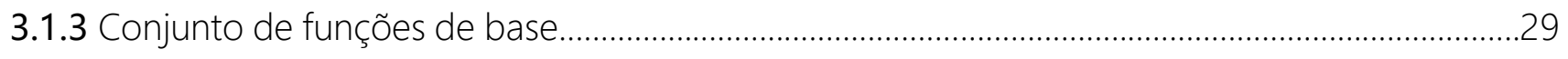

3.1.4 Pseudopotencial e funções de base SDD (Sttutgart-Dresden) ....................................................30

3.2 Métodos ab initio e aproximação de Born-Oppenheimer..............................................................36

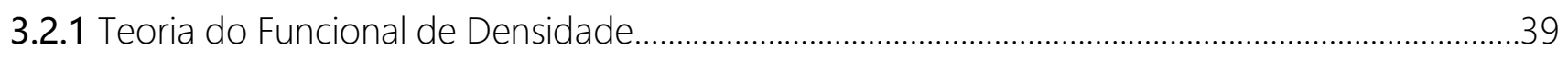

3.3 Superfície de energia potencial e estados de transição..................................................................42

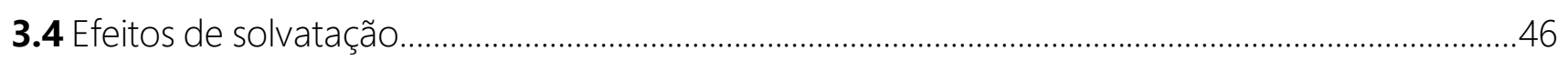

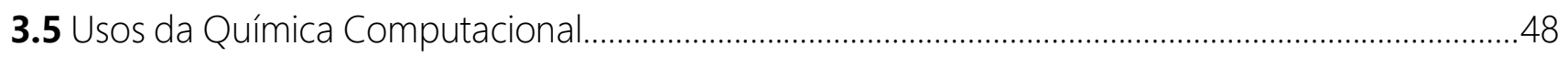




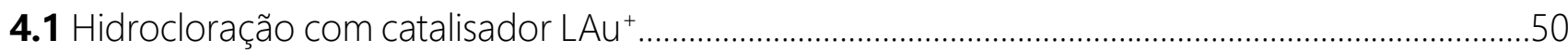

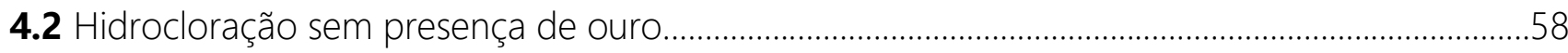

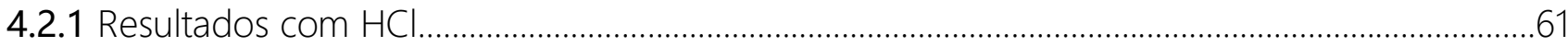

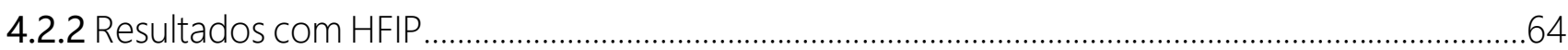

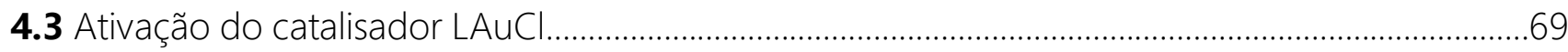

5. Conclusões.

6. Perspectivas

7. Referências 


\section{Introdução}

\subsection{Breve história e atualidade da catálise envolvendo ouro}

O ouro é um metal de coloração amarelada, encontrado, sobretudo, no mineral quartzo, mas também em rochas e pepitas. Seus principais estados de oxidação, os mais abundantes e estáveis, são o +1 e o +3, embora exista também sob as formas + 5 e -1.1-3 Em seu estado neutro, apresenta configuração eletrônica [Xe]4 $f^{14} 5 d^{10} 6 s^{1}$ e, apesar de o átomo ter o subnível $d$ completo, seus cátions possuem esse orbital incompleto, caracterizando o ouro como um metal de transição. É pouco abundante na crosta terrestre, equivalendo a 0,004 ppm (g.ton ${ }^{-1}$ ) - a título de comparação, o oxigênio, elemento químico mais abundante, ocorre em 455,000 ppm. ${ }^{1}$

No decorrer da existência humana, o ouro tem despertado fascínio por sua beleza. Em diversos momentos da história, foi considerado um metal valioso, extensamente usado para variados fins, nas mais diferentes culturas. Em algumas, como a egípcia e a dos povos pré-colombianos (astecas, maias e incas), possuía caráter simbólico religioso, estando ligado à imortalidade 4,5 - a famosa máscara mortuária do faraó Tutancâmon é feita inteiramente de ouro maciço. ${ }^{6}$ Dentro do sistema capitalista, fez parte do primeiro sistema monetário internacional, o padrão-ouro, em vigor de 1880 a 1914.4,7,8 Ainda hoje possui atuação ativa na economia, tendo se tornado uma forma de investimento $^{1,4,9}$ e movimentando o mercado de fabricação e comércio de joias. ${ }^{1,4}$ É também aplicado atualmente como componente de dispositivos eletrônicos (sendo tão utilizado para esse fim que é um negócio lucrativo recuperá-lo e reciclá-lo).4,6

A já mencionada máscara do faraó é uma prova da estabilidade e durabilidade do ouro como matéria prima: feita há mais de 3000 anos, ${ }^{6}$ permanece intacta. Justamente pela baixa reatividade de sua estrutura metálica, o ouro recebe a designação de metal nobre, não reagindo com o oxigênio presente no ar (tampouco com enxofre, responsável pelo escurecimento da prata). ${ }^{1}$ No entanto, o átomo de ouro pode produzir compostos com elementos de ametais - em especial, carbono, fósforo, oxigênio e cloro -, o que possibilita uma vasta, rica e eficiente reatividade que define um importante alicerce da atividade catalítica que o ouro exerce. ${ }^{10-14}$ Outras características de reatividade do átomo de ouro relevantes à catálise são: a forte ligação entre o ouro e o ligante, 
no caso da formação de compostos de coordenação; baixa tendência de sofrer oxidação; maior moleza e menor nucleofilicidade; e seu forte caráter de ácido de Lewis, o que explica a ativação dos elétrons $\pi$ de insaturações (tanto $\mathrm{Au}^{1+}$ quanto $\mathrm{Au}^{3+}$ ). 2,15,16

A catálise por ouro, tanto homogênea, quanto heterogênea, vem sendo amplamente estudada, experimentalmente, ao longo de décadas passadas. Seu desenvolvimento passou desde a crença de que o ouro era um metal inerte, sem nenhuma utilidade em catálise e síntese orgânica, até seus primeiros usos, nas décadas de 1970 e 80.10,11,13,17

Em 1973, Bond et al. produziram uma hidrogenação de alquenos, dienos e alquinos suportada em ouro, configurando tal reação como a primeira catálise heterogênea com ouro. ${ }^{18}$ Treze anos mais tarde, em 1986, Ito et al. reportaram a primeira catálise homogênea com Au(I), uma reação aldoólica entre isocianato e aldeídos, catalisada por um complexo cujo ligante era uma fosfina. ${ }^{19}$

Posteriormente, notáveis formas de catálise com ouro foram desenvolvidas: no que diz respeito à catálise heterogênea, destacaram-se a hidrocloração de acetileno para produção de cloreto de vinila (prevista em 1985 e feita experimentalmente em 1988)20-24 e a oxidação de CO a baixas temperaturas (1987), ${ }^{25}$ processo de grande importância ambiental, dado que o CO é um poluente atmosférico, tóxico aos seres vivos. Nas duas situações, o ouro se mostrou o melhor catalisador, um diferencial. ${ }^{11}$ No caso da hidrocloração, ainda houve a vantagem de o catalisador de ouro entrar em substituição ao tóxico cloreto de mercúrio, usado até então. ${ }^{21}$ Em 1998, foi reportada a primeira catálise homogênea por complexos de ouro(I) envolvendo a ativação da ligação tripla de um alquino ${ }^{26}$ - hoje, tais compostos de ouro catiônico ( $\mathrm{LAu}^{+}$, em que $\mathrm{L}$ é um ligante orgânico) se consolidaram como a principal forma homogênea de ativação eletrofílica de alquinos. ${ }^{10}$

Assim, nos anos 2000, teve início o que ficou conhecido como "a corrida catalítica do ouro" (catalytic gold rush), quando se iniciaram diversas pesquisas visando desenvolver processos catalíticos eficientes tendo o ouro como principal centro metálico.11,14,27

Atualmente, em se tratando da catálise heterogênea, o ouro continua sendo o melhor catalisador para a hidrocloração de acetileno..22,28 Dessa forma, uma recente, porém relevante utilização industrial da catálise heterogênea por ouro é a produção de cloreto de vinila, ${ }^{29}$ que, ao sofrer polimerização, constitui o policloreto de vinila (poliviny/ chloride, PVC), plástico amplamente utilizado pela indústria para produzir, por exemplo, materiais médicos e para construção civil e encanamento; papel filme para alimentos; móveis; dispositivos elétricos e eletrônicos; entre muitas outras aplicações em que o PVC está presente. ${ }^{30-32}$ 
Quanto à catálise homogênea com ouro, processo no qual catalisador e substrato encontram-se no mesmo estado físico e ocorrendo geralmente em fase condensada, ${ }^{17}$ a relevância reside na química organometálica e síntese orgânica, ${ }^{10,11,13,17,33}$ que possui como área de grande interesse produzir, seletivamente, novas ligaç̃̃es C-C ou C-heteroátomo entre dois fragmentos orgânicos. ${ }^{34}$ O principal mecanismo que permite a formação dessas ligações é o acoplamento cruzado organometálico, que, de maneira geral, consiste em três etapas - adição oxidativa, transmetalação, e eliminação redutiva -, principais etapas elementares da química organometálica (Figura 1). Como os nomes sugerem, há mudança do estado de oxidação do catalisador metálico ao longo do mecanismo, que se inicia com a oxidação do metal pelo substrato (um eletrófilo) na formação da ligação metal-substrato, configurando a etapa de adição oxidativa. O ciclo catalítico se fecha com a redução do metal e consequente regeneração do catalisador, caracterizando a eliminação redutiva. ${ }^{13,33-35}$

\section{Produto de acoplamento cruzado}

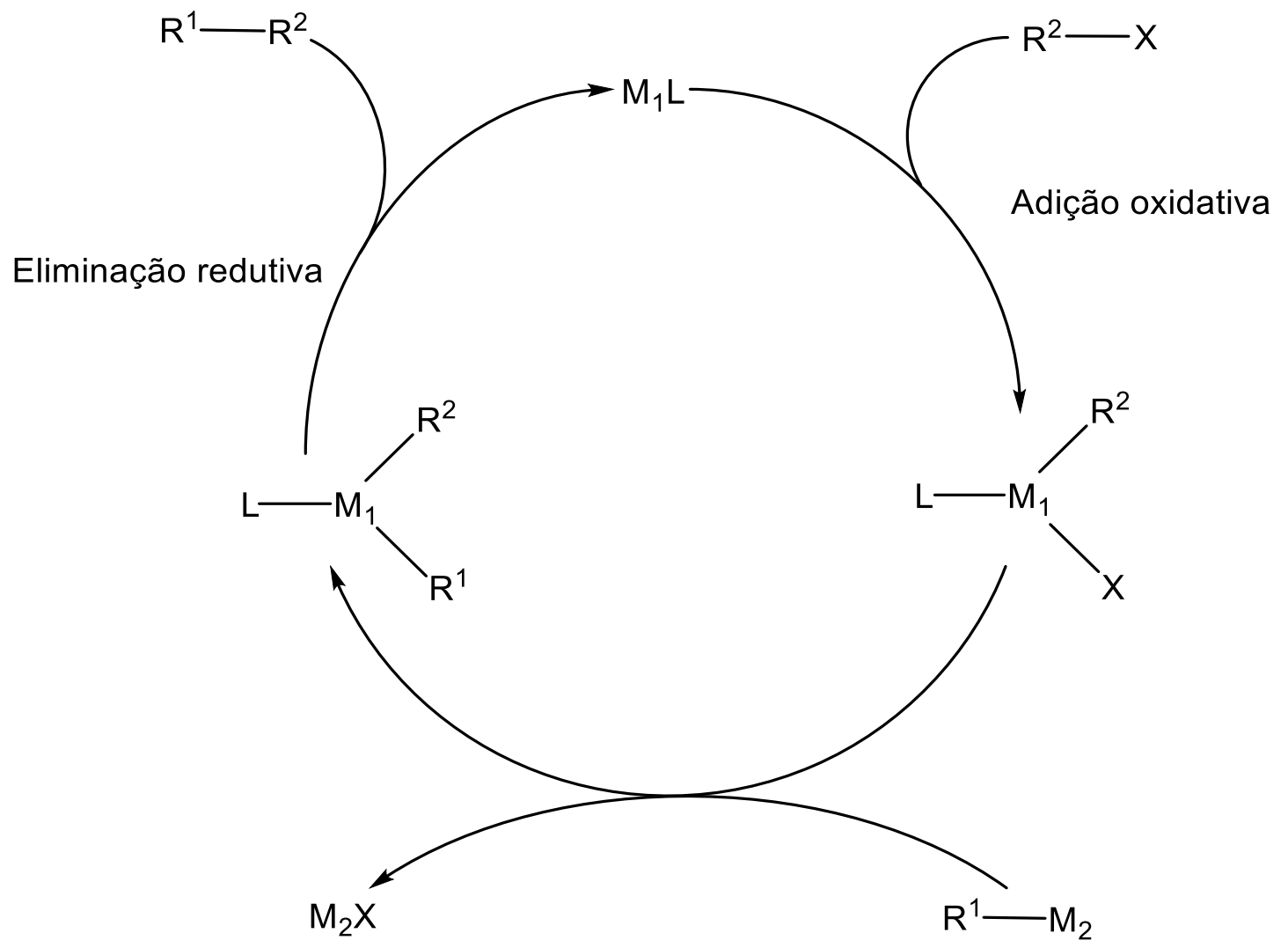

Transmetalação

Figura 1. Mecanismo geral de uma reação de acoplamento cruzado. $M_{1} L$ é o catalisador metálico e o substrato eletrófilo é a espécie $R^{2} X$. $M_{1}$ é o metal que sofre oxidação, $L$ é o ligante, $R^{1}$ e $R^{2}$ são porções orgânicas, $X$ é um halogênio ou sulfonato, e $M_{2}$ é outro metal inserido no meio reacional. ${ }^{35}$ 
O ouro possui alto potencial de oxidação, o que dificulta a participação desse metal como catalisador nas reações de acoplamento cruzado - o paládio, metal frequentemente usado nesse tipo de reação, possui potencial redox de 0,92 $\vee\left(\mathrm{Pd}^{0} / \mathrm{Pd}^{2+}\right)$; já o par $\mathrm{Au}^{1+} / \mathrm{Au}^{3+}$ apresenta potencial de 1,41 V.13,15-17,33,35-37 Contudo, proporcionadas certas condições, o ouro pode reagir por esse mecanismo, por exemplo, com a introdução de um forte oxidante no meio reacional; $13,33,35-37$ ou, para se evitar essa estratégia, utiliza-se radiação UV (fotocatálise). 13,37 Ainda, a partir da presença de paládio na etapa de transmetalação, pode-se gerar um organo-ouro in situ, 35,38 atuando como intermediário e dando prosseguimento à etapa final do mecanismo (eliminação redutiva). Assim, é obtida uma molécula composta por duas porções orgânicas, onde reside a nova ligação C-C, configurando-a como o produto de acoplamento cruzado.

Portanto, o ouro, junto com paládio, níquel, entre outros, faz parte dos metais de transição capazes de reagir via acoplamento cruzado organometálico, imprescindível na obtenção de novas moléculas orgânicas complexas de interesse tecnológico e econômico. ${ }^{34}$

Tendo em vista a reação de hidrocloração de alquinos, o produto obtido é um cloroalqueno, composto de importante uso em síntese orgânica: em conjunto com um alqueno/arila e sob a presença de compostos de coordenação com níquel ou paládio como centro metálico, possibilita a formação de novas ligações C-C via reação de Heck (ou Heck-Mizoroki) - um tipo de reação de acoplamento cruzado. ${ }^{33,39}$ Nessa reação, não há a etapa intermediária de transmetalação, mas sim a etapa conhecida como inserção migratória, na qual o ouro também pode participar. ${ }^{33}$

Dessa forma, a catálise homogênea com ouro se edifica sobretudo na ativação dos elétrons $\pi$ e nas etapas elementares dos mecanismos de acoplamento cruzado, 33,37 e ocorre, majoritariamente, pelo $\mathrm{Au}(\mathrm{I}),^{13}$ embora possa ocorrer também sob o estado Au(III). 14,33,37

Nas duas formas de catálise realizada pelo ouro, observa-se a possibilidade de se obter o produto segundo um mecanismo altamente seletivo, ${ }^{17,29,40}$ que se traduz em excelentes quimio, regio e estereosseletividades, 11,13,40 além de ocorrerem em condições brandas - baixas temperatura, pressão e quantidade de catalisador e substrato $-{ }^{16,17,40}$ sendo tolerantes ao oxigênio presente no ar ${ }^{29,41}$ e oferecendo uma boa versatilidade: são utilizadas em uma gama muito ampla de reações. 11,13,16,27,41 Tais características fazem a catálise por ouro ser atrativa industrialmente. 29,41,42

Outra vantagem do uso do ouro na catálise diz respeito ao enfoque ambiental: os princípios da Química Verde são cumpridos. ${ }^{43,44}$ Alguns deles são: o uso de oxidantes verdes; ${ }^{43}$ boa economia de átomos (maior incorporação possível dos átomos envolvidos na reação ao produto de interesse $\left.{ }^{45}\right)$, o que reduz o desperdício; 16,44 reações passíveis de ocorrer em temperatura 
ambiente $16,43,44$ e em solventes mais verdes e seguros, ${ }^{43,44}$ como a água, também podendo produzila como produto secundário. 15,13,29,43 Considerando a oxidação do metano em metanol (outro processo de suma importância ambiental) via fotocatálise com nanofolhas de ouro, a água atua como um catalisador ${ }^{46}$ e, novamente, a catálise é seletiva e se dá em condições brandas. Em sua forma metálica, o ouro é biocompatível: ${ }^{44,47}$ em contato com tecidos animais, não causa nenhuma reação adversa, não sendo tóxico, ${ }^{17,48}$ portanto, e evitando problemas de cunho ambiental. ${ }^{29,44}$

Assim, o ouro consiste em uma alternativa verde tanto para pesquisas quanto para produção em larga-escala, por exemplo, frente aos metais catalisadores usados nas indústrias petroquímica e automobilística. ${ }^{13}$

Na área da saúde, o ouro também possui seu destaque. Como a nobreza garante a biocompatibilidade (novamente, na sua forma metálica), é um metal que, diferentemente de outros - tais como níquel e cobre -, não provoca alergias;47,48 é usado na odontologia ${ }^{47}$ e os complexos de ouro(I) têm uma relevante atuação em medicina para os tratamentos de artrite reumatoide e câncer. ${ }^{47,49}$ No caso do último quadro clínico, o tratamento com ouro pode ocorrer também sob a forma de nanopartícula. ${ }^{28}$

Outro tópico em que o ouro apresenta seu valor é a síntese de produtos naturais ${ }^{10}$ - compostos orgânicos produzidos pelo metabolismo de quaisquer tipos de organismos vivos que possuem funcionalidades interessantes à vida humana, ${ }^{50}$ sendo úteis, por exemplo, para o tratamento de doenças e para as indústrias farmacêutica e de agroquímicos. ${ }^{51,52}$

O preço do ouro apresenta-se como principal desvantagem, e pode se tornar fator limitante para seu uso industrial em certos casos. ${ }^{29}$ Entretanto, há outros metais frequentemente usados em catálise, como a platina, ${ }^{53}$ que, em determinados momentos e contextos econômicos, pode chegar a ser mais cara que o ouro. ${ }^{27,54}$ Logo, apesar do preço, o custo-benefício justifica o uso do ouro como catalisador, pois há diversas e importantes vantagens e aplicações.

Por fim, a catálise por ouro é uma área em contínuo crescimento, que ainda não encontrou seu limite: permanecem em aberto possibilidades a serem exploradas. ${ }^{55}$ 


\subsection{Mecanismo da catálise homogênea por complexos de ouro(I): adição nucleofílica}

O mecanismo pelo qual a catálise homogênea com Au(l) ocorre é o de adição nucleofílica. 10,11,40,47,56,57 Para tanto, o catalisador $\mathrm{LAu}^{+}$é gerado in situ, usualmente pela pré-catálise da espécie LAuCl com sais de prata (Figura 2). ${ }^{58}$ Os ligantes orgânicos (L) geralmente usados são as fosfinas (tais como as ilustradas na Figura 3) e carbenos heterocíclicos de nitrogênio ( $N$ Heterocyclic Carbene, NHC) ${ }^{10,40}$ Os sais de prata atuam rompendo a forte ligação entre o átomo de ouro e o de cloro, promovendo, assim, a saída do cloreto e deixando o complexo catiônico de ouro. ${ }^{58}$

$$
\mathrm{LAuCl}+\mathrm{AgX} \longrightarrow \mathrm{LAu}^{+}+\mathrm{X}^{-}+\mathrm{AgCl} \downarrow
$$

Figura 2. Obtenção de ouro catiônico ( $\mathrm{LAu}^{+}$, sendo $\mathrm{L}$ um ligante orgânico) com sais de prata (AgX, em que $X$ é o contra-íon, tal como OTf, $\left.\mathrm{SbF}_{6}\right){ }^{58}$

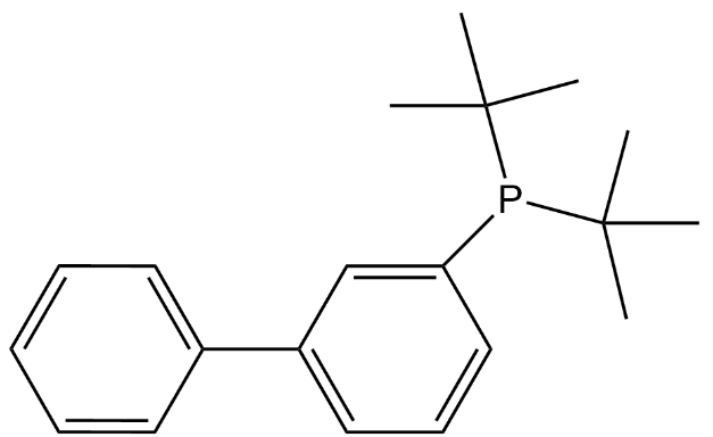

1<smiles>CC(C)c1cc(C(C)C)c(-c2ccccc2P(c2ccccc2)c2ccccc2)c(C(C)C)c1</smiles>

\section{2}

2-(Diphenylphosphino)-2', 4',6'-triisopropylbiphenyl

JohnPhos

(2-Biphenylyl)di-tert-butylphosphine

Figura 3. Exemplos de fosfinas usadas na catálise homogênea com ouro. ${ }^{59}$ 
Tendo a espécie ativa, $\mathrm{LAu}^{+}$, a catálise via adição nucleofílica ocorre, primeiramente, com a ativação do alquino (Figura 4). O ouro catiônico, com alta tendência de se ligar a elétrons fracamente ligados - como elétrons $\pi$ de insaturações, ${ }^{58}$ que se configuram como uma região nucleofílica -, se coordena ao alquino através da ligação tripla, caracterizando um ataque eletrofílico e formando o complexo $\pi(\mathbf{A})$. Dessa forma, o complexo se torna vulnerável ao ataque de um nucleófilo, que rege o mecanismo da reação e, assim, uma nova estrutura $\mathbf{( B H})$ se forma, com posterior liberação de um próton (B). Esse, ao ser protonado, leva à formação do alqueno anti $(\mathbf{P}$, produto de Markovnikov) e à regeneração do catalisador, fechando o ciclo catalíitico com a obtenção de LAu+. Não há mudança do estado de oxidação ao longo do mecanismo ${ }^{37} \mathrm{e}$ as espécies de Au(III) também ativam insaturações, com o nucleófilo adicionado em posição antiao átomo de ouro. 14-16,37

Além dos alquinos, outros substratos em que os complexos de ouro(I) podem atuar são os alquenos, alenos, eninos, ésteres propargílicos, entre outros, ${ }^{10,40,58}$ que também reagem via adição nucleofílica ou adição oxidativa. ${ }^{11,13}$

Ainda que, via de regra, a adição nucleofilica promovida por complexos de ouro resulte no produto anti, há exceções documentadas da geração do produto syn, ${ }^{60}$ por exemplo, no caso dos norbornenos como substrato. $11,40,47,61$ 


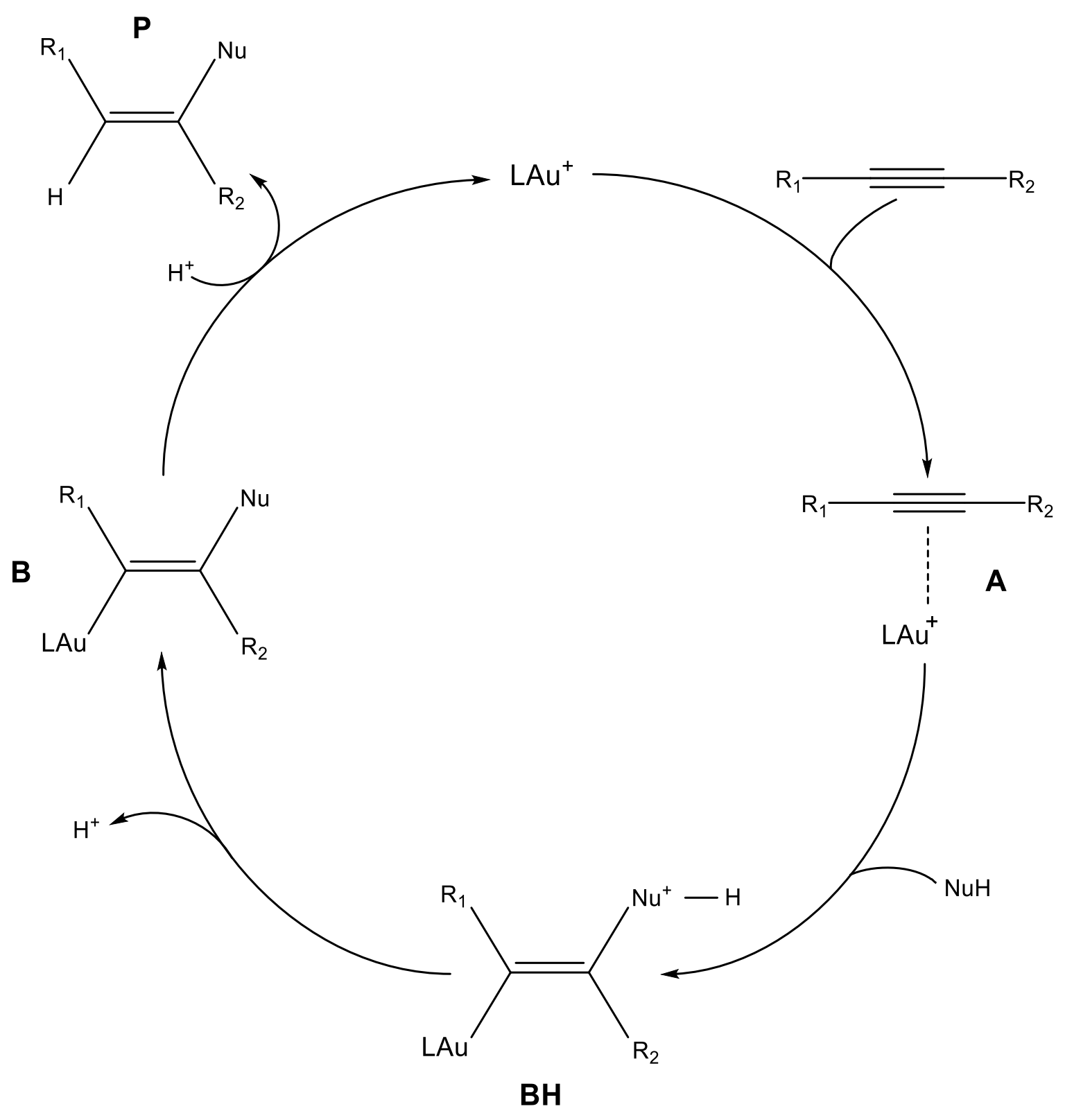

Figura 4. Mecanismo geral de adição nucleofilica proporcionado pela catálise homogênea de complexos de ouro(I), tendo alquinos como substrato e gerando o produto anti. L é o ligante orgânico, $R_{1}$ e $R_{2}$ são porções orgânicas ou H, e NuH é um nucleófilo, ainda ligado ao átomo de hidrogênio 


\subsection{Motivação do estudo}

A etapa da pré-catálise com sais de prata, ainda que comumente usada na catálise homogênea por ouro catiônico, 43,58,59,62-64 envolve algumas desvantagens: os sais de prata são higroscópicos e sensíveis à luz, o que dificulta seu manuseio; aumentam o custo total do processo e diminuem a economia de átomos. ${ }^{43}$

Ademais, não há consenso na literatura sobre os efeitos da prata na catálise por ouro. Há estudos que suportam que a prata interage com o ouro e o cloreto, formando espécies estranhas à catálise e podendo afetar a eficiência e seletividade da mesma, além de causar reações paralelas e gerar subprodutos ${ }^{62-64}$ - algo que, novamente, não está alinhado aos princípios da química verde.

Apesar de já existirem protocolos sem o uso dos sais de prata e que também geram a espécie $\mathrm{LAu}^{+}, 43,58$ é sempre interessante buscar novas alternativas que poderiam proporcionar o processo catalítico sem a necessidade de sais de prata, o que foi reportado recentemente por Xu e colaboradores no estudo da hidrocloração de alquinos catalisada por complexos LAuCl (Figura 5). ${ }^{59}$ Nesse trabalho, não houve o uso de sais de prata promovendo a pré-catálise e, provavelmente, não ocorreu o rompimento da ligação $\mathrm{Au}-\mathrm{Cl}$. Como não haveria a presença de $\mathrm{LAu}^{+}$, os autores sugerem que o catalisador seria ativado por ligações de hidrogênio, formando, inicialmente, um complexo de ligação de hidrogênio entre $\mathrm{HCl}$ e o solvente HFIP (A', Figura 6). Posteriormente, esse complexo se ligaria ao átomo de cloro do catalisador inativo, LAuCl, alongando a ligação $\mathrm{Au}-\mathrm{Cl}$ e formando um novo complexo (B'), que seria o catalisador ativo (Figura 6). Os produtos obtidos foram, exclusivamente, de configuração anti.
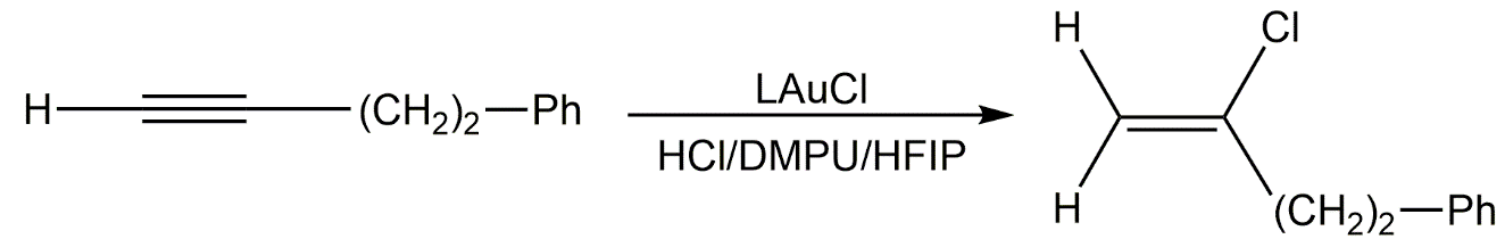

Produto anti

Figura 5. Reação de hidrocloração de alquino catalisada por complexos de Au(I). ${ }^{59}$ 

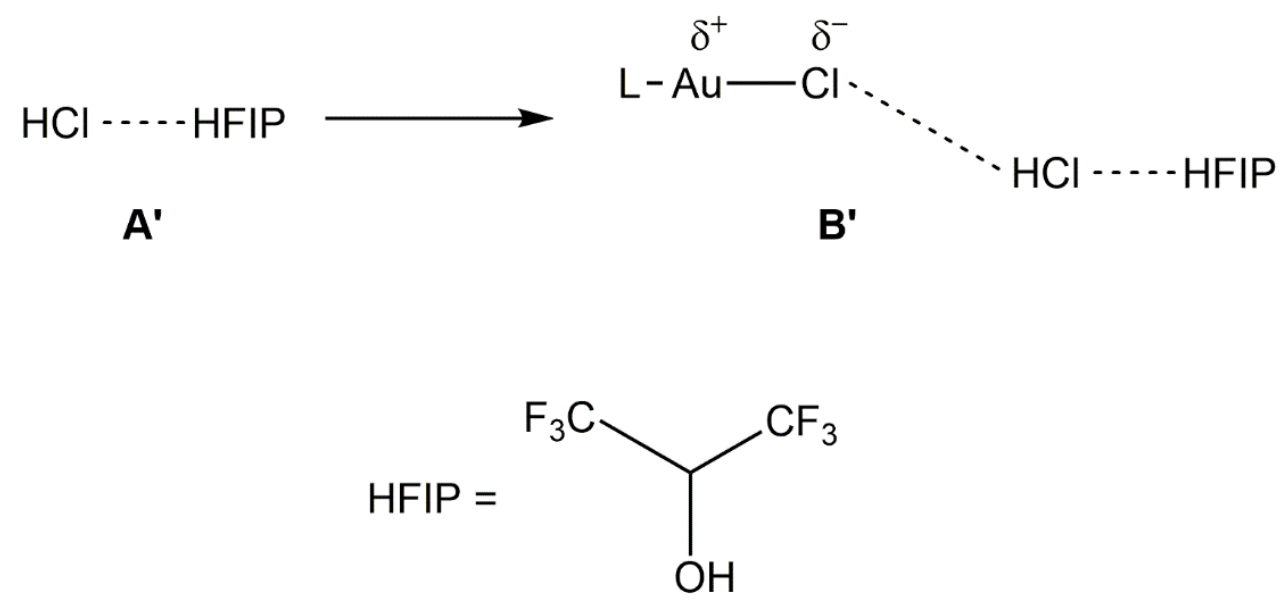

Figura 6. Complexos de ligação de hidrogênio, que seriam responsáveis pela ativação do catalisador $\mathrm{LA} u C I$ na reação de hidrocloração de alquinos sem a presença de sais prata. ${ }^{59}$

Entretanto, a literatura recente sugere que a hidrocloração de alquinos também resulta, majoritariamente, no produto de configuração syn. ${ }^{65}$ A ligação tripla seria rompida para formar uma dupla, porém, sem a presença de catalisadores de ouro ou qualquer outro metal (Figura 7). Em outras palavras, a presença de complexos de ouro(I) dirige a seletividade da reação, de modo que são produzidos, apenas, adutos de configuração anti.

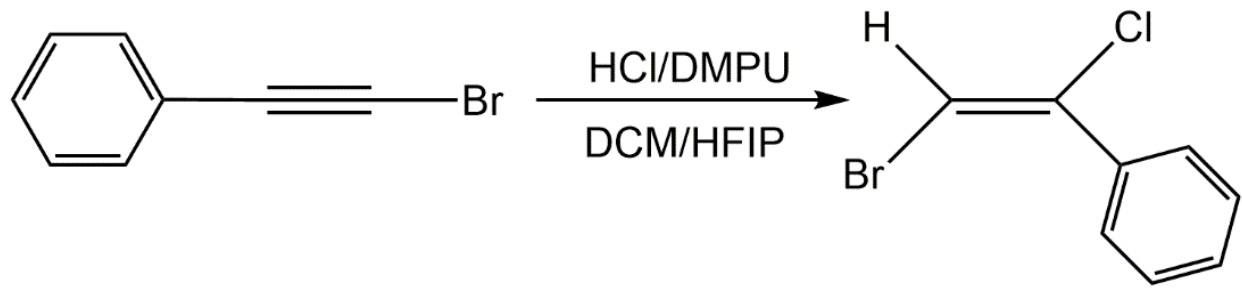

Produto syn

Figura 7. Reação de hidrocloração de alquinos sem a necessidade da presença de ouro, gerando o alqueno syn. ${ }^{65}$

Com auxílio da Teoria do Funcional de Densidade, método quântico capaz de prover boa acurácia a um custo computacional viável, ${ }^{16}$ o presente estudo busca entender como o mecanismo é seletivo de modo a promover as configurações anti e syn, na presença e na ausência do metal, respectivamente; e como o catalisador poderia ser ativado (Figura 6), oferecendo pistas sobre sua possível estrutura. 


\section{Metodologia}

O estudo foi desenvolvido sob a utilização da Teoria do Funcional de Densidade (Density Functional Theory, DFT). O funcional escolhido foi o B3LYP:66-71 há diversos trabalhos em catálise homogênea por ouro em que esse foi o funcional utilizado. ${ }^{16,64,72-77}$ Foram incluídos efeitos de dispersão (D3), ${ }^{78}$ que consideram interações de longo alcance (forças de London, ou dipolo induzido, atuantes em todas as moléculas), e adotadas duas funções de base de Pople para todos os átomos leves $(H, C$, $C l, P, F, O): 6-31 G(d, p)^{79,80}$ ou $6-31+G(d, p) .{ }^{81,82} \bigcirc$ que guiou tal escolha foi a presença de uma espécie aniônica no sistema, o cloreto - na sua presença, foi usada a base difusa. Para átomos pesados (Br e Au), foi utilizado o pseudopotencial SDD ${ }^{83}$ e as correspondentes bases adaptadas.

Os estados de transição (transition states, TS) foram caracterizados a partir de uma única frequência imaginária, comprovados pelas respectivas coordenadas de reações, usando-se o algoritmo IRC (Intrinsic Reaction Coordinate), conectando-os aos correspondentes reagentes e produtos. Os intermediários possuem apenas frequências reais (mínimos). Todos os cálculos foram executados considerando a temperatura padrão de 298,15 K, por meio do pacote Gaussian09. ${ }^{84}$ Os programas de visualização utilizados foram o GaussView, Molden ${ }^{85}$ e Chemcraft. ${ }^{86}$

Também pelo programa Gaussian09, foram realizadas algumas análises qualitativas de cargas APT (Atomic Polar Tensors). ${ }^{87}$ A escolha por essa carga (em detrimento das de Mulliken, por exemplo) se deve ao fato de as cargas APT serem menos dependentes das funções de base. Como o método (DFT) é quântico e a carga não é um observável, as cargas APT se tratam, na verdade, de tensores adimensionais.

O ligante orgânico $(L)$ usado nesse estudo da hidrocloração de alquinos é o da Figura 8b (2Biphenylyl(diphenyl)phosphine). Considerando os ligantes utilizados na hidrocloração catalisada por LAuCl, ${ }^{59}$ a estrutura cristalina de cada um deles foi procurada, a fim de termos um sistema o mais próximo possível da conformação característica do mínimo global. Infelizmente, apenas a estrutura cristalina do ligante JohnPhos (1, Figura 3) foi encontrada. ${ }^{88}$ Para o ligante 2 da Figura 3, foi encontrada a estrutura cristalina de uma molécula semelhante, com os grupos isopropil substituídos por hidrogênios (Figura 8a). ${ }^{89}$ Como o ligante 2 foi o de melhor rendimento no trabalho de Xu e colaboradores, ${ }^{59}$ para evitar uma busca conformacional do mesmo, e com o intuito de diminuir o custo computacional (uma vez que a estrutura da Figura 8a é mais simples), foi preferível usar esse modelo simplificado do ligante $\mathbf{2}$, e não o modelo real. Portanto, a molécula semelhante ao ligante $\mathbf{2}$ foi escolhida. 


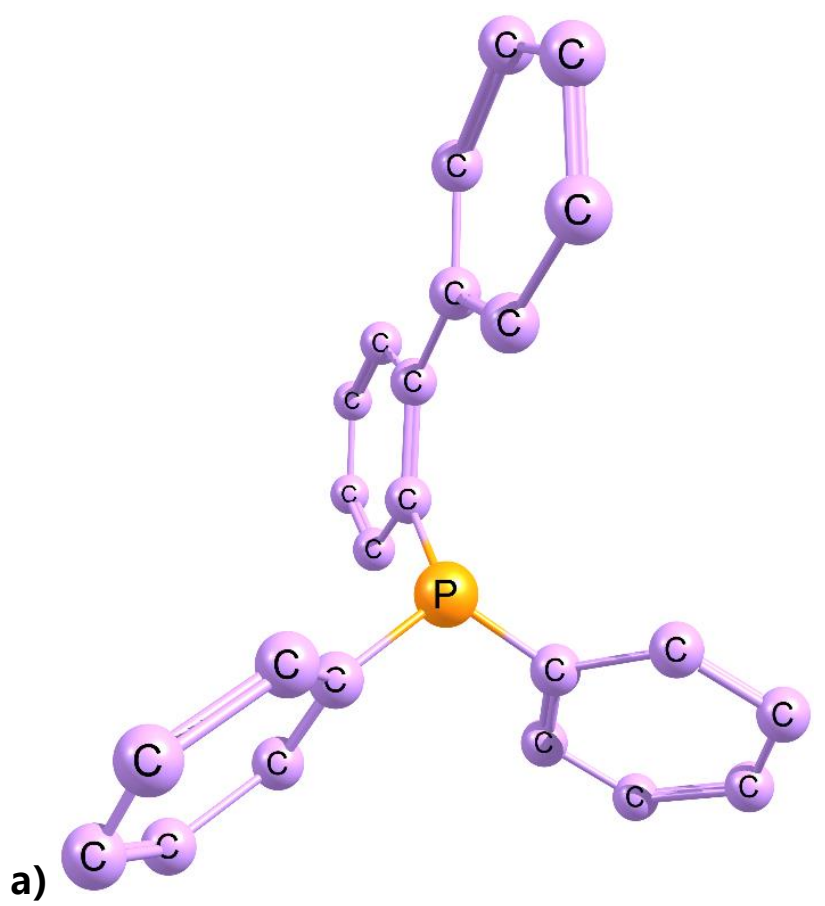

b)

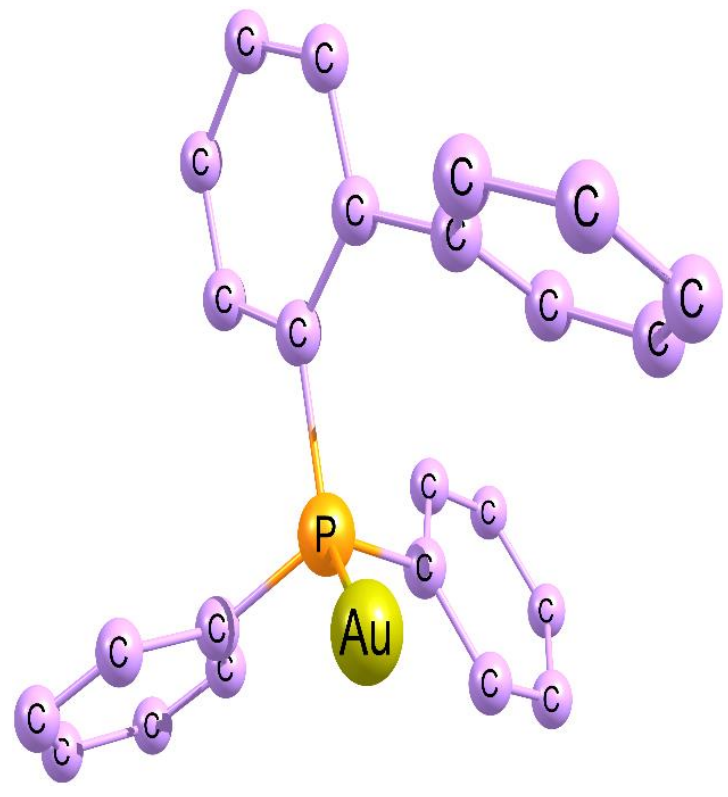

Figura 8. a) Estrutura cristalina do modelo simplificado do ligante 2 (Figura 3), utilizada nesse estudo (hidrogênios suprimidos); ${ }^{89}$ b) estrutura otimizada do ligante (B3LYP-D3, 6-31G(d,p)/SDD, água SMD), com o átomo de fósforo central ligado a um átomo de ouro, caracterizando o ouro catiônico $\left(\mathrm{LAu}^{+}\right)$

O modelo contínuo (implícito) de solvatação SMD (Universal Solvation Model based on Soluto Electron Density ${ }^{90}$ foi empregado para avaliar os efeitos dos solventes água e ciclohexanona, escolhidos com base nas constantes dielétricas. Xu e colaboradores reportaram o trabalho de hidrocloração de alquinos, tanto com ouro, quanto sem (Figuras 5 e 7), com utilização de HFIP (Figura 6) como solvente. ${ }^{59,65}$ A constante dielétrica do HFIP é igual a 15,7,91 e tal molécula não está listada na relação de solventes do Gaussian. ${ }^{92}$ Dessa forma, foram buscados os parâmetros físicoquímicos que caracterizam o HFIP para introduzi-los no inpute, assim, rodar os cálculos em HFIP implícito, utilizando o modelo SMD. ${ }^{92}$ Contudo, nem todos os parâmetros necessários foram encontrados. Assim sendo, para efetuarmos testes exploratórios, a ciclohexanona foi escolhida por ter sua constante dielétrica $(15,62)^{92}$ muito próxima à do HFIP. Contrastando com a constante do HFIP e ciclohexanona, a água também foi escolhida como exemplo de solvente, uma vez que, com seu dielétrico de 78,35,92 ficaria clara a sensibilidade do sistema ao valor do dielétrico em um modelo de solvente implícito. 


\section{Fundamentação teórica}

\subsection{O nascimento da Mecânica Quântica e a equação de Schrödinger}

Ao longo da história da ciência, diversas teorias, como a Teoria da Relatividade Restrita, ou a Lei da Gravitação Universal, foram criadas: cientistas se debruçaram sobre uma certa pergunta e, no intuito de respondê-la, construíram sua teoria. ${ }^{93}$ Com a mecânica quântica, algo um pouco diferente ocorreu.

Em 1885 e 1890, os físicos J. Balmer e J. Rydberg estudaram os espectros de linhas de emissão do átomo de hidrogênio; ${ }^{94-96}$ em 1900, na busca de explicar o problema da radiação do corpo negro, M. Planck surgiu com a ideia da quantização da energia, conceito usado posteriormente, em 1905, por A. Einstein em seus estudos sobre o efeito fotoelétrico; 96 em 1910, E. Rutherford conduziu o famoso experimento com emissão de partículas alfa (núcleos de hélio) por átomos de polônio bombardeadas numa fina película de ouro. Os resultados do experimento levaram à indicação de que o núcleo atômico é positivamente carregado e concentra quase toda a massa do átomo em um volume muito pequeno, enquanto o restante do átomo é composto pela eletrosfera, região do espaço ao redor do núcleo em que os elétrons estão arranjados, com a existência de grandes espaços vazios. ${ }^{94,96}$

Essas foram as principais ideias e experimentos que culminaram, em 1913, em um novo modelo atômico: o átomo de Bohr, o primeiro modelo atômico a propor níveis de energia quantizados (órbitas) ocupados por elétrons. Seu modelo trouxe resoluções com importantes sucessos: Bohr foi capaz de prever corretamente a energia do primeiro nível do átomo de hidrogênio. ${ }^{96}$ Além disso, propôs a primeira explicação para as linhas de emissão do hidrogênio - observadas por Balmer, Rydberg e outros -, resultado das transições eletrônicas entre os diferentes níveis de energia atômicos. No entanto, o modelo de Bohr não pôde explicar as linhas espectroscópicas para átomos multieletrônicos. Essa e outras restrições levaram a um modelo atômico mais abrangente, em vigência até hoje: o modelo atômico de Schrödinger. ${ }^{94,97}$

A partir dos trabalhos de Planck e Einstein previamente mencionados, entre outros, confirmou-se que a luz também tinha característica corpuscular, de partícula, além da natureza ondulatória. 
Então, em 1924, L. de Broglie imaginou se as partículas de matéria também teriam essa dualidade partícula-onda. Usando equações da relatividade restrita (de 1905) e da energia do fóton (Equação 1), De Broglie mostrou que a dualidade se estendia também à matéria (Equação 2). ${ }^{96}$

$$
E=h v
$$

em que $h$ é a constante de Planck, e $v$, a frequência da radiação eletromagnética

$$
\lambda=\frac{h}{m v}
$$

em que $\lambda$ é o comprimento de onda, $m$ é a massa, e $v$, a velocidade

A dualidade partícula-onda da matéria foi comprovada em 1927 por C. Davisson e L. Germer no experimento em que um feixe de elétrons sofreu difração - uma propriedade típica de ondas. Além disso, observou-se que a equação de De Broglie era obedecida. ${ }^{94}$

Outra enorme contribuição foi dada por W. Heisenberg, também em 1927, que ficou conhecida como Princípio da Incerteza - diferentemente de objetos macroscópicos, não seria possível determinar, simultaneamente e com igual precisão, o momento e a posição de uma partícula. ${ }^{95,97}$ Fala-se, então, em termos de probabilidade.

Em 1926, E. Schrödinger postulou a equação que se mostrou como a análoga quântica às equações clássicas de Newton, capaz de determinar as propriedades do sistema - tanto as presentes, quanto as futuras -, a partir de sua evolução temporal. ${ }^{97,98}$

Dessa forma, a mecânica quântica é uma teoria que não foi criada da mesma maneira que outras; é uma teoria que foi sendo construída por desenvolvimento matemático e experimentos feitos por diversos cientistas ao longo de muitos anos, partindo de diferentes ideias e observações.

A equação de Schrödinger dependente do tempo ${ }^{98}$ tem a forma

$$
\frac{\mathrm{i} \hbar \delta \Psi}{\delta t}=\widehat{H} \Psi
$$

em que i é a unidade imaginária; $\hbar$ é a constante de Planck $(h)$ dividida por $2 \pi$; $\widehat{H}$ é o operador hamiltoniano, soma dos operadores mecânico-quânticos da energia cinética $(\widehat{T})$ e energia potencial $(\widehat{V})$,

$$
\widehat{H}=\widehat{T}+\widehat{V}
$$

que corresponde à energia total do sistema. 
Assim, a equação pode ser reescrita como

$$
\frac{\mathrm{i} \hbar \delta \Psi}{\delta t}=\frac{-\hbar^{2}}{2 m} \frac{\delta^{2} \Psi}{\delta x^{2}}+V \Psi
$$

O hamiltoniano opera na função de onda $(\Psi)$, que leva esse nome em lembrança ao caráter ondulatório da mecânica quântica. Pode ser chamada também de função de estado, ${ }^{96}$ uma vez que contém toda a informação acerca do estado da partícula.

A função de onda $\Psi$ pode ser escrita, valendo-se do método de separação de variáveis, em termos de sua parte espacial, $\psi(x)$, e temporal, $\varphi(t) \cdot 98$

$$
\Psi=\Psi(x, t)=\psi(x) \varphi(t)=\psi \varphi
$$

Substituindo a Equação 6 na Equação 5, obtemos a equação de Schrödinger independente do tempo

$$
\widehat{H} \psi=E \psi
$$

uma equação de autovetores e autovalores. Em química, é a equação de Schrödinger mais comumente usada, uma vez que se trabalha com estados estacionários (não há uma evolução temporal). ${ }^{96,98}$ Quando se trabalha com estados excitados (como ocorre, por exemplo, em fotoquímica), em que há evolução do sistema ao longo do tempo, opta-se pela equação de Schrödinger dependente do tempo. ${ }^{96}$ Em qualquer uma das equações, o objetivo é o mesmo: conhecer a energia total. Neste trabalho, todos os cálculos consideram a equação independente do tempo.

A função de onda é a solução da equação de Schrödinger ${ }^{94}$ No caso de a equação independente do tempo ser resolvida para o átomo de hidrogênio, as funções de onda são chamadas de orbitais. Elevadas ao quadrado $\left(|\psi|^{2}\right)$, resultam na densidade de probabilidade de se encontrar o elétron. ${ }^{95,96}$ Assim, a equação de Schrödinger, em companhia da dualidade partícula-onda e da incerteza, edificam o mais moderno modelo atômico, baseado em uma visão mecânico-quântica e, portanto, probabilística. 


\subsubsection{Efeitos relativísticos no átomo de ouro}

A nova teoria da estrutura da matéria, a mecânica quântica, cujos alguns de seus pilares são a equação de Schrödinger e o princípio da incerteza de Heisenberg, possui como característica a natureza probabilística. Até então, toda a física tinha caráter determinístico, com posição e momento conhecidos simultaneamente e com igual precisão.

Em mecânica quântica, calculamos o valor médio de um observável - a soma das suas probabilidades de acordo com o peso de cada uma. ${ }^{96}$ Indo para o átomo, sabemos que o valor médio da velocidade radial de um elétron $1 s\left(\langle v\rangle_{1 s}\right)$ equivale, em unidades atômicas, ao seu número atômico $(Z)$ :

$$
\left\langle v>_{1 s}=\int_{-\infty}^{+\infty} \psi_{1 s}^{*} \hat{v} \psi_{1 s} \mathrm{~d} \tau=\langle 1 s|\hat{v}| 1 s\rangle=Z\right.
$$

Assim, para o átomo de ouro, $\langle\boldsymbol{v}\rangle_{1 s}=79$. Considerando a velocidade da luz $(\boldsymbol{c})$ como 137 (também em unidades atômicas), a velocidade do elétron $1 s$ no ouro equivale a, aproximadamente, 57,7\% da velocidade da luz. 2,3,15,99 Então, à medida que o número atômico aumenta, as velocidades dos elétrons mais próximos do núcleo tornam-se cada vez mais altas, comparáveis à velocidade da luz. Em 1928, P. Dirac percebeu, ao analisar a equação de Schrödinger, que a mesma dizia respeito a partículas com velocidades muito inferiores à da luz. Buscando então unificar as duas maiores teorias físicas da época, a relatividade restrita e a mecânica quântica, concebeu uma nova teoria, ainda mais abrangente que a mecânica quântica em vigência: a mecânica quântica relativística. ${ }^{99,100}$ Todos os átomos são mais corretamente descritos considerando a relatividade restrita do que usando-se apenas a equação de Schrödinger não relativística. Como nos átomos leves os efeitos relativísticos são extremamente pequenos, ${ }^{99}$ tornam-se irrelevantes, e a mecânica quântica não relativística fornece respostas acuradas. No entanto, no caso do ouro, dado seu elevado número atômico, tais efeitos não podem ser desprezados. Dessa forma, o átomo de ouro já não é bem descrito pela mecânica quântica tradicional, ${ }^{99}$ necessitando da nova descrição quântica para elétrons cujas velocidades são próximas a $\boldsymbol{c}$.

Seguindo o que Einstein teorizou como a relatividade restrita, a proximidade da velocidade da luz leva a um aumento da massa do elétron, algo observado a partir da equação da massa relativística:2,3,15,99 


$$
m_{\text {relativística }}=\frac{m_{0}}{\left(1-\left[\frac{v}{c}\right]^{2}\right)^{\frac{1}{2}}}
$$

Em que $m_{0}$ é a massa inercial, e $v$ é a velocidade. Fazendo a substituição na Equação 9 dos valores de velocidade mostrados acima, sabemos que a massa relativística representa, para o ouro, um aumento de $22 \%$ da massa inercial $\left(m_{\text {relativística }}=1,22 m_{0}\right) \cdot{ }^{3,99}$ Como o raio de Bohr $\left(a_{0}\right)$ pode ser escrito na forma

$$
a_{0}=\frac{\hbar^{2}}{m_{0} e^{2}}
$$

em que $e$ é a carga elétrica elementar,

e o valor médio do raio do orbital 1 s equivale a 3/2 do raio de Bohr:96

$$
\langle r\rangle_{1 s}=\frac{3}{2} a_{0}
$$

o raio de Bohr e do orbital $1 s$ são diretamente proporcionais, e o aumento da massa inercial do elétron, devido à sua alta velocidade, leva a uma diminuição em $22 \%$ de $a_{0} \cdot{ }^{99}$ Isso significa que ocorre a contração do raio do orbital $1 s$ (também em 22\%), que fica ainda mais próximo do núcleo e, ${ }^{15}$ portanto, mais estabilizado. ${ }^{2,3}$ Tal fenômeno é conhecido como contração relativística (efeito relativístico direto), ${ }^{101}$ que ocorre também para todos os outros orbitais $\boldsymbol{S}$, bem como para os orbitais $p_{i}^{2,3,15}$ proporcionando uma maior carga nuclear efetiva sentida por esses elétrons. Consequentemente, há uma desestabilização dos orbitais $d$ e $f$, a expansão relativística (efeito relativístico indireto), 3,101 que faz com que a carga nuclear efetiva sentida por eles seja menor, graças à blindagem proporcionada pelos orbitais $s$ e $p$. $^{15,102}$

Tais efeitos relativísticos passam a ser mais pronunciados, de modo que não podem mais ser ignorados, a partir do Hf $(Z=72)$, atingindo absoluta importância sobretudo a partir da platina, ${ }^{3}$ de número atômico 78, e explicam as propriedades físicas e químicas do ouro. Além dos efeitos mencionados, vale ressaltar que a mecânica quântica relativística também explica outro aspecto que influencia a química: o spin eletrônico.96,99

Começando pela cor do ouro, para explicá-la, serão mencionados brevemente alguns conceitos de óptica. Uma das radiações eletromagnéticas emitidas pela luz solar é a que se encontra na faixa do visível, também conhecida como luz branca. Quando decomposta, sabe-se que é formada por 7 cores, com as respectivas nuances: vermelho, laranja, amarelo, verde, azul, índigo e violeta. No entanto, dessas 7, há 3 cores primárias - vermelho, verde e azul (sistema RGB) - que, somadas, resultam na luz branca. Todas as outras cores (secundárias e terciárias) são obtidas pelas diferentes 
combinações entre as cores primárias, que não podem ser decompostas, sendo chamadas também de cores puras. Por exemplo, ao se misturar verde e vermelho, amarelo é obtido. Dessa forma, azul e amarelo são cores complementares: quando superpostas, dão a luz branca. 103

Uma das razões pelas quais enxergamos algo colorido é que, quando a luz visível incide sobre um objeto, um fóton de determinada frequência do espectro visível é absorvido, enquanto os outros fótons são refletidos, que se configuram na cor vista. Esse processo de absorção ocorre devido ao fato de que a energia do fóton (Equação 1) é exatamente igual ao gap de energia em que é possível ocorrer uma excitação eletrônica. Assim, vemos a cor complementar da radiação absorvida. ${ }^{103,104}$

Quando a luz branca incide sobre o ouro, o fóton de frequência da cor azul ( 440-485 nm, que equivale a 2,4 eV usando a Equação 1) 15,102 é absorvido, e das cores verde e vermelha, refletidos. Portanto, enxergamos o ouro como sendo amarelo. A promoção eletrônica ocorre entre os orbitais $5 \boldsymbol{d}$ e o orbital semipreenchido $6 \boldsymbol{s}^{2,15,99}$ Esse gap só possui tal valor de energia, sendo possível absorver radiação na frequência do azul, graças aos efeitos relativísticos: com a contração do orbital $6 s$ e expansão do $5 \boldsymbol{d}$, os orbitais ficam mais "próximos" energeticamente e, assim, o gap de energia se torna menor. Sem a contração/expansão relativísticas, a diferença energética seria maior, e veríamos o ouro da mesma forma que enxergamos a prata, que absorve na faixa da radiação ultravioleta $(3,7 \mathrm{eV})^{102}$ e não a vemos colorida. ${ }^{2}$

fato de o orbital $6 s$ do ouro sofrer contração, se tornando mais estável, traz algumas consequências: faz com que seja muito dispendioso energeticamente remover o elétron, o que aumenta a energia de ionização do ouro; 15,16,101,102 garante uma maior afinidade eletrônica:16,99,101,102 e, pensando em termos de reatividade, aumenta a eletronegatividade do ouro e faz com que seja um forte ácido de Lewis; 2,15,16,101 gera ligações mais fortes; ${ }^{15,16,101}$ e resulta no caráter nobre, ${ }^{2,101}$ com baixa tendência de sofrer oxidação. ${ }^{15,102}$ Porém, se reduz mais facilmente, produzindo o estado de oxidação $-1.3,101,102$

Da mesma forma, também há consequências decorrentes da expansão dos orbitais $5 d$, como permitir uma maior polarizabilidade da nuvem eletrônica, tornando o metal mais mole e menos nucleofílico. ${ }^{15,16}$ Permite também que o ouro atinja estados de oxidação mais altos. ${ }^{101}$

São esses os efeitos que explicam a dificuldade de o ouro participar de ciclos de adição oxidativa (seção 1.1). ${ }^{13,15,16}$ É evidente, portanto, que os efeitos relativísticos, ao influenciar as propriedades físico-químicas do ouro, também afetam sua reatividade. 


\subsubsection{Conjunto de funções de base}

As funções de base são um conjunto de funções que constroem funções de onda para descrever os elétrons em um determinado átomo, com base no método variacional. A equação de Schrödinger só pode ser resolvida exatamente para sistemas monoeletrônicos, como o átomo de hidrogênio. Para todos os demais sistemas, atômicos ou moleculares, recorre-se a métodos de aproximação para obtenção e minimização da energia. No caso do método variacional (Equação 12), ${ }^{96}$ uma função tentativa $\phi$ é determinada como uma combinação linear de algumas funções conhecidas e pertinentes ao sistema; tal combinação é definida como sendo o conjunto de bases. Quanto mais funções formando o conjunto de bases, maior o "tamanho" da base (e o custo computacional). ${ }^{105,106}$

$$
E_{\phi}=\frac{\int \phi^{*} \widehat{H} \phi \mathrm{d} \tau}{\int \phi^{*} \phi \mathrm{d} \tau}=\frac{\langle\phi|\widehat{H}| \phi\rangle}{\langle\phi \mid \phi\rangle}
$$

Em que $E_{\phi}$ é energia mínima obtida pela integração por todo o espaço, sempre em um limite superior à verdadeira energia do estado fundamental, $E_{0}$. Portanto, $E_{\phi} \geq E_{0}$; e $\phi=\psi_{0}$, se $\phi$ for a exata função de onda do estado fundamental.

Há algumas funções largamente usadas para descrever orbitais, como as gaussianas (GaussianType Orbitals, GTO), proporcionais a $\exp \left(-\alpha r^{2}\right)$, em que $r$ é a distância ao núcleo do orbital molecular formado na combinação linear das funções, e $\alpha$ é o parâmetro exponencial. Há também as funções de Slater (Slater-Type Orbitals, STO), proporcionais a exp $(-\zeta r$ ) (em que $\zeta$ também é um parâmetro exponencial), sendo mais parecidas com as funções de onda exatas do átomo de hidrogênio. No entanto, as gaussianas são as preferenciais para formar o conjunto de funções de base, por serem de mais rápida resolução do ponto de vista computacional. ${ }^{105}$

Neste trabalho, são utilizadas funções difusas (cuja representação é com o caractere +, segundo a simbologia sugerida por Pople) e de polarização. Quando se tem um conjunto de funções de base, e se adicionam funções à camada de valência cujo $\alpha$ é menor, é caracterizada a função de base difusa, usada para ânions por conferir maior flexibilidade à nuvem eletrônica. As funções extras possuem mesmo momento angular orbital das funções já existentes no conjunto de funções de base. No caso de funções $p$ (para o átomo de hidrogênio) e $\boldsymbol{d}$ (para átomos do terceiro período da tabela periódica, por exemplo) serem adicionadas ao conjunto de funções de base, temos então 
as funções de polarização. ${ }^{105}$ Ou seja, para funções de polarização, são adicionadas funções de diferentes momentos angulares (simetria superior).

\subsubsection{Pseudopotencial e funções de base SDD (Sttutgart-Dresden)}

SDD é a determinação dada ao pseudopotencial construído para representar os elétrons mais internos do átomo considerado "pesado", de modo que são abordadas, principalmente, as correções escalares relativísticas (discutidas na seção 3.1.2) esperadas para esses átomos. Os pseudopotenciais são conhecidos como Effective Core Potentials, ECP. 107,108

O átomo pode ser descrito como sendo formado por uma parte interna, composta pelo núcleo e pelos elétrons mais próximos (core), juntamente com os elétrons de valência. O potencial do átomo é, portanto, o potencial da parte interna em adição ao potencial dos elétrons mais externos. Se apenas o potencial da camada de valência é levado em conta (já que é onde se dá a ligação química e as reações), desconsiderando o potencial interno, então um novo potencial é criado, o pseudopotencial, que descreve os elétrons mais externos por uma pseudofunção (função de estado). Portanto, os elétrons internos são representados por um potencial, e os de valência, por funções de base, adaptadas ao respectivo pseudopotencial. ${ }^{108}$ Por exemplo, no átomo de carbono, de configuração eletrônica $1 s^{2} 2 s^{2} 2 p^{2}$, os elétrons $1 s$ e $2 s$ seriam representados pelo potencial; já os elétrons $2 p$, por funções de base. No átomo de ouro, apenas o elétron $6 s$ é tratado explicitamente. Tal artifício garante cálculos mais rápidos, com uma menor quantidade de memória utilizada, já que apenas os elétrons de valência (e não todos os presentes no átomo) são representados por funções de base, viabilizando um menor custo computacional. ${ }^{16}$

No pseudopotencial SDD, sua atuação consiste também em realizar uma parte das correções relativísticas. Há duas que são de grande importância em química: as correções escalares e as angulares. As escalares são aquelas que dizem respeito exclusivamente às velocidades dos elétrons ${ }^{107}$ e que foram abordadas na seção 3.1 .2 (efeitos relativísticos diretos e indiretos). Para o átomo de ouro, dada a forte presença dos efeitos relativísticos escalares, que não podem ser desprezados, o uso das bases adaptadas ao pseudopotencial SDD é absolutamente necessário. Já para o átomo de bromo $(Z=35)$, tais efeitos são menos relevantes. No entanto, isso não significa 
que não estejam presentes. Dessa forma, o uso do pseudopotencial SDD se justifica ao garantir maior acurácia na descrição do bromo, bem como ao proporcionar maior rapidez aos cálculos.

Já as correções angulares consideram o acoplamento spin-órbita, ${ }_{101}^{101}$ que pode ser entendido como o momento angular total - quando o momento angular do movimento do elétron e do spin, intrínseco às partículas, são somados. ${ }^{96,109} \mathrm{O}$ acoplamento spin-órbita está presente em todos os átomos, desde o hidrogênio. ${ }^{96}$ No entanto, sua contribuição só passa a ser de maior relevância nos átomos que atingem os orbitais $4 \boldsymbol{d}$ e $5 \boldsymbol{d}\left(5^{\circ}\right.$ e $6^{\circ}$ período da tabela periódica, respectivamente). ${ }^{2}$ Na mecânica quântica de Schrödinger, o spin é um postulado, ${ }^{99,109}$ e o acoplamento spin-órbita, considerado como uma perturbação no hamiltoniano; ${ }^{15}$ na mecânica quântica relativística, o spin surge naturalmente, ${ }^{96}$ ao se resolver a equação de Dirac - válida para férmions, partículas fundamentais ou compostas cujo spin é fracionário $(s=1 / 2)$, como elétrons, ou prótons e nêutrons, respectivamente:110

$$
\mathrm{i} \hbar \frac{\delta \Psi^{\prime}}{\delta t}=\widehat{H}_{\mathrm{r}} \Psi^{\prime}
$$

Apresentada na sua forma hamiltoniana ${ }^{111}$ na Equação 13 e obtida substituindo o hamiltoniano relativístico, ${ }^{110-112} \widehat{H}_{\mathbf{r}}$, na Equação 3 (a equação de Schrödinger dependente do tempo). Essa é a equação correspondente à união feita por Dirac entre a mecânica quântica de Schrödinger e a relatividade restrita, mencionada na seção 3.1.2.

$$
\widehat{H}_{\mathrm{r}}=\hat{\alpha} c \hat{p}+\hat{\beta} m c^{2}
$$

Em que $m$ é a massa inercial do férmion; $c$, a velocidade da luz; $\hat{p}$ é o operador do momento linear (na direção arbitrária $\boldsymbol{x}$ ):96

$$
\hat{p}=-\mathrm{i} \hbar \frac{\delta}{\delta x}
$$

E $\hat{\alpha}$ e $\hat{\beta}$ são matrizes quadradas de ordem 4, ${ }^{110,112,113}$ conhecidas como matrizes de Dirac. ${ }^{113}$ Possuem uma relação de anticomutatividade entre si. ${ }^{110,112,114}$

A matriz $\hat{\beta}$, de forma abreviada, é igual a

$$
\hat{\beta}=\left(\begin{array}{cc}
I & 0 \\
0 & -I
\end{array}\right)
$$

Em que $I$ é a submatriz identidade 2x2. Portanto,

$$
\hat{\beta}=\left(\begin{array}{cccc}
1 & 0 & 0 & 0 \\
0 & 1 & 0 & 0 \\
0 & 0 & -1 & 0 \\
0 & 0 & 0 & -1
\end{array}\right)
$$


Já a matriz $\hat{\alpha}$, de forma abreviada, é igual a

$$
\hat{\alpha}=\left(\begin{array}{ll}
0 & \sigma \\
\sigma & 0
\end{array}\right)
$$

Em que $\sigma$ são as matrizes de spin de Pauli (que aparecem no operador do spin, $\hat{S}$, em que $\left.\hat{S}=\frac{\hbar}{2} \sigma\right)^{998,110}$

$$
\begin{aligned}
& \sigma=\sigma_{x}+\sigma_{y}+\sigma_{z} \\
& \sigma_{x}=\left(\begin{array}{cc}
0 & 1 \\
1 & 0
\end{array}\right) \\
& \sigma_{y}=\left(\begin{array}{cc}
0 & -i \\
i & 0
\end{array}\right) \\
& \sigma_{z}=\left(\begin{array}{cc}
1 & 0 \\
0 & -1
\end{array}\right)
\end{aligned}
$$

Então, por exemplo, $\hat{\alpha}_{x}$ é igual a

$$
\begin{gathered}
\hat{\alpha}_{x}=\left(\begin{array}{cccc}
0 & 0 & 0 & 1 \\
0 & 0 & 1 & 0 \\
0 & 1 & 0 & 0 \\
1 & 0 & 0 & 0
\end{array}\right)=\left(\begin{array}{cc}
0 & \sigma_{x} \\
\sigma_{x} & 0
\end{array}\right) \\
\hat{\alpha}=\hat{\alpha}_{x}+\hat{\alpha}_{y}+\hat{\alpha}_{z}=\left(\begin{array}{cc}
0 & \sigma_{x} \\
\sigma_{x} & 0
\end{array}\right)+\left(\begin{array}{cc}
0 & \sigma_{y} \\
\sigma_{y} & 0
\end{array}\right)+\left(\begin{array}{cc}
0 & \sigma_{z} \\
\sigma_{z} & 0
\end{array}\right)
\end{gathered}
$$

As matrizes de Dirac também são chamadas de matrizes gama, por receberem a notação $\gamma^{\mu}$, em que $\mu=0,1,2$, 3. A matriz $\hat{\beta}$ também recebe a designação de $\gamma^{0}$, e $\hat{\beta} \hat{\alpha}=\gamma^{\mu}$, por exemplo, $\hat{\beta} \hat{\alpha}_{x}=$ $\gamma^{1} .115,116$

Desenvolvendo a Equação 13, temos

$$
\begin{gathered}
\mathrm{i} \hbar \frac{\delta \Psi^{\prime}}{\delta t}=\left(\widehat{\alpha} c\left[-\mathrm{i} \hbar \frac{\delta}{\delta x}\right]+\widehat{\beta} m c^{2}\right) \Psi^{\prime} \\
\mathrm{i} \hbar \frac{\delta \Psi^{\prime}}{\delta t}+\hat{\alpha} c\left[\mathrm{i} \hbar \frac{\delta}{\delta x}\right] \Psi^{\prime}-\hat{\beta} m c^{2} \Psi^{\prime}=0
\end{gathered}
$$


Ou, apresentando a Equação 26 em outra forma:

$$
\mathrm{i} \hbar\left[\frac{\delta}{\delta t}+\hat{\alpha} c \frac{\delta}{\delta x}\right] \Psi^{\prime}-\hat{\beta} m c^{2} \Psi^{\prime}=0
$$

Dividindo a Equação 27 por c , obtemos

$$
\mathrm{i} \hbar\left[\frac{\delta}{c \delta t}+\hat{\alpha} \frac{\delta}{\delta x}\right] \Psi^{\prime}-\hat{\beta} m c \Psi^{\prime}=0
$$

Multiplicando a Equação 28 por $\hat{\beta}$,

$$
\mathrm{i} \hbar \hat{\beta}\left[\frac{\delta}{c \delta t}+\hat{\alpha} \frac{\delta}{\delta x}\right] \Psi^{\prime}-\hat{\beta}^{2} m c \Psi^{\prime}=0
$$

Como a matriz $\hat{\beta}$ elevada ao quadrado resulta na identidade $4 \times 4,{ }^{110}$ a Equação 29 é igual a

$$
\mathrm{i} \hbar\left[\hat{\beta} \frac{\delta}{c \delta t}+\hat{\beta} \hat{\alpha} \frac{\delta}{\delta x}\right] \Psi^{\prime}-m c \Psi^{\prime}=0
$$

A expressão em colchetes na Equação 30, $\left[\hat{\beta} \frac{\delta}{c \delta t}+\hat{\beta} \hat{\alpha} \frac{\delta}{\delta x}\right]$, também pode ser escrita como

$$
\left[\hat{\beta} \frac{\delta}{c \delta t}+\hat{\beta} \hat{\alpha} \frac{\delta}{\delta x}\right]=(\hat{\beta}, \hat{\beta} \hat{\alpha})\left(\frac{\delta}{c \delta t}, \frac{\delta}{\delta x}\right)=\left(\gamma^{\mu}\right)\left(\delta_{\mu}\right)
$$

Portanto, a Equação 30 fica

$$
\left(\mathrm{i} \hbar \gamma^{\mu} \delta_{\mu}-m c\right) \Psi^{\prime}=0
$$

Forma mais comumente conhecida da equação de Dirac para um férmion livre e que diz respeito às transformações de Lorentz na teoria da relatividade especial. ${ }^{111,116,117}$ 
A função de onda $\Psi^{\prime}$, conhecida como função de onda de Dirac, possui uma diferença frente à função de estado da mecânica quântica não relativística, que é o fato de possuir 4 componentes, sendo caracterizada como um vetor (matriz coluna) 4x1:3,115,116

$$
\begin{aligned}
\Psi^{\prime}=\Psi^{\prime}(x, t) & =\left(\begin{array}{l}
\Psi_{1}(x, t) \\
\Psi_{2}(x, t) \\
\Psi_{3}(x, t) \\
\Psi_{4}(x, t)
\end{array}\right)=\left(\begin{array}{l}
\Psi_{\Theta} \\
\Psi_{\theta}
\end{array}\right) \\
\Psi_{\Theta} & =\left(\begin{array}{l}
\Psi_{1}(x, t) \\
\Psi_{2}(x, t)
\end{array}\right) \\
\Psi_{\theta} & =\left(\begin{array}{l}
\Psi_{3}(x, t) \\
\Psi_{4}(x, t)
\end{array}\right)
\end{aligned}
$$

A função de onda de Dirac $\Psi^{\prime}$ pode ser entendida como sendo formada por dois vetores de 2 elementos (duas matrizes coluna $2 \times 1, \Psi_{\Theta}$ e $\Psi_{\theta}$ ), também chamados de spinors.98,112,113,116 Dessa forma, a função de onda de Dirac se trata de um bispinor., ${ }^{3,14}$ Voltando então à Equação 13, 0 hamiltoniano relativístico opera sobre o bispinor.

Outro ponto chave de diferença entre a equação de Schrödinger (Equação 5) e a equação de Dirac (Equação 25) diz respeito às derivadas relativas ao tempo e espaço. Na relatividade restrita, o tempo e o espaço estão intrinsecamente ligados, variando simultaneamente e formando o chamado espaço-tempo. ${ }^{93,117}$ A equação de Schrödinger não é relativística, ou seja, não é adequada para situações em que $v \approx c$ pois a taxa de variação temporal e espacial não é a mesma, já que a derivada temporal é de ordem 1, enquanto a espacial, de ordem 2. Diferentemente, a equação de Dirac, ao incorporar a relatividade restrita, possui as duas derivadas de ordem 1, sendo, portanto, uma equação relativística. ${ }^{112}$

Tendo em vista um sistema de um elétron, adiciona-se ao hamiltoniano relativístico o termo da energia potencial, $\widehat{V}: 2,13,118-120$

$$
\begin{gathered}
\widehat{H}_{\mathrm{r}}^{\prime}=\hat{\alpha} c \hat{p}+\hat{\beta} m c^{2}+\widehat{V} \\
\widehat{V}=-\frac{1}{r}
\end{gathered}
$$

(em unidades atômicas)

Em que $r$ é a distância do elétron ao núcleo e $m$, a massa do elétron. 
Assim, para tratar questões de química quântica relativística, aplica-se $\widehat{H}_{\mathrm{r}}^{\prime}$ - conhecido como hamiltoniano de Dirac-Coulomb-Breit -, 2,113 na equação de Schrödinger independente do tempo (Equação 7), resultando na equação de Dirac independente do tempo para um sistema monoeletrônico. ${ }^{110,113,119}$ É partir desse tratamento que, na verdade, se resolve de fato o átomo de hidrogênio: todos os quatro números quânticos, incluindo o de spin, tornam-se conhecidos por meio da resolução da equação de Dirac.3,121,122 O spin deixa, então, de ser um postulado, para se tornar uma das soluções da equação.

Por fim, no caso de um sistema atômico multieletrônico (átomo ou íon atômico), o operador do potencial eletrostático em $\widehat{H}_{\mathrm{r}}^{\prime}$ fica

$$
\widehat{V}=-\sum_{i=1}^{N} \frac{N}{r_{i}}+\sum_{i<j}^{N} \frac{1}{r_{i j}}
$$

Em que $N$ é o número de elétrons. O primeiro termo se refere à atração entre os elétrons e o núcleo, contabilizada do elétron 1 até o elétron $N$, e o segundo termo se refere à repulsão intereletrônica. $\bigcirc$ operador $\widehat{V}$ é atribuído de maneira similar ao hamiltoniano não relativístico para mais de um elétron. ${ }^{96,98,109}$

Desse modo, o hamiltoniano relativístico para um sistema atômico multieletrônico é118-120

$$
\begin{gathered}
\widehat{H}_{\mathrm{r}}^{\prime}=\sum_{i=1}^{N} \widehat{H}_{\mathrm{r}_{i}}-\sum_{i=1}^{N} \frac{N}{r_{i}}+\sum_{i<j}^{N} \frac{1}{r_{i j}} \\
\widehat{H}_{\mathrm{r}_{i}}=\hat{\alpha}_{i_{\xi}} c \hat{p}_{i_{\xi}}+\hat{\beta} m c^{2}
\end{gathered}
$$

Em que $\xi$ corresponde às direções $x, y$ e $z$ do elétron $i$. 


\subsection{Métodos ab initio e aproximação de Born-Oppenheimer}

Proveniente do latim e significando "do início", um método ab initio é todo tipo de método quântico aplicado para sistemas de muitos corpos que os trata sem utilização de qualquer parâmetro empírico ou dado experimental, ou seja, os sistemas são descritos inteiramente valendo-se das equações e métodos de aproximação da mecânica quântica. ${ }^{123}$

O método de Hartree-Fock foi um dos métodos pioneiros nesse tipo de desenvolvimento. Os elétrons são tratados através de um campo médio - cada elétron sente, "enxerga" o outro, como parte do campo médio gerado, mas não interagem entre si. Hartree-Fock é, portanto, um método em que não se considera a energia envolvida na interação entre os elétrons, que são descritos por funções de onda monoeletrônicas. ${ }^{105}$

A diferença de energia entre o valor exato e a energia obtida pelo método é definida como a energia de correlação, sendo expressa pela seguinte equação:96,105

$$
E_{\text {corr }}=E_{\text {exata }}-E_{\mathrm{HF}}
$$

Em que $E_{\text {corr }}$ é a energia de correlação eletrônica, $E_{\text {exata }}$ é a energia verdadeira (obtida experimentalmente, ou a energia da exata função de onda, caso fosse conhecida para um sistema de mais de um elétron), e $E_{\mathrm{HF}}$ é a energia calculada pelo método de Hartree-Fock.

A correlação eletrônica torna-se progressivamente mais relevante à medida que cresce o número de elétrons do sistema. Portanto, incluí-la é um parâmetro fundamental para se obter um resultado mais próximo do experimental.96,105 Vários métodos, conhecidos como pós-Hartree-Fock, ou baseados na teoria do funcional de densidade, foram desenvolvidos buscando-se contornar tal limitação. ${ }^{123}$

Um ponto em comum a todos os métodos ab initio é a aproximação Born-Oppenheimer, 95,96,98,109 em que é feita uma modificação no operador hamiltoniano. ${ }^{124}$ Como dito anteriormente, o hamiltoniano considera a energia total do sistema. Tendo em vista um hamiltoniano molecular (ou atômico com mais de um elétron), são levadas em conta as energias cinéticas e potenciais dos núcleos e elétrons, de modo que o hamiltoniano assume a forma

$$
\widehat{H}=\widehat{T}_{\mathrm{N}}+\widehat{T}_{\mathrm{e}}+\widehat{V}_{\mathrm{NN}}+\widehat{V}_{\mathrm{ee}}+\widehat{V}_{\mathrm{Ne}}
$$

Em que o índice $\mathrm{N}$ se refere aos núcleos e o índice e, aos elétrons. Os termos $\widehat{T}_{\mathrm{N}}+\widehat{T}_{\mathrm{e}}$ se referem à parte do operador hamiltoniano que trata da energia cinética do núcleo e dos elétrons; $\widehat{V}_{\mathrm{NN}}+\widehat{V}_{\mathrm{ee}}$ 
se referem à energia potencial de repulsão entre os núcleos e entre os elétrons, respectivamente, enquanto a atração entre o núcleo e os elétrons é obtida com o operador $\widehat{V}_{\mathrm{Ne}}$.

A função de onda da parte espacial $(\psi)$ também pode ser dividida pelo método de separação de variáveis:

$$
\psi=\psi(R, r)=\psi_{\mathrm{e}}(R ; r) \psi_{\mathrm{N}}(R)
$$

em que $\psi(R, r)$ é a função de onda espacial total, das coordenadas dos núcleos $(R)$ e elétrons $(r)$; $\psi_{\mathrm{N}}(R)$ é a função de onda que refere aos núcleos, e $\psi_{\mathrm{e}}(R ; r)$ é a função de estado dos elétrons, dependentes da posição nuclear.

A equação de Schrödinger independente do tempo (Equação 7) pode ser expressa então:

$$
\left(\widehat{T}_{\mathrm{N}}+\widehat{T}_{\mathrm{e}}+\widehat{V}_{\mathrm{NN}}+\widehat{V}_{\mathrm{ee}}+\widehat{V}_{\mathrm{Ne}}\right) \psi_{\mathrm{e}}(R ; r) \psi_{\mathrm{N}}(R)=E \psi_{\mathrm{e}}(R ; r) \psi_{\mathrm{N}}(R)
$$

Entretanto, os elétrons possuem velocidade muito maior que o núcleo, uma vez que os primeiros são muito mais leves. Os núcleos são, portanto, relativamente mais lentos (e daí se diz que estão "fixos"). Dessa forma, o termo da energia cinética do núcleo no hamiltoniano não opera na função de estado eletrônica, somente na função de onda nuclear, $\psi_{\mathrm{N}}(R)$ (Equação 45). Da mesma forma, o termo da energia cinética dos elétrons não atua na função de onda nuclear, e sim na eletrônica, $\psi_{\mathrm{e}}(R ; r)$ (Equação 46).

$$
\begin{gathered}
\widehat{T}_{\mathrm{N}} \psi_{\mathrm{e}}(R ; r) \psi_{\mathrm{N}}(R) \cong \psi_{\mathrm{e}}(R ; r) \widehat{T}_{\mathrm{N}} \psi_{\mathrm{N}}(R) \\
\widehat{T}_{\mathrm{e}} \psi_{\mathrm{e}}(R ; r) \psi_{\mathrm{N}}(R) \cong \psi_{\mathrm{N}}(R) \widehat{T}_{\mathrm{e}} \psi_{\mathrm{e}}(R ; r)
\end{gathered}
$$

Assim, a equação de Schrödinger pode ser reescrita na forma

$$
\psi_{\mathrm{e}}(R ; r) \widehat{T}_{\mathrm{N}} \psi_{\mathrm{N}}(R)+\psi_{\mathrm{N}}(R) \widehat{T}_{\mathrm{e}} \psi_{\mathrm{e}}(R ; r)+\left(\widehat{V}_{\mathrm{NN}}+\widehat{V}_{\mathrm{ee}}+\widehat{V}_{\mathrm{Ne}}\right) \psi_{\mathrm{e}}(R ; r) \psi_{\mathrm{N}}(R)=E \psi_{\mathrm{e}}(R ; r) \psi_{\mathrm{N}}(R)
$$

Dividindo tudo por $\psi_{\mathrm{e}}(R ; r) \psi_{\mathrm{N}}(R)$, chegamos na seguinte equação:

$$
\frac{\widehat{T}_{\mathrm{N}} \psi_{\mathrm{N}}(R)}{\psi_{\mathrm{N}}(R)}+\frac{\widehat{T}_{\mathrm{e}} \psi_{\mathrm{e}}(R ; r)}{\psi_{\mathrm{e}}(R ; r)}+\left(\widehat{V}_{\mathrm{NN}}+\widehat{V}_{\mathrm{ee}}+\widehat{V}_{\mathrm{Ne}}\right)=E
$$




$$
\frac{\widehat{T}_{\mathrm{e}} \psi_{\mathrm{e}}(R ; r)}{\psi_{\mathrm{e}}(R ; r)}+\left(\hat{V}_{\mathrm{NN}}+\widehat{V}_{\mathrm{ee}}+\widehat{V}_{\mathrm{Ne}}\right)=E-\frac{\widehat{T}_{\mathrm{N}} \psi_{\mathrm{N}}(R)}{\psi_{\mathrm{N}}(R)}
$$

Multiplicando a última Equação 49 por $\psi_{\mathrm{e}}(R ; r)$, obtemos

$$
\widehat{T}_{\mathrm{e}} \psi_{\mathrm{e}}(R ; r)+\left(\hat{V}_{\mathrm{NN}}+\widehat{V}_{\mathrm{ee}}+\widehat{V}_{\mathrm{Ne}}\right) \psi_{\mathrm{e}}(R ; r)=\left(E-\widehat{T}_{\mathrm{N}}\right) \psi_{\mathrm{e}}(R ; r)
$$

Observando o lado esquerdo da Equação 50, nota-se, ao retomar a Equação 42, que está escrito sob a forma do hamiltoniano eletrônico (ou seja, excluindo-se a energia cinética dos núcleos) operando na função de onda eletrônica:

$$
\left(\widehat{T}_{\mathrm{e}}+\widehat{V}_{\mathrm{NN}}+\widehat{V}_{\mathrm{ee}}+\widehat{V}_{\mathrm{Ne}}\right) \psi_{\mathrm{e}}(R ; r)=\left(E-\widehat{T}_{\mathrm{N}}\right) \psi_{\mathrm{e}}(R ; r)
$$

Dessa forma, obtemos a equação de Schrödinger eletrônica:

$$
\widehat{H}_{\mathrm{e}} \psi_{\mathrm{e}}(R ; r)=E_{\mathrm{e}}(R) \psi_{\mathrm{e}}(R ; r)
$$

Em que $\widehat{H}_{\mathrm{e}}$ é o hamiltoniano eletrônico e $E_{\mathrm{e}}(R)$, a energia eletrônica.

Multiplicando a Equação 49 por $\psi_{\mathrm{N}}(R)$, obtemos

$$
\widehat{T}_{\mathrm{e}} \psi_{\mathrm{N}}(R)+\left(\widehat{V}_{\mathrm{NN}}+\widehat{V}_{\mathrm{ee}}+\widehat{V}_{\mathrm{Ne}}\right) \psi_{\mathrm{N}}(R)=E \psi_{\mathrm{N}}(R)-\widehat{T}_{\mathrm{N}} \psi_{\mathrm{N}}(R)
$$

que também pode ser escrita como, ao se passar o termo $-\widehat{T}_{\mathrm{N}} \psi_{\mathrm{N}}(R)$ para o lado esquerdo

$$
\left(\widehat{T}_{\mathrm{e}}+\widehat{T}_{\mathrm{N}}+\widehat{V}_{\mathrm{NN}}+\widehat{V}_{\mathrm{ee}}+\widehat{V}_{\mathrm{Ne}}\right) \psi_{\mathrm{N}}(R)=E \psi_{\mathrm{N}}(R)
$$

Configurando a equação de Schrödinger nuclear. Dessa forma, são obtidas equações de Schrödinger separadas para elétrons e núcleos, de modo que os movimentos eletrônicos e nucleares se encontram desacoplados. Vale frisar que os núcleos não estão fixos, estáticos, de forma absoluta; o que ocorre é que o movimento nuclear é desprezível em relação ao movimento eletrônico devido à maior massa. ${ }^{123}$

Aplicando-se a equação de Schrödinger eletrônica, obtemos a função de onda eletrônica, bem como a energia, que, neste trabalho, será referida como energia potencial, ou energia eletrônica. 


\subsubsection{Teoria do Funcional de Densidade}

DFT é uma teoria quântica que também remonta ao ano 1927. Sua história começou com o modelo de Thomas-Fermi, ${ }^{125}$ um modelo estatístico baseado na distribuição de carga, ou seja, na densidade eletrônica, $\rho(r)$, de um gás de elétrons não interagentes - sem efeitos de troca e correlação -, cujo objetivo era calcular a energia de um átomo multieletrônico. ${ }^{125,126}$

$$
\begin{gathered}
N=\int \rho(x, y, z) \mathrm{d} x \mathrm{~d} y \mathrm{~d} z \\
\text { Ou } \\
N=\int \rho(r) \mathrm{d} r
\end{gathered}
$$

em que $N$ é o número de elétrons

Em 1930, Dirac incluiu a energia de troca, originando o modelo de Thomas-Fermi-Dirac. Contudo, ainda havia falhas: na energia cinética, uma vez que o modelo de elétrons não interagentes não é coerente com um sistema real, de elétrons interagentes; e faltava considerar a energia de correlação. ${ }^{126}$ Por outro lado, foi notável que, pela primeira vez, uma alternativa à função de onda foi proposta para se calcular a energia de um átomo.

Em 1964, foi elaborado o primeiro teorema de Hohenberg-Kohn, que mostra como a densidade eletrônica é intercambiável com a função de onda. A partir da densidade eletrônica do estado fundamental, é determinada a atração entre os elétrons e o núcleo - o que, na linguagem da teoria, é conhecido como potencial externo $(\nu)$-, fornecendo o hamiltoniano. Podemos obter, portanto, a função de onda, e a energia. Dessa forma, torna-se evidente o tanto de informação que a densidade eletrônica carrega. ${ }^{105}$

Com isso fica claro, então, que a entidade fundamental da teoria do funcional de densidade é a densidade eletrônica, que apresenta a vantagem de ser uma observável acessível, por se tratar de uma entidade física, que pode ser medida experimentalmente; 123 a função de onda, diferentemente, não possui um significado físico direto, sendo uma representação matemática, algo que pode ser um tanto abstrato. ${ }^{105}$

Outro desdobramento do primeiro teorema é a dependência da energia em relação ao potencial externo. ${ }^{127}$ Além disso, a energia é uma função da densidade eletrônica que, por sua vez, é uma função das coordenadas espaciais $(\rho(x, y, z))$, o que caracteriza a energia como um funcional - daí 
o nome da teoria: podemos, de maneira simplificada, entender um funcional como uma "função de outra função". A energia pode ser representada, portanto, como $E_{v}[\rho(r)]$.

Já o segundo teorema de Hohenberg-Kohn, baseado no método variacional (Equação 12), mostra que a energia, $E_{v}[\rho(r)]$, deve ser maior ou igual à energia verdadeira do estado fundamental $\left(E_{0}\right): 105$

$$
E_{v}[\rho(r)] \geq E_{0}
$$

Em 1965, a teoria daria um salto rumo à sua elaboração como teoria quântica exata e capaz de calcular a energia sem a função de onda: W. Kohn e L. J. Sham desenvolveram, tendo como base a equação de Schrödinger, um conjunto de equações representativas de um sistema fictício de elétrons não interagentes, porém, cuja densidade eletrônica é igual a de um sistema real, com elétrons interagentes, o que, por fim, resultou na equação de energia da DFT:105

$$
E_{\mathrm{DFT}}=E_{v}[\rho(r)]=T_{\mathrm{eni}}[\rho(r)]+V_{\mathrm{Ne}}[\rho(r)]+V_{\mathrm{ee}}[\rho(r)]+T_{\mathrm{ei}}[\rho(r)]+\Delta V_{\mathrm{ee}}[\rho(r)]
$$

Em que $T_{\text {eni }}[\rho(r)]$ é a energia cinética dos elétrons não interagentes; $V_{\mathrm{Ne}}[\rho(r)]$ é a atração entre os elétrons e o núcleo (potencial externo); $V_{\text {ee }}[\rho(r)]$ é a repulsão de Coulomb entre os elétrons; $T_{\text {ei }}[\rho(r)]$ é a energia cinética dos elétrons interagentes, e $\Delta V_{\text {ee }}[\rho(r)]$ é o termo que contabiliza toda interação de natureza quântica entre os elétrons - portanto, diferentemente do método Hartree-Fock, DFT computa a correlação eletrônica. Os dois últimos termos, $T_{\text {ei }}[\rho(r)]$ e $\Delta V_{\text {ee }}[\rho(r)]$, configuram o que é chamado de funcional de troca e correlação $\left(E_{\mathrm{xc}}[\rho(r)]\right)$ - universal, porém não conhecido: para se resolvê-lo, são feitas aproximações. Daí surge a imensa variedade de funcionais utilizados nos cálculos de química computacional, como o B3LYP. 66-71 Dessa forma, a Equação 57 pode ser expressa também por

$$
E_{v}[\rho(r)]=T_{\mathrm{eni}}[\rho(r)]+V_{\mathrm{Ne}}[\rho(r)]+V_{\mathrm{ee}}[\rho(r)]+E_{\mathrm{xc}}[\rho(r)]
$$

A primeira e mais simples aproximação feita para o funcional de troca e correlação é conhecida como aproximação LDA (Local Density Approximation). Nesse caso, o funcional $E_{\mathrm{xc}}[\rho(r)]$ depende apenas da densidade eletrônica em dado ponto do espaço. Por isso, fala-se em densidade local. Vale ressaltar que isso não significa que a densidade eletrônica seja homogênea por toda a molécula (como ocorre no modelo do gás de elétrons uniforme, não interagentes). ${ }^{105,123}$

Nas aproximações feitas para o funcional de troca e correlação, há a classificação dos funcionais como puros ou híbridos. A diferença entre ambos reside no fato de que nos híbridos há a inclusão de alguma porcentagem da energia de troca Hartree-Fock. Tais artifícios visam dar maior acurácia ao cálculo. Contudo, aumentam o custo computacional. O funcional B3LYP, usado neste trabalho, 
caracteriza-se como um funcional híbrido, contendo 20\% da energia de troca Hartree-Fock, segundo exposto na Equação 59 abaixo:105

$$
E_{\mathrm{Xc}}^{\mathrm{B} 3 \mathrm{LYP}}[\rho(r)]=(1-a) E_{\mathrm{x}}^{\mathrm{LSDA}}[\rho(r)]+a E_{\mathrm{x}}^{\mathrm{HF}}[\rho(r)]+b \Delta E_{\mathrm{x}}^{\mathrm{B}}[\rho(r)]+(1-c) E_{\mathrm{c}}^{\mathrm{LSDA}}[\rho(r)]+c E_{\mathrm{c}}^{\mathrm{LYP}}[\rho(r)]
$$

Em que $E_{\mathrm{x}}^{\mathrm{LSDA}}[\rho(r)]$ é o funcional de troca LSDA (Local Spin Density Approximation), aproximação que se configura como uma sofisticação à aproximação LDA por incluir as autofunções (autoestados) $\alpha$ e $\beta$ do spin do elétron no átomo/molécula;i ${ }^{123} E_{\mathrm{x}}^{\mathrm{HF}}[\rho(r)]$ é o funcional de troca Hartree-Fock; $\Delta E_{\mathrm{X}}^{\mathrm{B}}[\rho(r)]$ é o funcional que introduz uma correção ao funcional de troca LSDA; ${ }^{\cdot 6,69}$ $E_{\mathrm{C}}^{\mathrm{LSDA}}[\rho(r)]$ é o funcional de correlação LSDA; $E_{\mathrm{C}}^{\mathrm{LYP}}[\rho(r)]$ é o funcional de correlação utilizado no funcional LYP; 66,128 e $a, b$ e $c$ são coeficientes de valores 0.20, 0.72, e 0.81, respectivamente, obtidos por meio de um ajuste linear de mínimos quadrados de dados experimentais, como energias de atomização e de ionização. ${ }^{69,105}$ Tais coeficientes caracterizam-se, portanto, como semi-empíricos. ${ }^{69}$ Essa é mais uma característica atribuída a alguns funcionais híbridos: além da inclusão da troca Hartree-Fock, alguns podem incluir também parâmetros baseados em dados experimentais, como é o caso do B3LYP, em que os três parâmetros, $a$, $b$ e $c$, levam o "3" ao nome do funcional. Já as letras referem-se aos sobrenomes dos pesquisadores Becke, Lee, Yang e Parr. ${ }^{123}$

Cada funcional utilizado nos cálculos de química computacional (como B3LYP, PBE, M06, entre muitos outros) se trata de uma diferente aproximação ao funcional de troca e correlação $\left(E_{\mathrm{xc}}[\rho(r)]\right)$ - cada um possui sua própria equação.

DFT é, então, uma teoria exata (Equações 57 e 58), mas que deve ser resolvida de maneira aproximada, por não se conhecer $E_{\mathrm{xc}}[\rho(r)] .^{105,123}$ Então, essa é a questão principal envolvendo o uso da teoria do funcional de densidade: encontrar o melhor funcional que descreva o sistema, ${ }^{123}$ uma vez que não há maneira ordenada, metódica, de conhecê-lo. ${ }^{96}$

Se o funcional de troca e correlação fosse conhecido, a energia da função tentativa, $E_{v}[\rho(r)]$, apresentada no segundo teorema de Hohenberg-Kohn (Inequação 56), seria igual à energia verdadeira do estado fundamental. Portanto, DFT como teoria exata é variacional. Porém, ao serem feitas as aproximações, a energia pode resultar em valores menores do que a energia calculada experimentalmente. ${ }^{105}$

Nesse trabalho, DFT foi a teoria escolhida buscando a melhor correlação entre a qualidade dos resultados e o custo computacional. Pelo fato de a entidade fundamental ser a densidade eletrônica, que depende apenas das 3 coordenadas espaciais, DFT garante uma boa acurácia, ao considerar a energia de correlação eletrônica, a um custo computacional menor que os métodos 
baseados na função de onda eletrônica. Nesses, há uma função de onda para cada elétron, em que cada um depende das 3 coordenadas espaciais e 1 coordenada de spin. Assim, DFT é um método que permite o estudo de sistemas maiores, além de ser largamente usado na literatura para descrever sistemas catalíticos. No que diz respeito à catálise com ouro, a premissa se mantém.

Como qualquer método, DFT também apresenta limitações. Uma delas é se tratar de um método desenvolvido para o estado fundamental - estados excitados necessitam de outra descrição da teoria, conhecida como TD-DFT ( Time Dependent Density Functional Theory). Além disso, DFT não descreve bem sistemas de caráter multirreferencial/multiconfiguracional, em que mais de uma função de onda (determinante de Slater) é necessária para a descrição dos estados. ${ }^{129}$

\subsection{Superfície de energia potencial e estados de transição}

Uma reação química pode ser definida como uma transformação da matéria, a partir do rearranjo de átomos em novas posições. A superfície de energia potencial (Potential Energy Surface, PES), representada na Figura 9, mapeia todos os possíveis rearranjos, ou caminhos reacionais. Aplicandose a equação de Schrödinger eletrônica (Equação 52), obtemos a energia potencial das espécies participantes da reação química. Dessa forma, cada uma, com sua respectiva energia, posicionase diferentemente uma em relação à outra e, a partir da conexão entre as espécies, surge a PES para uma determinada reação. ${ }^{105}$

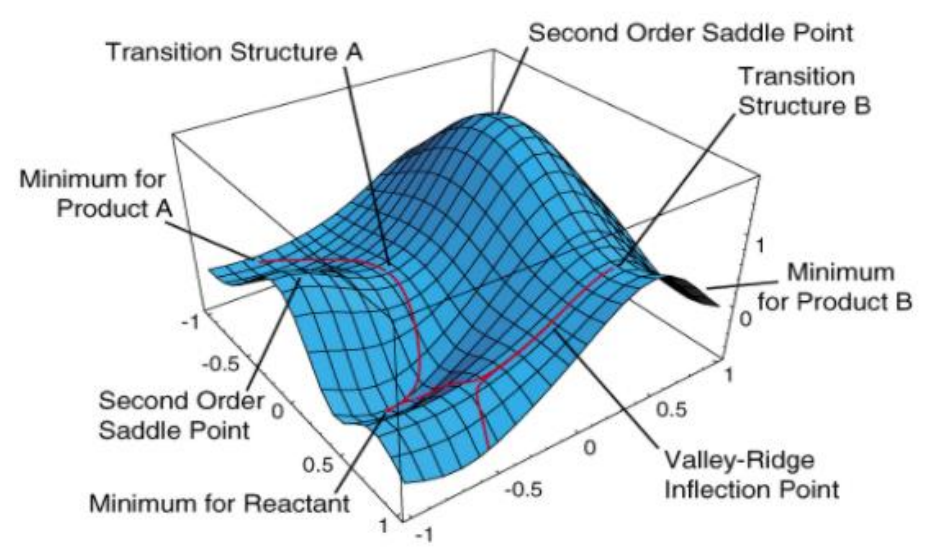

Figura 9. Exemplo de superfície de energia potencial, com alguns pontos estacionários demarcados. Disponivel em https://medium.com/chempute/introduction-to-computational-chemistry-calculations-pes-and-saddle-point22389fc362f0, acesso em 24/06/2021. 
Cada átomo possui as três coordenadas espaciais, $x$, ye $z$. Dessa forma, as dimensões da superfície são definidas por $3 N$ (em que $N$ é o número de átomos), que resultam no número de parâmetros geométricos (coordenadas internas), $q$ (Equação 60). Tal propriedade é o que confere à PES um caráter multidimensional. ${ }^{123}$

$$
3 N=q=\left\{q_{1}, q_{2}, \ldots, q_{\mathrm{n}}\right\}
$$

Recorrendo-se à sua topologia, definimos pontos importantes, como os que têm a primeira derivada da energia $(E)$ em relação às coordenadas internas igual à zero $\left(\frac{\delta E}{\delta q}=0\right)$, que podem ser pontos de máximo ou mínimo. Esses são os pontos locais ou globais, também conhecidos como pontos estacionários. O processo de otimização de geometria se baseia justamente na procura de algum ponto estacionário. ${ }^{123}$

Temos ainda o ponto de sela - máximo em uma ou mais direções, e mínimo nas outras -, que é o que define um estado de transição: um ponto de sela na PES. O fato de ser ponto de máximo em apenas uma direção, a do caminho reacional, confere outra característica aos estados de transição: ser um ponto de sela de $1^{a}$ ordem. ${ }^{123}$ Quando o algoritmo IRC é implementado, sempre a partir do estado de transição, determina-se a descida para os pontos de mínimo, que se configuram nos respectivos reagentes e produtos.

Então, para um ponto estacionário, cuja primeira derivada é zero, há três possíveis identidades: ser um ponto de máximo, mínimo, ou de sela. Para poder caracterizá-los e distingui-los, recorre-se às segundas derivadas $\left(\frac{\delta^{2} E}{\delta q_{\mathrm{i}} \delta q_{\mathrm{j}}}\right)$, cuja matriz é chamada de hessiana, uma matriz quadrada de ordem igual à $q x q_{\text {i }}$ que possui $q$ autovalores distintos. ${ }^{130}$ Quando a matriz hessiana possui apenas autovalores reais positivos (o que corresponde a $\frac{\delta^{2} E}{\delta q_{\mathrm{i}} \delta q_{\mathrm{j}}}>0$ ), sabe-se que é um ponto de mínimo; se são reais negativos $\left(\frac{\delta^{2} E}{\delta q_{\mathrm{i}} \delta q_{\mathrm{j}}}<0\right)$, é um ponto de máximo; e se há apenas um autovalor negativo, entre todos os outros positivos, define-se como um ponto de sela de $1^{a}$ ordem, o estado de transição. Todas as outras estruturas participantes da reação química são mínimos. ${ }^{123}$

A matriz hessiana também é conhecida como matriz das constantes de força. ${ }^{123}$ Isso porque seus autovalores são, na verdade, as constantes de força $(k)$ do oscilador harmônico quântico (aproximação usada para descrever a ligação química), cuja frequência ( $v$ ) é dada por: 


$$
v=\frac{1}{2 \pi} \sqrt{\frac{k}{m}}
$$

em que $m$ é a massa do oscilador

Como para o estado de transição há um único autovalor negativo, $k<0$ (cuja interpretação física é de que não há força restauradora), a frequência obtida é imaginária. ${ }^{123}$ No caso dos mínimos, como todos os autovalores são positivos, as frequências são reais.

O autovetor da matriz hessiana que corresponde ao único autovalor negativo e que resulta na frequência imaginária é chamado de vetor de transição, que se relaciona com a ligação de interesse a ser rompida/formada para gerar o estado de transição. Portanto, uma definição mais completa do estado de transição é se tratar de um ponto de sela de primeira ordem na PES, que possui uma única frequência imaginária, advinda do único autovalor negativo, ${ }^{123}$ associado ao vetor de transição.

Todo o desenvolvimento da PES faz parte da Teoria do Estado de Transição, formulada por H. Erying, M. Polanyi e colaboradores nos anos 1930. Além do que foi apresentado, a teoria diz que há uma etapa de pré-equilíbrio entre reagentes e estado de transição para, por fim, resultar em uma etapa irreversível de formação do produto:105,123

$$
\mathrm{A}+\mathrm{B} \rightleftharpoons[\mathrm{AB}]^{\ddagger} \longrightarrow \mathrm{C}
$$

Os reagentes, sendo um ponto de mínimo, devem subir em energia para atingir o ponto de máximo no caminho reacional, o estado de transição. A energia necessária para formá-lo pode ser chamada de altura da barreira - entendida como a variação entre o fundo do poço do estado de transição e reagentes -, representada na Figura 10 abaixo: 


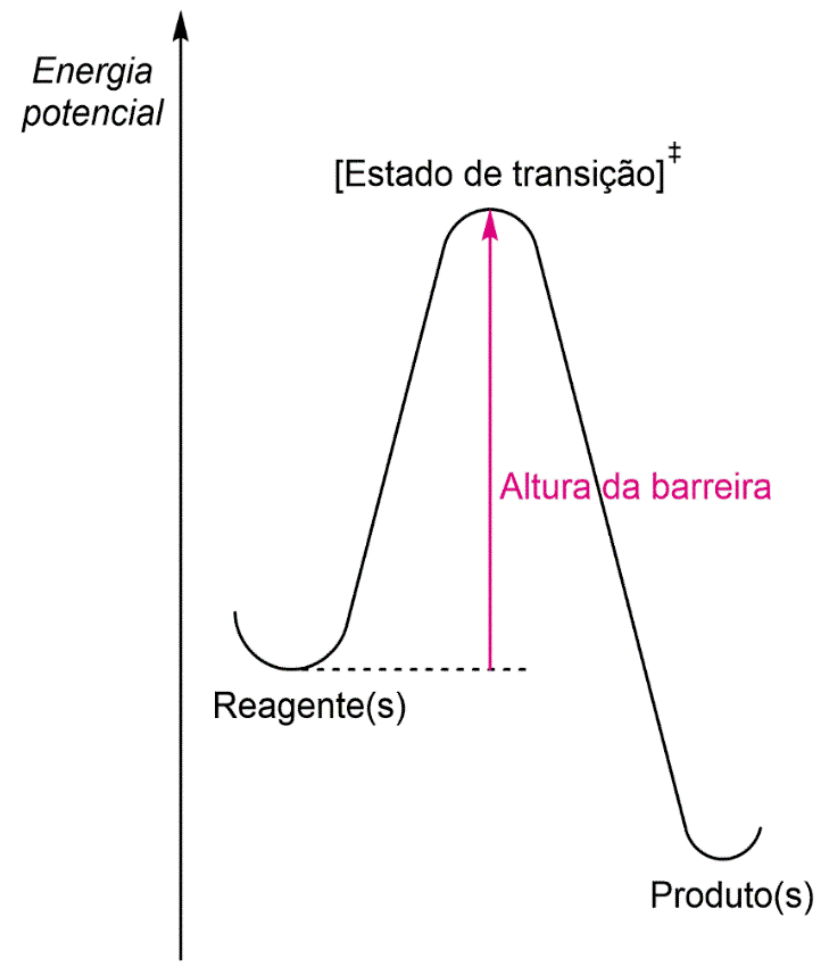

Figura 10. Recorte de uma PES genérica, ilustrando a altura da barreira entre estado de transição e o respectivo reagente

Portanto, tendo em vista as Figuras 9 e 10, os perfis energéticos construídos de modo a representar uma reação química nada mais são do que um recorte da PES.

Apesar do sucesso da teoria do estado de transição, vale ressaltar que ainda há limitações a serem vencidas, como a inclusão do tunelamento, 109 fenômeno mecânico-quântico em que há probabilidade de formação de produtos mesmo sem a energia suficiente para formar o estado de transição ${ }^{105}$ - daí que é dito que a partícula (no caso de reações químicas, geralmente um elétron, átomo de hidrogênio ou próton) penetra em uma região de energia classicamente proibida. ${ }^{95}$ 


\subsection{Efeitos de solvatação}

A influência da solvatação nas reações químicas já é bem conhecida. Em alguns casos, a solvatação pode ser decisiva para direcionar qual produto será obtido, influenciar a cinética etc.39 Tendo em vista a catálise homogênea por ouro e as reações de hidrocloração que sustentam este trabalho, 59,65 tais processos costumam acontecer em fase condensada. Dessa forma, tendo em vista a importância da solvatação, e para melhor descrever o sistema computacionalmente, se faz necessária a utilização de modelos que a simulem. Há duas grandes classes desses modelos: a solvatação explícita e a implícita.

Para se determinar o quanto interagem soluto e solvente, faz-se uso da variação da energia livre de solvatação $\left(\Delta G_{\text {solv }}\right)$, considerando o equilíbrio entre a fase gasosa e a líquida:131

$$
\begin{gathered}
\mathrm{A}_{(\mathrm{g})} \rightleftharpoons \mathrm{A}_{(\mathrm{l})} \\
K=\mathrm{e}^{-\frac{\Delta G_{\text {solv }}}{R T}}=\frac{\mathrm{A}_{(\mathrm{l})}}{\mathrm{A}_{(\mathrm{g})}}
\end{gathered}
$$

em que $K$ é a constante de equilíbrio, $T$, a temperatura e $R$, a constante dos gases ideais Assim, quanto maior for a interação soluto-solvente, mais o equilíbrio se deslocará para a direita e menor (mais negativa) será a variação de energia livre de solvatação.

A natureza das forças intermoleculares que regem a interação pode ser classificada como de cunho eletrostático $\left(\Delta G_{\text {elet }}\right)$ e não eletrostático $\left(\Delta G_{\text {nelet }}\right)$. As forças eletrostáticas são as que envolvem atração/repulsão entre cargas, obedecendo a lei de força de Coulomb, proporcional a $\frac{1}{r^{2}}$ (em que $r$ é a distância entre as cargas). ${ }^{109}$ São as mais relevantes para descrever o fenômeno da solvatação. ${ }^{131,132}$ Já as forças não eletrostáticas se configuram, por exemplo, na repulsão de troca e nas interações dispersivas ${ }^{131,132}\left(\Delta G_{\text {disp,rep }}\right)$ - entre um dipolo instantâneo e o induzido, ${ }^{109}$ presentes em todas as moléculas ${ }^{95}$ e causadas pela correlação eletrônica $-1^{133}$ também conhecidas como forças de London, e cuja porção atrativa é a força de van der Waals, 109,133 proporcional a $\frac{1}{r^{7}}$ (justificando a classificação como de longo alcance). ${ }^{109}$

Nos modelos implícitos (ou contínuos), considera-se que o soluto, com todos os seus átomos, encontra-se numa cavidade envolvida pela constante dielétrica do solvente, o que determina a separação física entre solvente e soluto. Dessa forma, o solvente não é estruturalmente representado, constituindo um meio contínuo e uniforme, em que se fixa o valor da constante 
dielétrica $(\boldsymbol{\varepsilon}),{ }^{90,131}$ uma medida do quão polar ou não um solvente é - quanto maior for a constante, maior a polaridade. Por ela, são representadas as forças eletrostáticas, ${ }^{131}$ bem como a capacidade de induzir a polarização do soluto (tratado quanticamente) ${ }^{131}$ e a interação com a densidade de carga. $^{90}$ Parte-se da suposição que as interações eletrostáticas entre soluto e solvente não dependem do solvente representado estruturalmente. ${ }^{85}$ Dessa forma, a constante dielétrica atua como um campo médio gerado pelo solvente, em que o soluto, apesar de não sentir a presença e influência de cada molécula do solvente, sente o efeito do todo, de todas as camadas de solvatação, ou seja, sente de maneira indireta a ação do solvente.

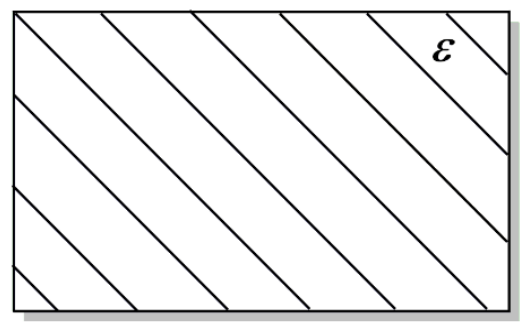

Contínuo dielétrico

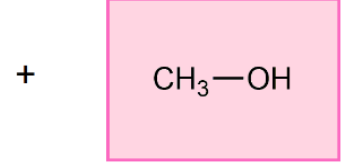

Soluto

\section{Formação da} cavidade

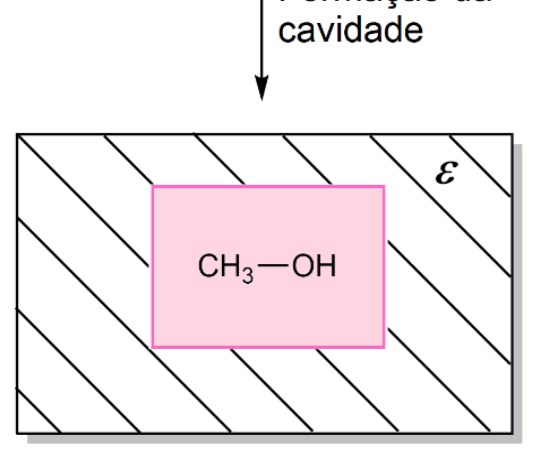

Figura 11. Representação da formação da cavidade nos modelos implícitos de solvatação (soluto genérico). Adaptado de Grant, G. H.; Richards, W. G. Computational Chemistry. Oxford Science Publications, 1995

Dentro dos modelos implícitos, destaca-se nesse trabalho o SMD. Tal modelo considera a tensão superficial na interface soluto-solvente e, com relação à variação de energia livre, são levadas em conta as interações de curto alcance entre solvente e soluto, configurando, assim, a primeira camada de solvatação e o SMD como um modelo implícito moderno e acurado. ${ }^{90}$

A formação da cavidade ( $\left.\Delta G_{\text {cav }}\right)$ também se configura como uma força de cunho não eletrostático. Portanto, no SMD (e em outros modelos contínuos), a variação total de energia livre de solvatação $\left(\Delta G_{\text {solv }}\right)$ é expressa da seguinte maneira: ${ }^{132}$ 


$$
\Delta G_{\text {solv }}=\Delta G_{\text {elet }}+\Delta G_{\text {nelet }}
$$

em que $\Delta G_{\text {elet }}$ é a energia livre de solvatação referente às forças eletrostáticas, e $\Delta G_{\text {nelet, às não }}$ eletrostáticas

$$
\Delta G_{\text {nelet }}=\Delta G_{\text {cav }}+\Delta G_{\text {disp,rep }}
$$

Em que $\Delta G_{\text {nelet }}$ é a energia livre de solvatação referente às forças não eletrostáticas, $\Delta G_{\text {cav }}$ é a energia livre envolvida na formação da cavidade do soluto no solvente, e $\Delta G_{\text {disp,rep }}$ é a energia livre de solvatação referente às forças dispersivas e de repulsão de troca

Já na solvatação explícita, diferentemente da implícita, as moléculas de solvente aparecem estruturalmente completas, e são alocadas de acordo com as interações eletrostáticas que imaginamos que ocorram, o que acarreta um maior custo computacional em relação à solvatação implícita. Dependendo de quantas moléculas de solvente são modeladas no cálculo, a solvatação explícita pode ser chamada também de microsolvatação, em que apenas algumas moléculas de solvente são alocadas em torno do soluto. Vale ressaltar que toda microsolvatação é uma solvatação explícita, mas nem toda solvatação explícita é uma microsolvatação, em que há um limite de moléculas explícitas a serem dispostas, podendo tornar-se uma alternativa mais acurada um cálculo de dinâmica (simulação) molecular, capaz de acompanhar a evolução temporal, conhecendo todas as posições passadas e futuras, ao aplicar a equação da $2^{a}$ lei de Newton - um cálculo clássico, portanto, determinístico. Assim, a distribuição das moléculas se torna mais realista, com algumas camadas de solvatação.

\subsection{Usos da Química Computacional}

A Ciência pode ser entendida como um conjunto de técnicas que, ao criar um método investigativo, nos permite obter conhecimento acerca de como a natureza e o mundo ao nosso redor funcionam. Para tanto, é um ofício que requer observação e experimentação, a fim de se comprovar os resultados. Ainda que a obtenção de dados empíricos seja o veredito do método científico, mostrando o que ocorre de fato ou não, quais são as condições necessárias para se atingir determinado resultado, a química computacional fornece poderosas ferramentas de previsão. 
Tendo o conhecimento da geometria molecular, energias e barreiras, locais de maior reatividade, bem como a completa caracterização de uma reação química, entende-se melhor quais seriam as propriedades físico-químicas, permitindo conhecer de antemão quais seriam os reagentes e caminhos reacionais mais viáveis, e economizando tempo e recursos (humanos e financeiros) antes de realizar o experimento no laboratório. ${ }^{123}$

É interessante notar também que o uso da química computacional permite elucidar questões que, experimentalmente, podem não ser tangíveis. Além da caracterização dos estados de transição, outro exemplo possível de ser citado é a determinação do maior estado de oxidação do ouro. Em 1986, foi determinado experimentalmente o estado $+7\left(\mathrm{AuF}_{7}\right)^{3,134}$ No entanto, em 2007, a partir de cálculos que incluíram o uso da teoria do funcional de densidade, a evidência teórica é de que, na verdade, o estado de oxidação mais alto que o ouro atinge é o +5 , $^{135}$ informação relevante para a preparação de compostos de ouro e para se entender sua reatividade.

Portanto, a química computacional é uma área com variadas possibilidades, desde a pesquisa de base até a aplicada, chegando em larga-escala, com grande utilidade nas indústrias de interesse químico, como farmacêuticas, de agroquímicos, e de materiais. ${ }^{123}$

\section{Resultados e Discussão}

Os resultados apresentados encontram-se divididos em três seções:

4.1 Hidrocloração com catalisador $\mathrm{LAu}^{+}$

4.2 Hidrocloração sem presença de ouro

4.2.1 Resultados com HCl

4.2.2 Resultados com HFIP

4.3 Ativação do catalisador LAuCl 


\subsection{Hidrocloração com catalisador $\mathrm{LAu}^{+}$}

A reação de estudo é a presente na Figura 12, cujo mecanismo teve como base o que foi ilustrado na Figura 4. É a mesma apresentada na Figura 5, porém, não com LAuCl, mas sim com $L A u^{+}$. Apesar de não haver descrição experimental dessa reação, com ouro catiônico, uma vez que a alta afinidade entre o ouro e o cloreto costuma envenenar o catalisador, ${ }^{59,136}$ a reação foi escolhida como sistema modelo para estudo do mecanismo pelos seguintes motivos: para comparação da regiosseletividade com a hidrocloração sem ouro; e para servir como base nos estudos da ativação do catalisador LAuCl (seção 4.3), atuando como um grupo controle.

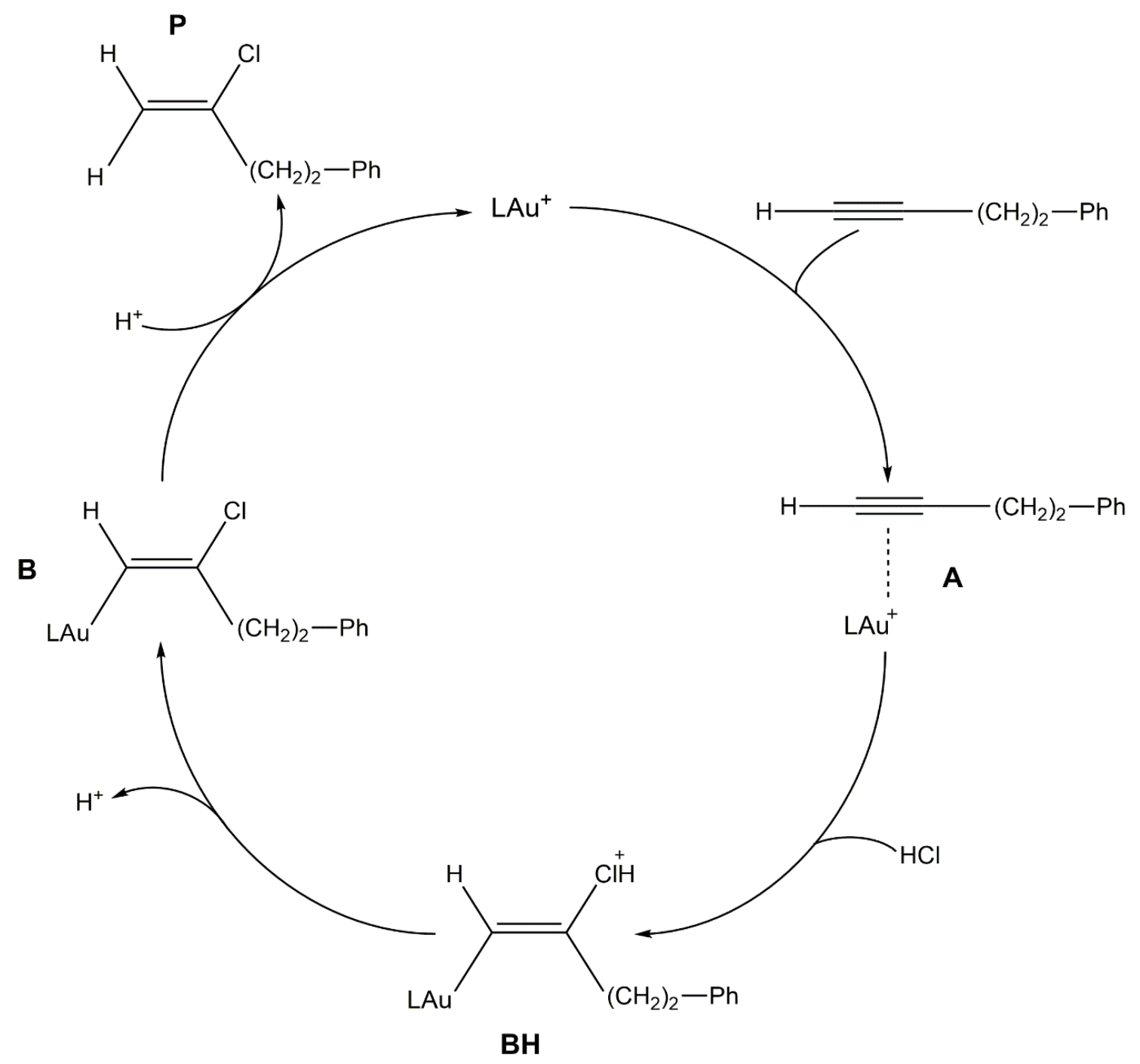

Figura 12. Ciclo catalítico da reação escolhida como sistema modelo. O nucleófilo é o cloro da molécula de $\mathrm{HCl}$ 
As otimizações das estruturas do ciclo catalítico (Figura 12) foram realizadas, em solvente implícito (água e ciclohexanona), a fim de se determinar a termodinâmica do sistema. Com base nos resultados dos cálculos, foi verificado que a estrutura BH não se estabiliza: a ligação dupla volta para uma ligação tripla, com a saída do $\mathrm{HCl}$. Em suma, obtém-se a estrutura $\mathbf{A}$, com o HCl livre. Portanto, a estrutura BH foi descartada do ciclo, dando origem ao novo ciclo abaixo (Figura 13).

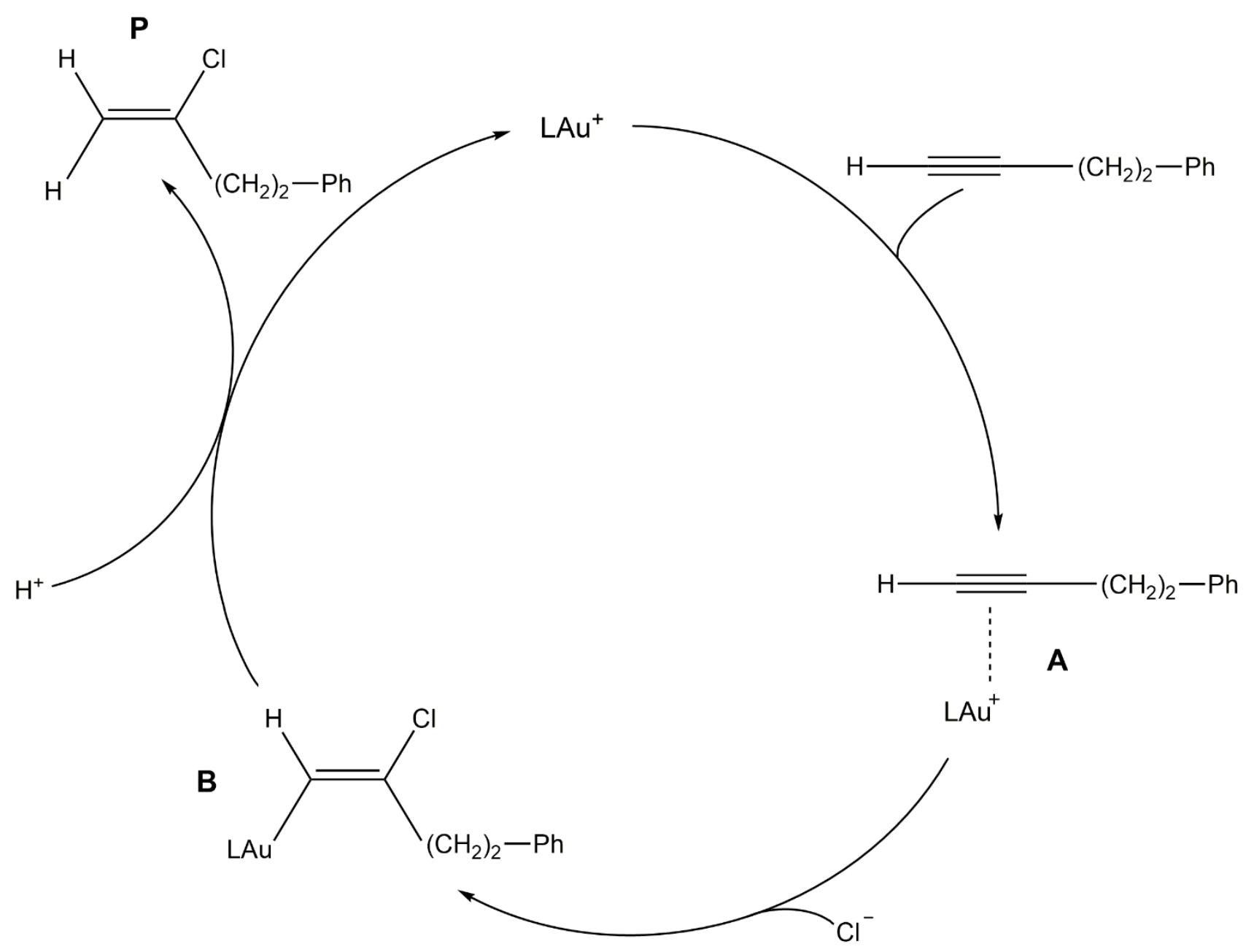

Figura 13. Ciclo catalítico obtido feitas as otimizações do ciclo mostrado na Figura 12. O nucleófilo é o cloreto 
Nesta seção, tanto o conjunto de funções de base com adição de bases difusas, quanto sem, foram usados. A função de base sem difusa foi escolhida a priori por apresentar um menor custo computacional, possibilitando, assim, a obtenção mais rápida de resultados. Uma vez obtidos, a fim de melhorar a acurácia, foi incluída a base difusa, já que a reação se dá na presença de cloreto, uma espécie aniônica.

A partir disso, e ainda considerando-se a base sem difusa, observa-se nos resultados evidenciados na Tabela 1 que a reação é exotérmica e exergônica. Tendo em vista a comparação entre água e ciclohexanona, a diferença foi menor que $1 \mathrm{kcal}^{\mathrm{mol}}{ }^{-1} \mathrm{em}$ termos de $\triangle H, \triangle G, \triangle Z P E$ e $\triangle E$ (energia potencial). Uma discussão a respeito dessa pequena diferença entre as energias relativas nos dois solventes (apesar da grande discrepância das constantes dielétricas) é apresentada ao final da seção 4.2 .2 .

Tabela 1. Energia relativa do produto $(\mathbf{P})$, proveniente do ciclo catalítico da Figura 13 em solvente implícito (SMD)

\begin{tabular}{|c|c|c|c|c|}
\hline & \multicolumn{4}{|c|}{ Energia relativa de P (kcal.mol-1) } \\
\hline & $\boldsymbol{\Delta} \boldsymbol{\Delta}$ & $\boldsymbol{\Delta} \boldsymbol{Z P E}$ & $\boldsymbol{\Delta H}$ & $\boldsymbol{\Delta} \boldsymbol{G}$ \\
\hline Água $(\boldsymbol{\varepsilon}=\mathbf{7 8 , 3 5 )}$ & $-34,3$ & $-29,1$ & $-30,4$ & $-19,9$ \\
\hline $\begin{array}{c}\text { Ciclohexanona } \\
(\boldsymbol{\varepsilon}=\mathbf{1 5 , 6 2 )}\end{array}$ & $-33,5$ & $-28,4$ & $-29,7$ & $-19,2$ \\
\hline
\end{tabular}

A partir dos resultados da termodinâmica presentes na Tabela 1, escolheu-se seguir apenas em água para caracterização do perfil energético do ciclo da Figura 13: há reações de adição nucleofílica catalisadas de forma homogênea por $\mathrm{LAu}^{+}$, em água, descritas na literatura. ${ }^{137-139}$ Além disso, a água se trata de um solvente de menor custo, verde, facilmente obtido e manipulado.

Nas Figuras 14 e 15, encontram-se representados os perfis energéticos caracterizados com as bases $6-31 G(d, p)$ e $6-31+G(d, p)$, respectivamente. 


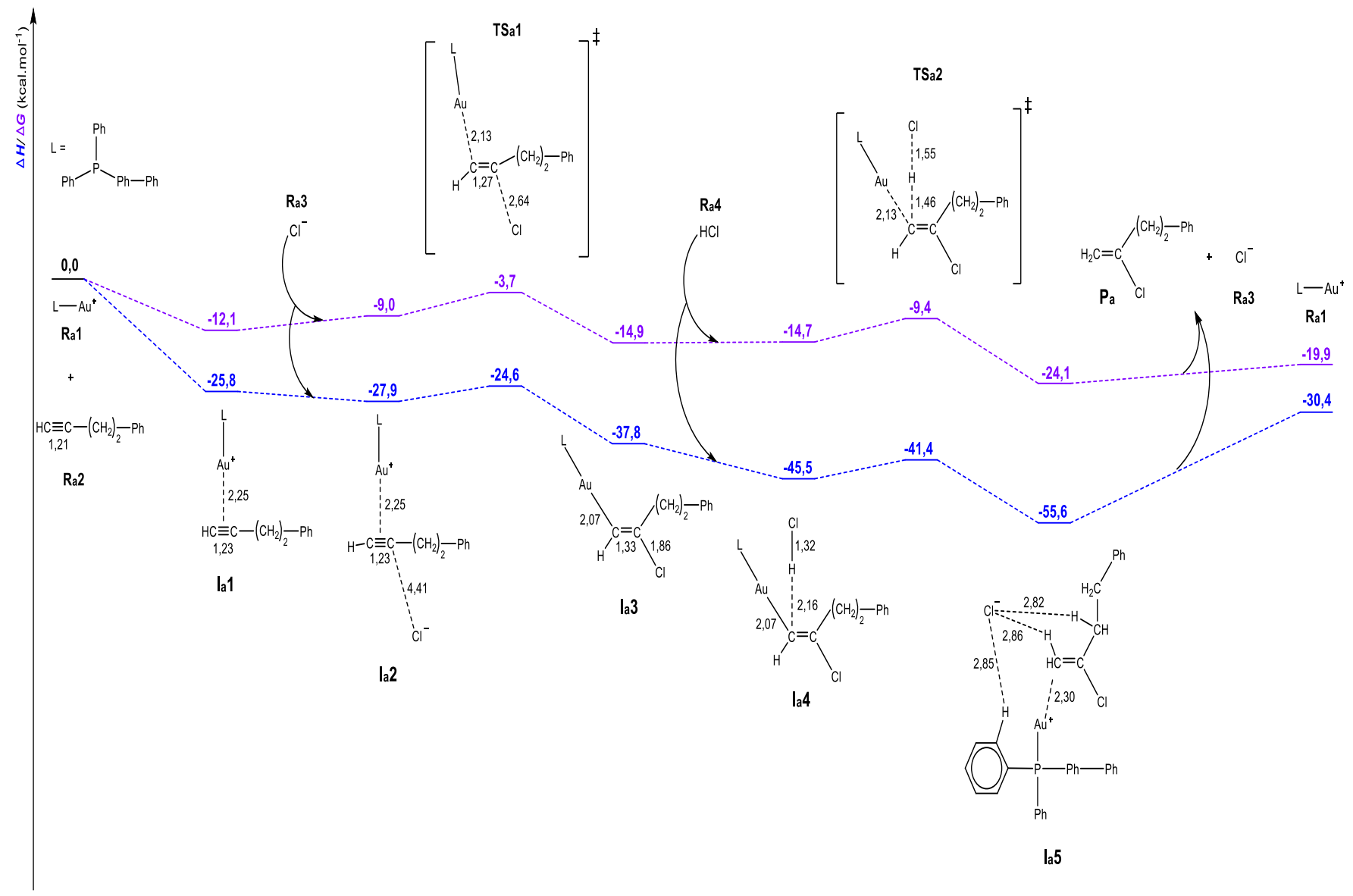

Figura 14. Perfil energético ( $\Delta H$ em azul e $\Delta G$ em roxo) da reação de hidrocloração de alquino catalisada de forma homogênea pelo complexo $\mathrm{LAu}^{+}$, sob a metodologia B3LYP-D3, 6-31G(d,p)/SDD, em água (SMD). Distâncias em Ångström e energias em kcal.mol-1 


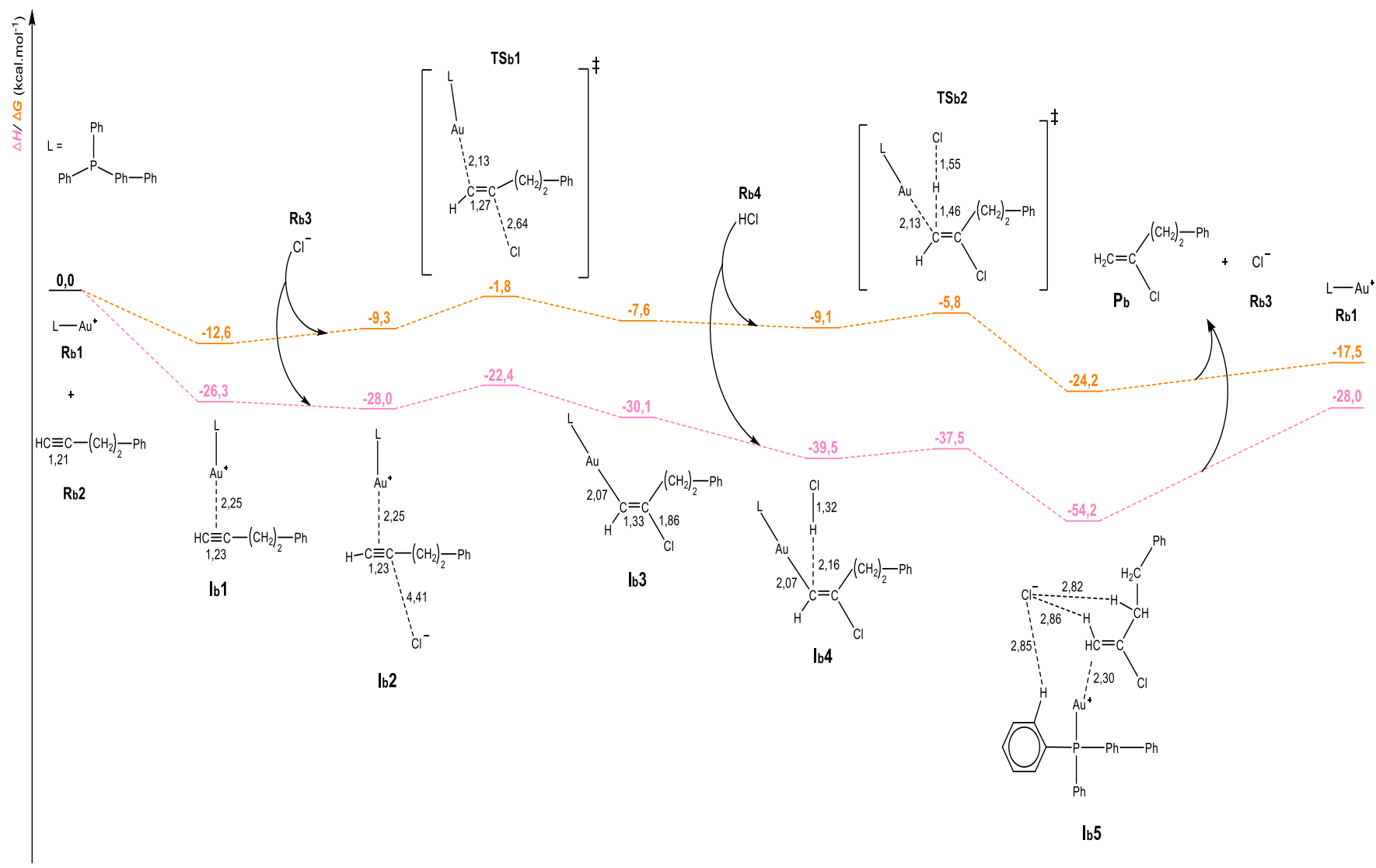

Figura 15. Perfil energético ( $\Delta H$ em rosa e $\Delta G$ em laranja) da reação de hidrocloração de alquino catalisada de forma homogênea pelo complexo $L A u^{+}$, sob a metodologia B3LYP-D3, 6-31+G(d,p)/SDD, em água (SMD). Distâncias em Ångström e energias em $\mathrm{kcal}^{-\mathrm{mol}^{-1}}$

De maneira geral, nos dois perfis, há uma grande estabilização entálpica com a coordenação dos reagentes (formação dos complexos de van der Waals), em la1/lb1, la2//b2 e la4/lb4. Tal coordenação também significa perder graus de liberdade, algo constatado na penalização entrópica, o que leva a um aumento em $\Delta G$.

Na espécie la1/lb1, ocorre a ativação eletrofilica do alquino. A ligação tripla compreende uma região rica em elétrons, e o ouro catiônico atua como um eletrófilo (pela carga positiva, mas também por ser um bom ácido de Lewis graças à contração do $6 s$ ), ${ }^{15}$ se aproximando em torno de $2 \AA$ ao atrair os elétrons $\pi$, deixando-os mais disponíveis. Ocorre, então, um estiramento da ligação tripla em 0,2 $\AA$, o que permite o início da reação ao possibilitar a aproximação do nucleófilo (cloreto) em la2//b22, uma vez que o carbono que sofre o ataque nucleofílico adquire uma maior carga parcial positiva com a ativação do alquino (Tabela 3). A presença do eletrófilo é necessária para ativar o alquino pois, senão, a repulsão entre alquino e nucleófilo é muito grande, ${ }^{40}$ dificultando a ocorrência da reação. 
Com a ativação do alquino e subsequente ataque nucleofílico, uma das ligações $\pi$ da espécie la2/lb2 se rompe, formando uma ligação intermediária ao atingir o primeiro estado de transição, TSa1/TSb1, até configurar a ligação dupla em la3/lb3.

Após a passagem pelo TSa1/TSb1, a reação se processa mais facilmente (com a formação dos intermediários la3/lb3 e la4/lb4), até passar pelo segundo estado de transição que, chegando ao seu intermediário posterior, la5//b5, configura a etapa de maior irreversibilidade da reação - de -9,4 kcal.mol-1 em energia livre para -24,1 kcal.mol-1 (de TSa2 para la5), e -5,8 kcal.mol ${ }^{-1}$ em energia

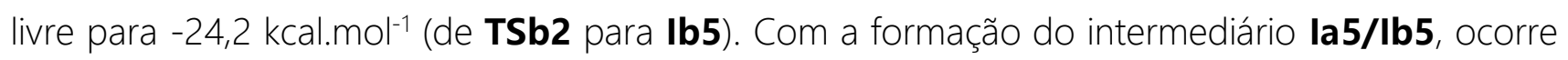
a descoordenação das espécies, regenerando o catalisador.

No primeiro estado de transição (TSa1/TSb1), é a posição do ouro que define a seletividade anti. Pelo fato de o ouro ser um átomo "grande" em relação aos outros presentes no sistema de estudo (na referência 1 há valores de raios covalentes e iônicos dos elementos em questão), é criada uma dificuldade para o cloreto se ligar ao lado do ouro no carbono adjacente ao carbono terminal (em que o ouro se liga). Portanto, o ouro proporciona um impedimento estérico e resta ao cloreto entrar em oposição ao metal. Finalmente, no segundo estado de transição (TSa2/TSb2), com a saída do ouro, o próton entra, formando o produto anti (Pa/Pb).

Podemos observar certas diferenças, explicitadas nas Tabelas 2 e 3, entre as alturas das barreiras dos estados de transição e as cargas das espécies presentes na reação ao incluir as funções de base difusas.

Tabela 2. Comparação das alturas das barreiras com e sem base difusa, referentes à hidrocloração de alquino nas Figuras 14 e 15

\begin{tabular}{|c|c|c|c|c|}
\hline & \multicolumn{3}{|c|}{ Alturas das barreiras $\left(\mathrm{kcal}^{\mathrm{m}} \mathrm{mol}^{-1}\right)$} \\
\hline & \multicolumn{2}{|c|}{$\boldsymbol{\Delta}$} & \multicolumn{2}{c|}{$\boldsymbol{G}$} \\
\hline & TS1 & TS2 & TS1 & TS2 \\
\hline $\mathbf{6 - 3 1 G ( d , p )}$ & 3,3 & 4,1 & 5,3 & 5,3 \\
\hline $\mathbf{6 - 3 1 + G ( d , p )}$ & 5,6 & 2,0 & 7,5 & 3,3 \\
\hline
\end{tabular}


Tabela 3. Relação da carga presente no carbono que sofre o ataque nucleofílico, desde o alquino isolado (Ra2/Rb2) até o intermediário la2//b2

\begin{tabular}{|c|c|}
\hline Espécie & $\begin{array}{c}\text { Carga APT no carbono que } \\
\text { sofre o ataque nucleofílico }\end{array}$ \\
\hline $\mathrm{Ra} 2$ & 0,063 \\
\hline $\mathrm{Rb} 2$ & 0,073 \\
\hline $\mathrm{la} 1$ & 0,326 \\
\hline $\mathrm{lb} 1$ & 0,316 \\
\hline $\mathrm{la} 2$ & $-0,172$ \\
\hline $\mathrm{Ib} 2$ & 0,600 \\
\hline
\end{tabular}

Tendo em vista a Tabela 2, sem a base difusa, para a entalpia, a etapa determinante é referente ao TSa2; para a energia livre, é inconclusivo. Com a difusa, é a formação do TSb1 que requer maior energia - tanto para a entalpia quanto para energia livre. Isso evidencia a maior adequação do conjunto de funções de base difusas para sistemas que envolvam a presença de espécies aniônicas. Pode-se dizer o mesmo em relação às cargas APT apresentadas na Tabela 3, que apresenta, ainda, um resultado divergente para la2, exatamente a espécie em que ocorre a entrada do cloreto.

Outra maneira de realizar a análise da "etapa determinante" é por meio do modelo do span de energia. ${ }^{140}$ Em linhas gerais, para uma reação catalisada, não há uma etapa determinante, mas sim uma zona determinante caracterizada pela estrutura de mais baixa energia livre, até a estrutura de mais alta energia livre (e que não necessariamente ocorre entre espécies adjacentes no perfil energético). Analisando-se a Figura 14, a zona determinante é de la1 a TSa1, no valor de 8,4 kcal.mol-1; já para a Figura 15, a zona determinante é de Ib1 a TSb1, equivalendo a 10,8 $\mathrm{kcalmol}^{-1}$. Nesse último caso, temos uma convergência de resultados referente ao TSb1, tanto para a análise por etapa determinante (altura da barreira), quanto por span de energia. Porém, isso nem sempre será verdade - não necessariamente as duas análises convergem. Em relação ao span, a análise pela altura da barreira, ainda que possa ser válida e útil, oferece conclusões mais limitadas para processos catalíticos. Isso porque o span avalia a reação como um todo; a altura da barreira, por sua vez, foca em pontos isolados.

De qualquer forma, seja pela análise do span ou da etapa determinante, as duas funções de base mostraram que as barreiras de energia são baixas, factíveis à temperatura ambiente, o que possibilitaria uma reação fácil de ocorrer, e que resulta no produto anti, conforme esperado. ${ }^{59}$ 


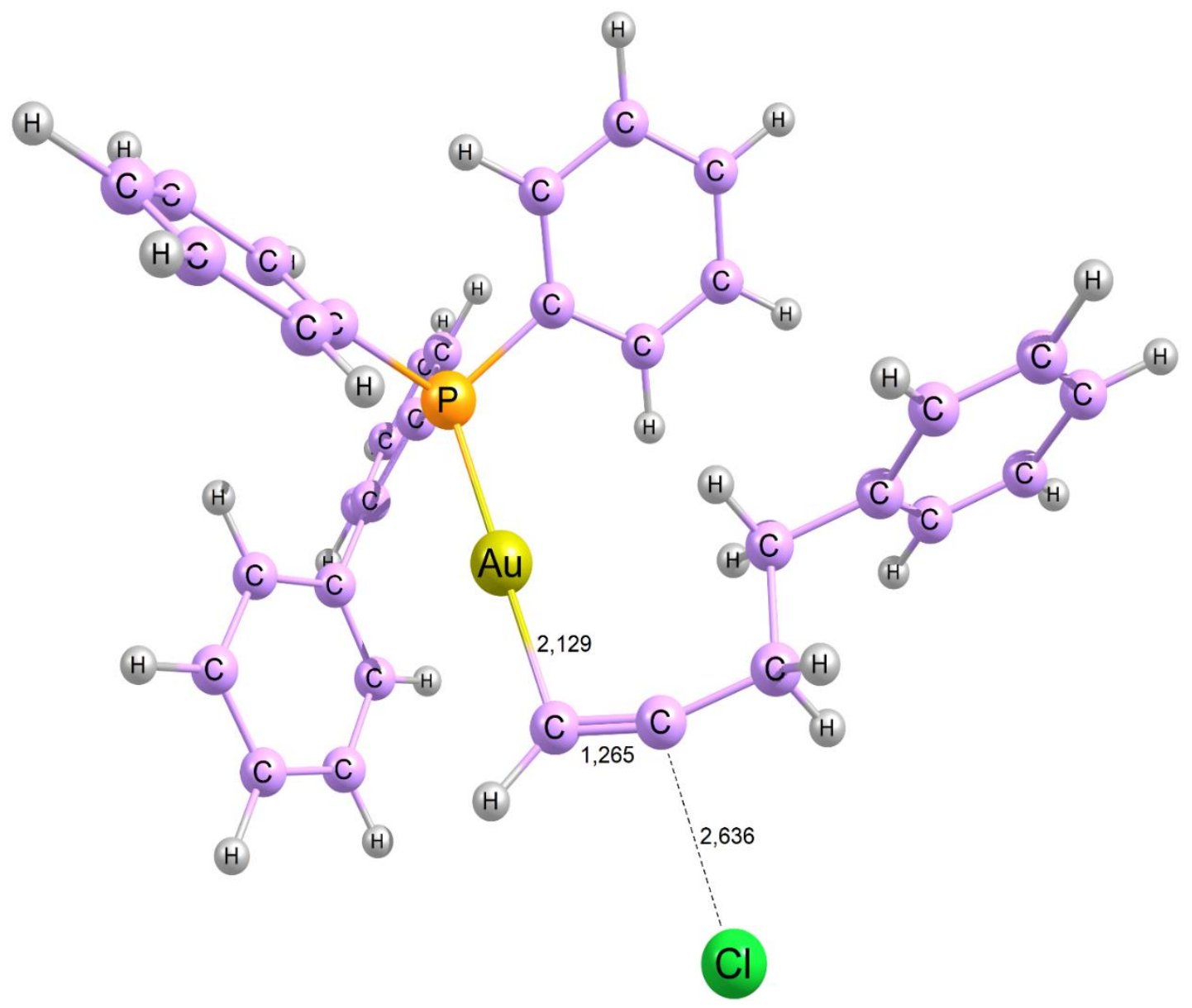

Figura 16. Primeiro estado de transição, TSb1, da reação catalisada por ouro catiônico. A frequência imaginária é referente à cloração, no valor de $152,13 \mathrm{i} \mathrm{cm}{ }^{-1}$. Distâncias em Ångström 


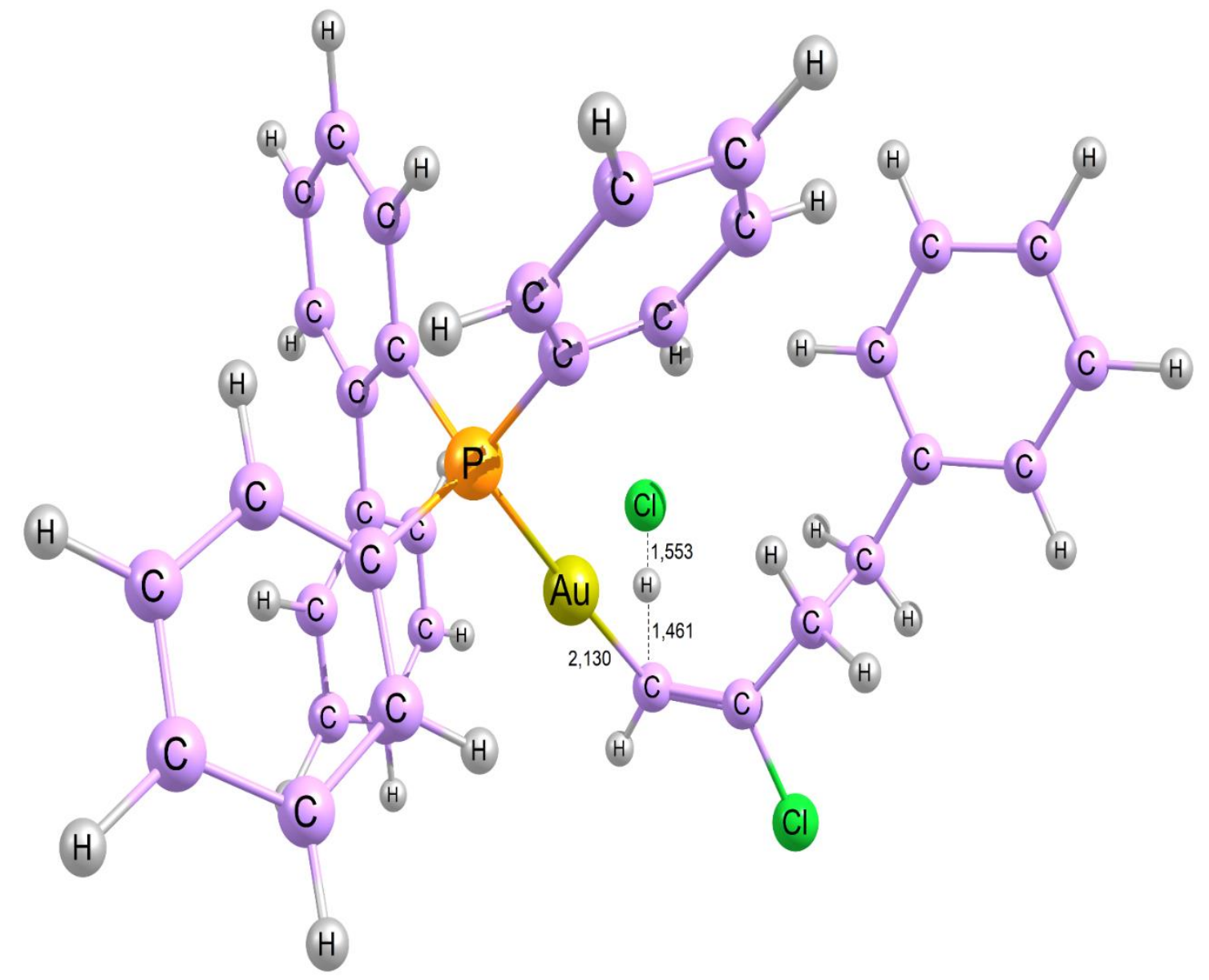

Figura 17. Segundo estado de transição, TSb2, da reação catalisada por ouro catiônico. A frequência imaginária é referente à desprotonação do $\mathrm{HCl}$, no valor de $981,26 \mathbf{i} \mathrm{cm}^{-1}$. Distâncias em Ångström

\subsection{Hidrocloração sem presença de ouro}

O objetivo central ao se estudar tal reação foi relativo à regiosseletividade. Contudo, houve outro ponto de interesse, que diz respeito à função do HFIP. Isso porque o HFIP é um composto em comum com a reação catalisada por LAuCl:59 a reação conduzida na ausência de catalisadores de ouro também foi feita em presença de $\mathrm{HCl}$ e HFIP, em que se sugere que o complexo $\mathbf{A}^{\prime}$ (Figura 6) é formado e conduz à obtenção do produto syn. Quando o HFIP não está presente no meio reacional, a reação sem ouro se processa com baixíssimo rendimento. ${ }^{65}$ Dessa forma, temos um indicativo de que o HFIP possui papel importante no curso da reação. A fim de entendermos a 
função de cada molécula ( $\mathrm{HCl}$ e HFIP) no sistema sem ouro, buscou-se a caracterização da reação em duas partes: uma somente com HCl (Figura 18), e outra somente com HFIP (Figura 19). Em toda esta seção, somente o conjunto de funções de base com inclusão da função difusa foi utilizado.

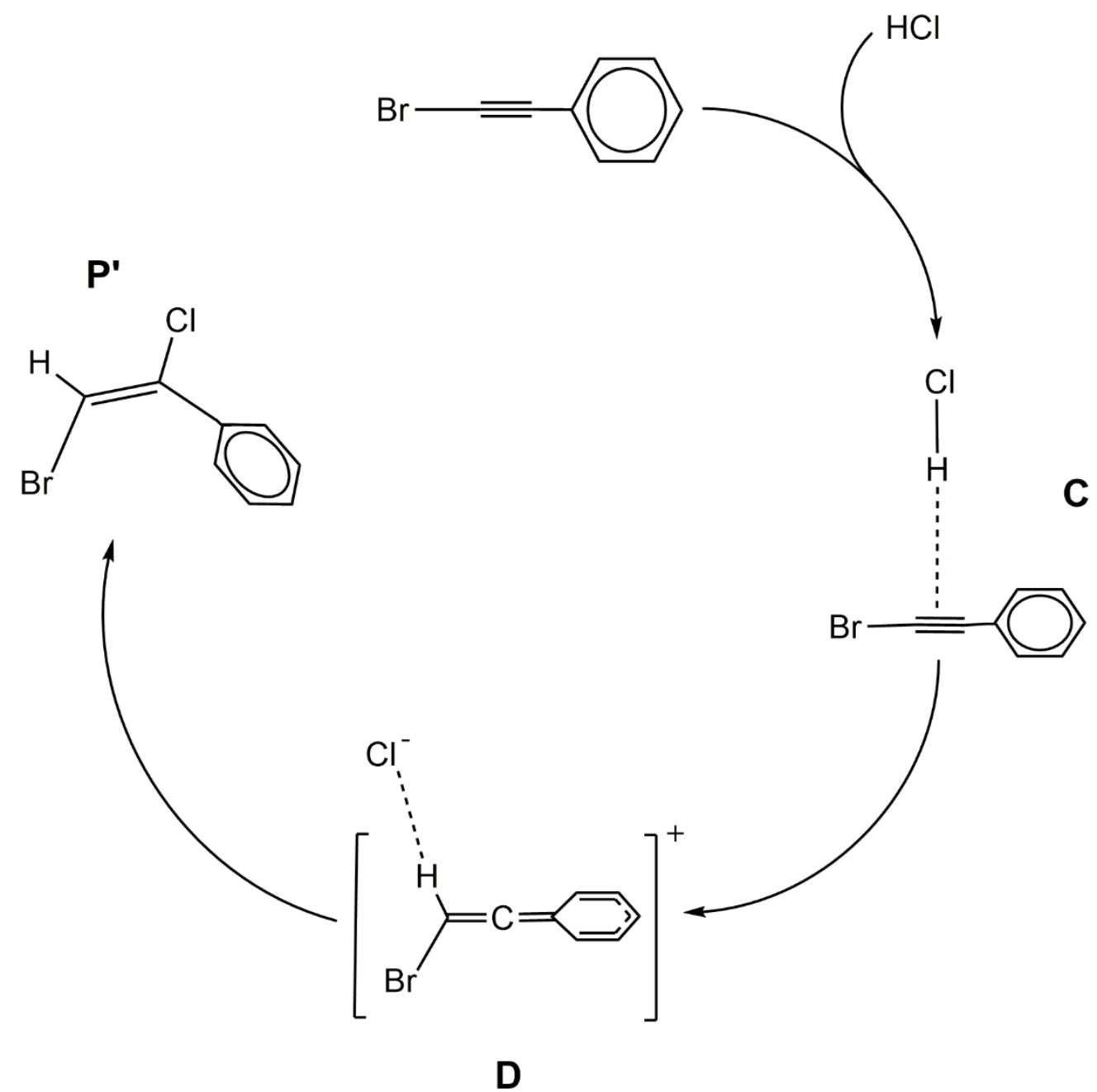

Figura 18. Reação de hidrocloração de alquino apenas com HCl, sem o HFIP 


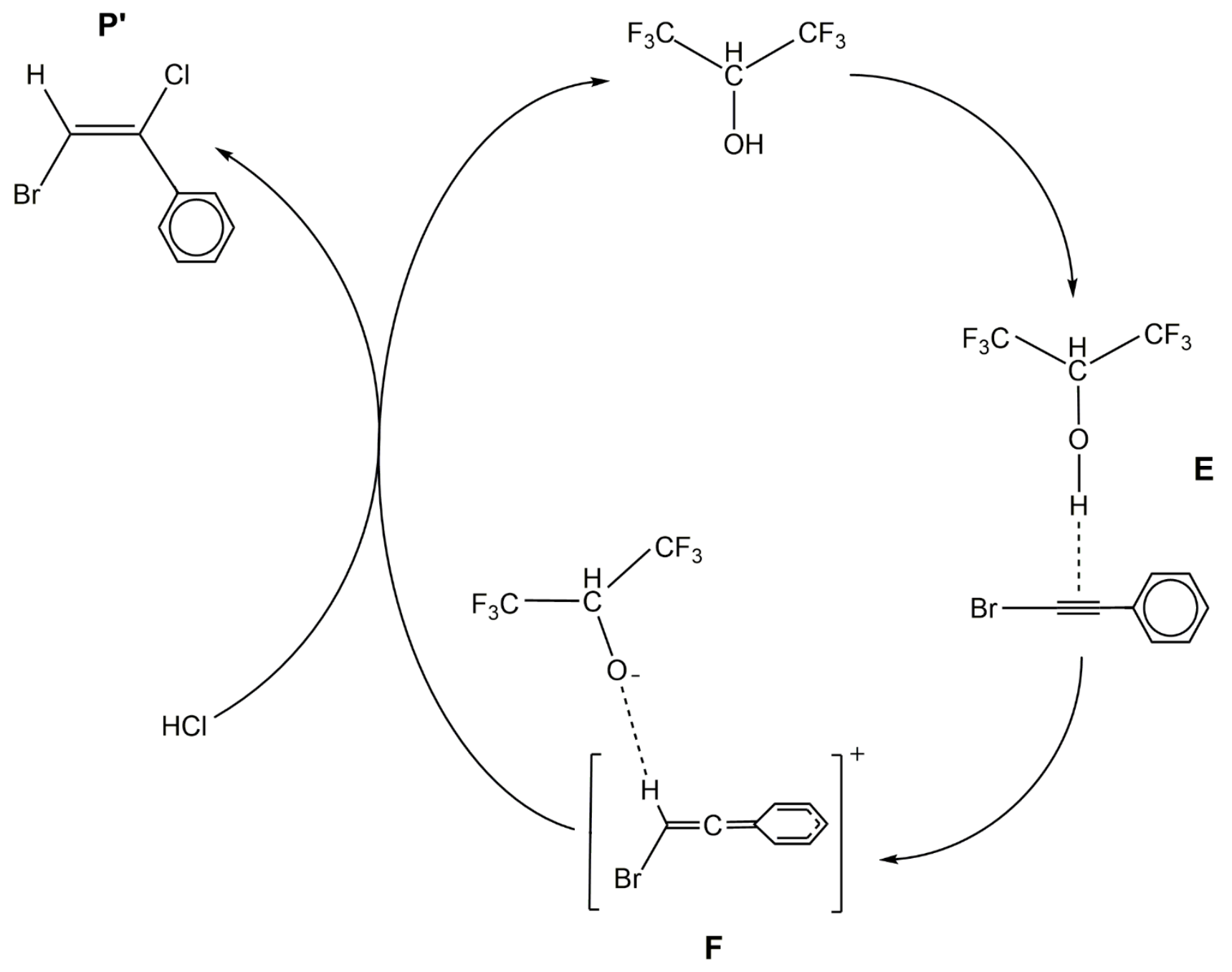

Figura 19. Ciclo catalítico da hidrocloração de alquino em presença de HFIP 


\subsubsection{Resultados com $\mathrm{HCl}$}

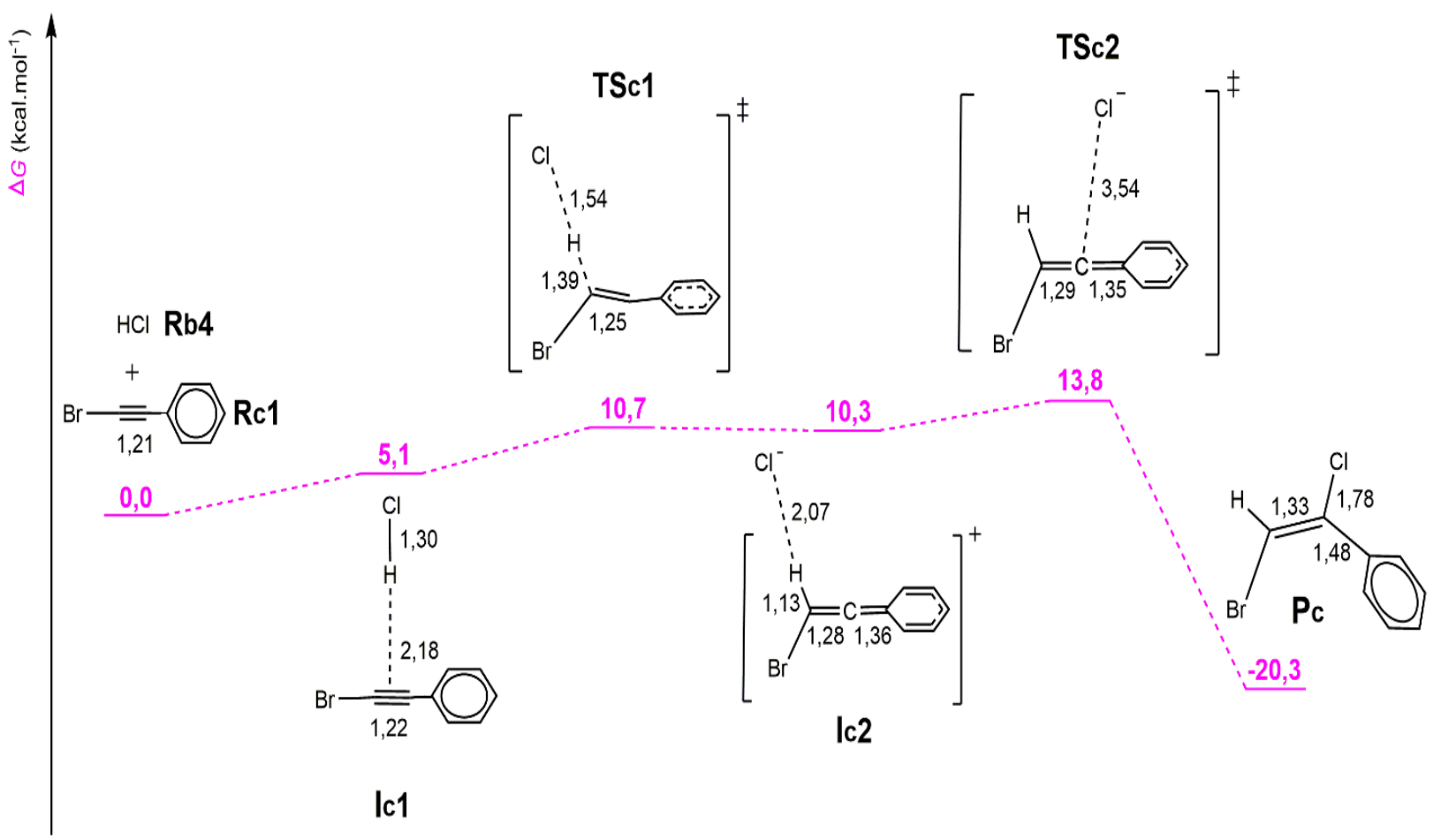

Figura 20. Perfil de energia livre da reação de hidrocloração de alquino sem catálise por ouro, com obtenção do produto syn, Pc, sob a metodologia B3LYP-D3, 6-31+G(d,p)/SDD, em água (SMD). Distâncias em Ångström e energias em kcal.mol-1

Analisando-se o perfil da Figura 20, podemos observar que, primeiramente, a aproximação do hidrogênio do $\mathrm{HCl}$ - um eletrófilo - provoca um ligeiro aumento no comprimento da ligação tripla, 0,1 A menor frente à reação com ouro, caracterizando uma ativação do alquino um tanto menos efetiva. Isso ocorre devido à carga positiva presente no metal, que atrai de forma mais eficiente os elétrons da insaturação; aqui, o hidrogênio permanece ligado, possuindo, portanto, apenas a carga parcial positiva. Isso traz as seguintes implicações termodinâmicas:

- O ouro, ao se coordenar com o alquino, garante uma maior estabilização entálpica: Ib1 possui valor de $\Delta H$ equivalente à -26,3 $\mathrm{kcal}^{\mathrm{mol}}{ }^{-1}$, enquanto Ic1, $-1,3 \mathrm{kcal}^{\mathrm{mol}}{ }^{-1}$;

- Consequentemente, a perda de graus de liberdade, observada pelo valor de $\Delta G$, é mais pronunciada em Ib1 do que em Ic1. 
Nos cálculos, apesar de o $\mathrm{HCl}$ aparecer como molécula, pensando no sistema realístico, em água, a molécula de $\mathrm{HCl}$ se dissocia. Sendo assim, o $\mathrm{HCl}$ pode ser entendido como uma fonte de prótons e cloretos que viabiliza a ocorrência da reação (o mesmo pode ser dito para a reação com ouro). Portanto, no sistema real, a interação observada seria entre alguma espécie do próton solvatado (e não o hidrogênio ligado) e a ligação tripla. Tal atração é o que promove o estiramento da insaturação, preparando o alquino para reagir.

Além disso, as barreiras de energia são baixas, configurando etapas reversíveis; a etapa de formação do produto $\mathbf{P c}$ é a única irreversível. Os reagentes separados, $\mathbf{R b 4}$ e Rc1, são as espécies que mais se concentram em comparação aos intermediários Ic1 e Ic2. Dessa forma, pode-se afirmar que a demanda energética aparente da reação é de 13,8 $\mathrm{kcal}^{\mathrm{mol}} \mathrm{m}^{-1}$, entre TSa2 e os reagentes separados. É também nesse estado de transição que é decidida a seletividade para a formação do produto syn, em detrimento da formação do produto anti, apresentado no perfil energético da Figura 21 a seguir:

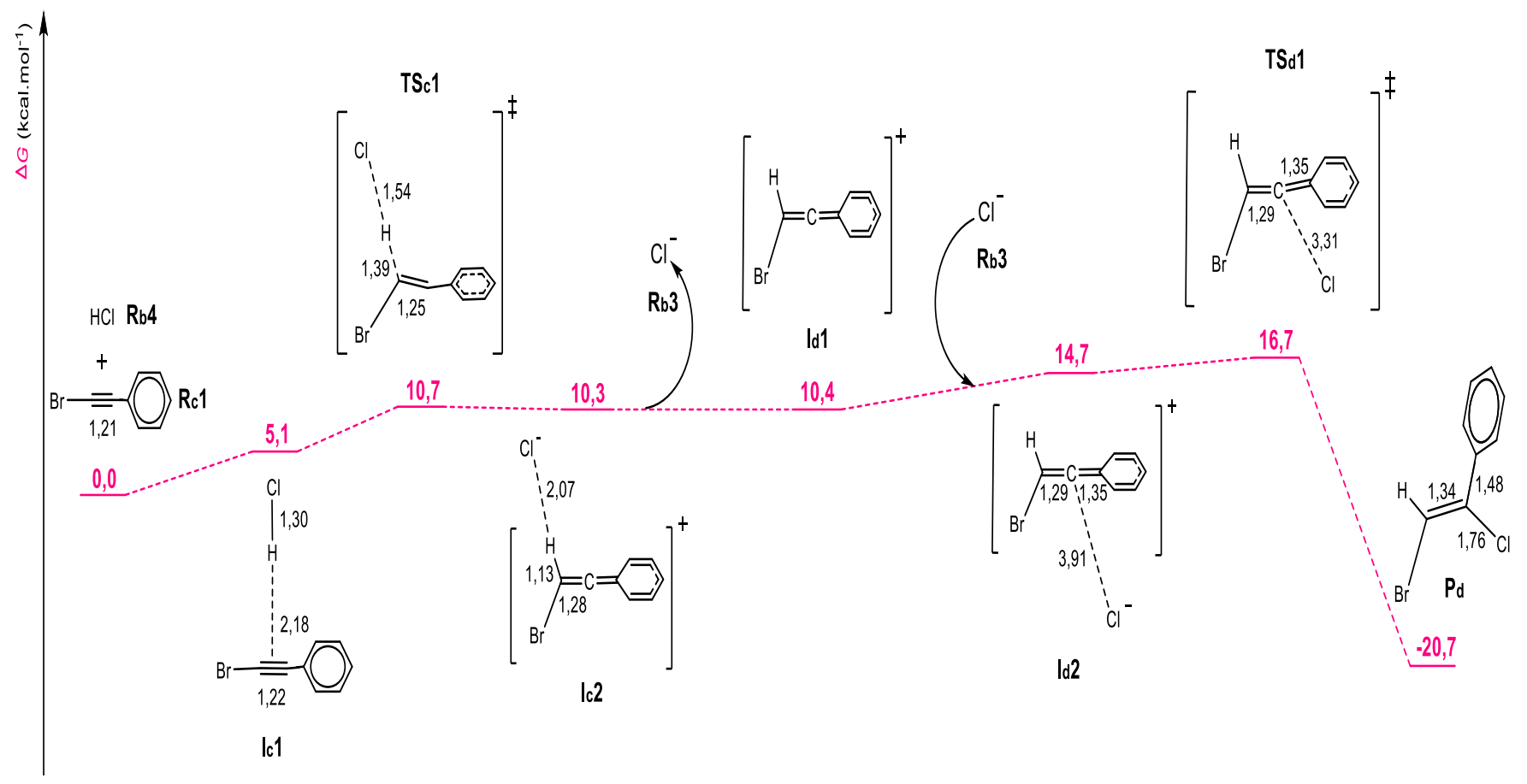

Figura 21. Perfil de energia livre da reação de hidrocloração de alquino sem catálise por ouro, com obtenção do produto anti, Pd, sob a metodologia B3LYP-D3, 6-31+G(d,p)/SDD, em água (SMD). Distâncias em Ångström e energias em kcal.mol-1

Ainda que o produto anti proporcione grande estabilização, equivalente ao produto syn, no caso da reação formando o produto anti a demanda energética aparente é de $16,7 \mathrm{kcal}^{\text {.mol-1 }}$ - daí a 
formação majoritária do produto $s y n_{1}^{65}$ cujo estado de transição requer $3 \mathrm{kcal}^{\mathrm{mol}}{ }^{-1}$ a menos para ser produzido. O que explica essa diferença de energia é o impedimento estérico proporcionado pelo átomo de bromo: o ataque do cloreto na posição syn é mais livre para formar o TSc2. Portanto, apesar de $16,7 \mathrm{kcal}^{\mathrm{mol}}{ }^{-1}$ ser viável à temperatura ambiente, é preferível formar o produto syn, o que está de acordo com os resultados experimentais. ${ }^{65}$

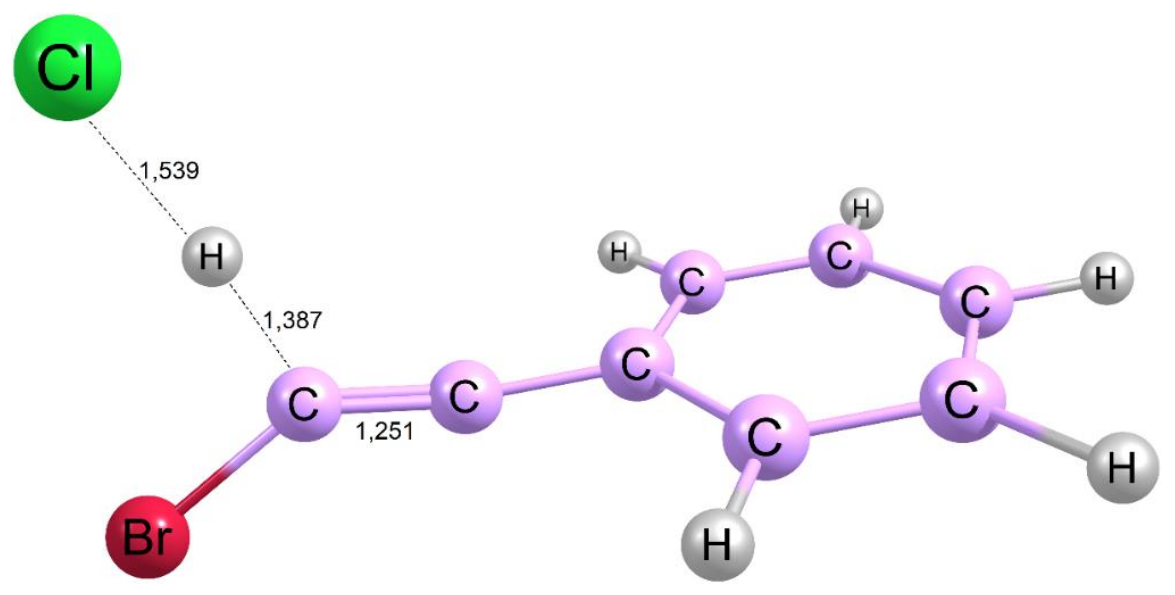

Figura 22. Primeiro estado de transição, TSc1, da reação de hidrocloração na ausência de ouro. A frequência imaginária é referente à desprotonação do $\mathrm{HCl}$, no valor de $869,04 \mathrm{i} \mathrm{cm}^{-1}$. Distâncias em Ångström
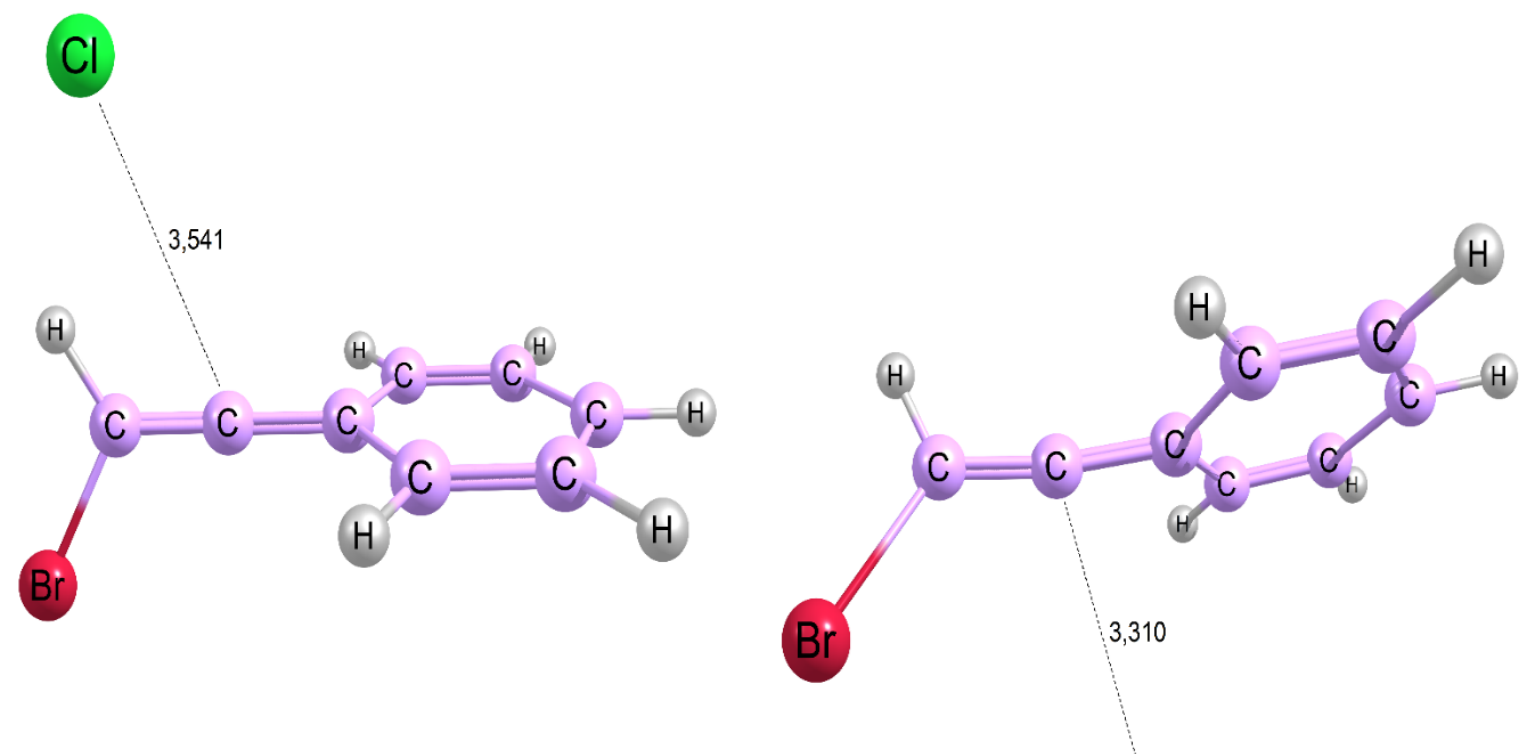

CI

Figura 23. TSc2 $\left(58,77 \mathbf{i} \mathrm{cm}^{-1}\right)$ e TSd1 $\left(71,52 \mathbf{i ~ c m}{ }^{-1}\right)$, respectivamente. Distâncias em Ångström 


\subsubsection{Resultados com HFIP}

Os estados de transição da reação exibida na Figura 19 foram buscados. No entanto, após diversas tentativas, não foram encontrados.

Conforme pode ser observado na Figura 24, a diferença de energia livre entre le2 e os reagentes separados seria, pelo menos, superior a $30 \mathrm{kcal}^{\mathrm{mol}}{ }^{-1} \mathrm{em} \Delta G$, o que, em comparação aos perfis estudados neste projeto, se configura em um caminho reacional pouco favorável.

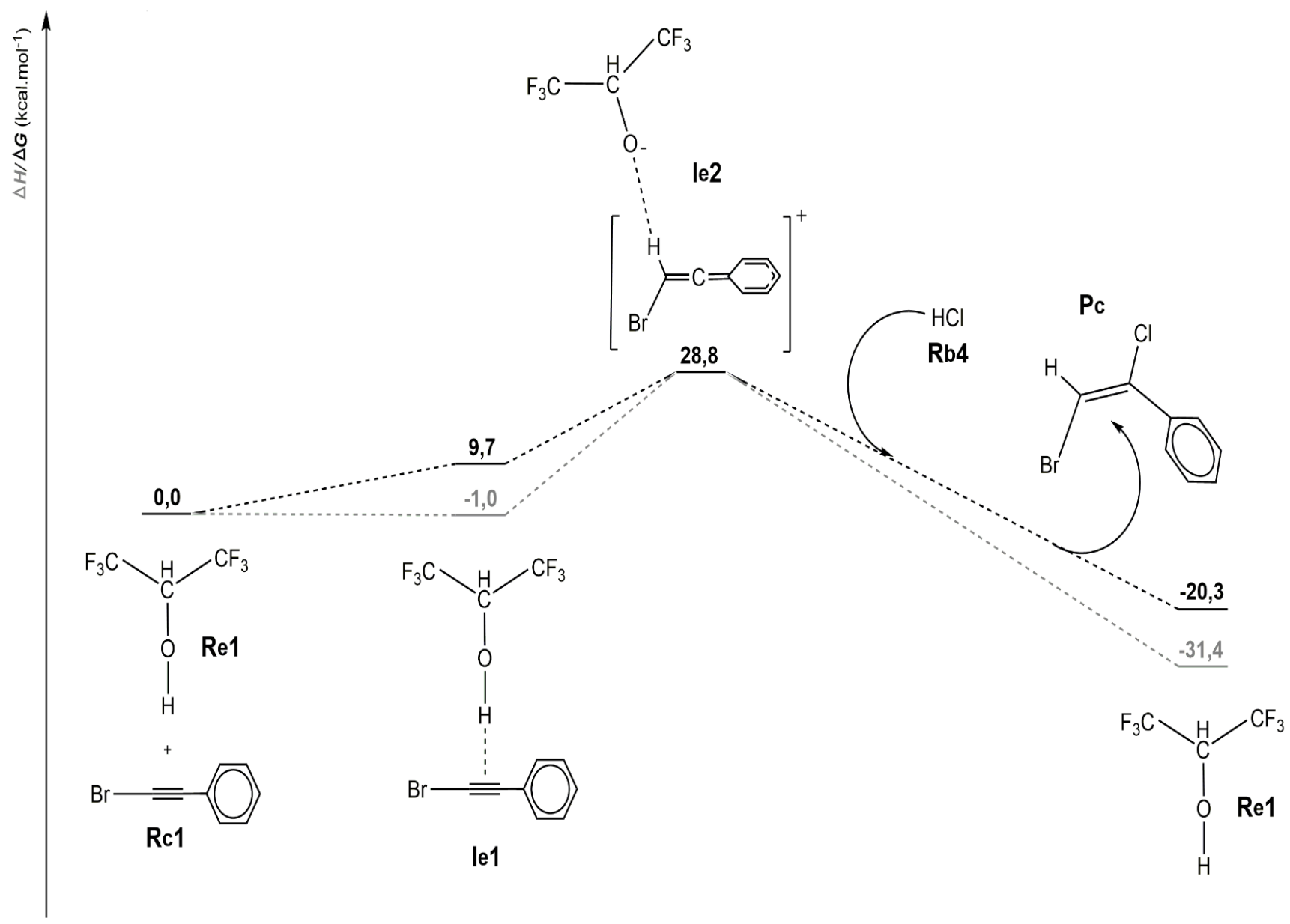

Figura 24. Resultados da termodinâmica do ciclo da Figura 19, sob a metodologia B3LYP-D3, 6-31+G(d,p)/SDD, em água (SMD) 
Dessa forma, inferiu-se que a reação não se processa por tal caminho, abrindo possibilidades alternativas para explicar a função do HFIP na reação. As hipóteses que se mostraram viáveis foram duas principais: o HFIP contribuiria ao influenciar a constante dielétrica do meio, o que seria passível de verificação ao se comparar os resultados da reação de hidrocloração de alquino sem ouro em água (Figura 20) com os da caracterização em ciclohexanona; ou, o HFIP faria sua contribuição de maneira explícita, estabilizando os estados de transição (TSc1 e TSc2, Figura 20). No TSc1, poderia estabilizar das seguintes formas: interagindo com o cloreto (Figura 25a); com o próton (Figura 25b); ou com a ligação tripla (Figura 25c). No TSc2, poderia estabilizar o cloreto (Figura 26a), ou ativar o carbono que sofre o ataque nucleofílico, deixando-o mais positivo (Figura 26b). A seguir, são apresentados os resultados oriundos de tais hipóteses.

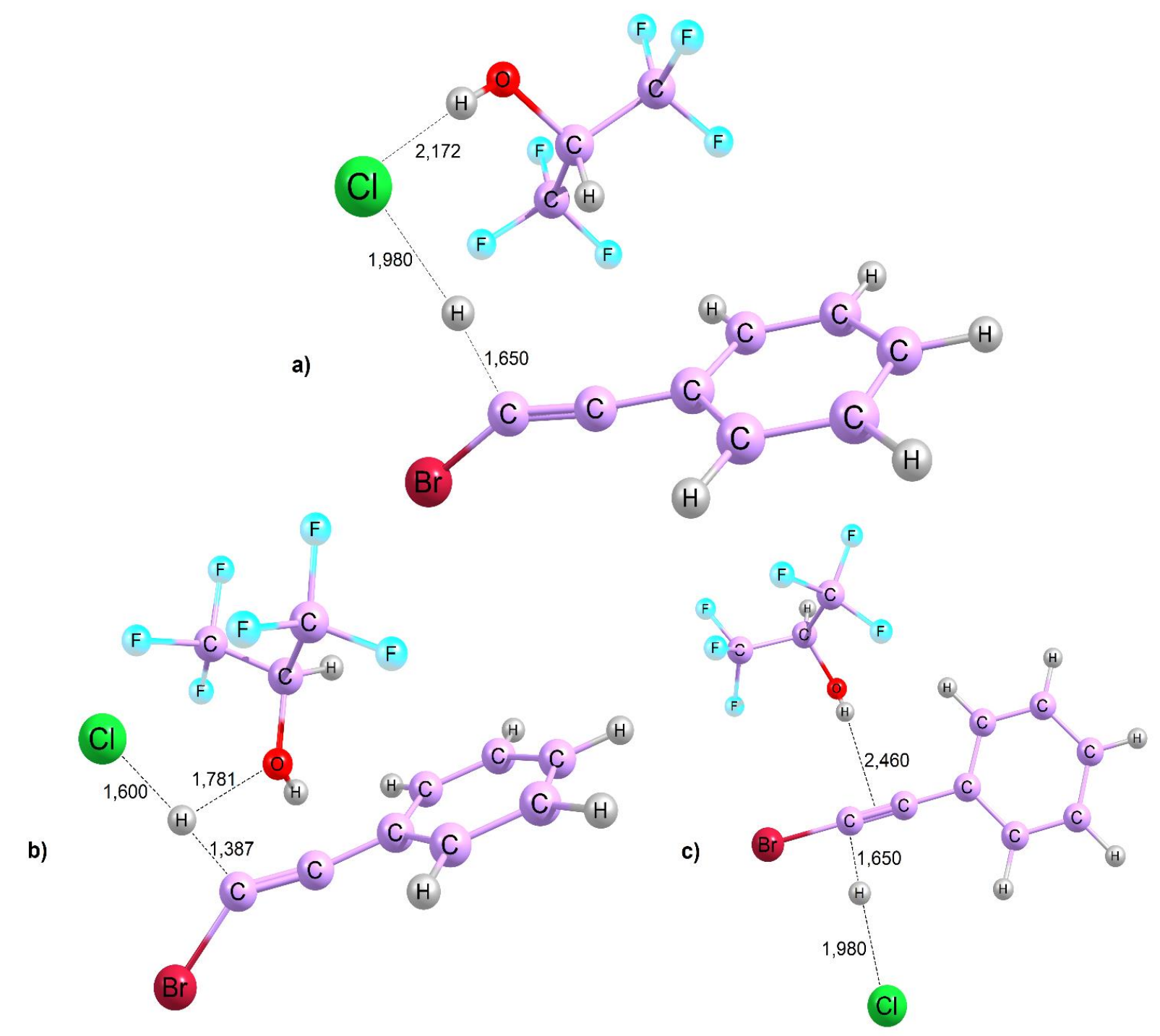

Figura 25. Exemplos de tentativas de se obter o primeiro estado de transição (TSc1) com uma molécula de HFIP explícito 


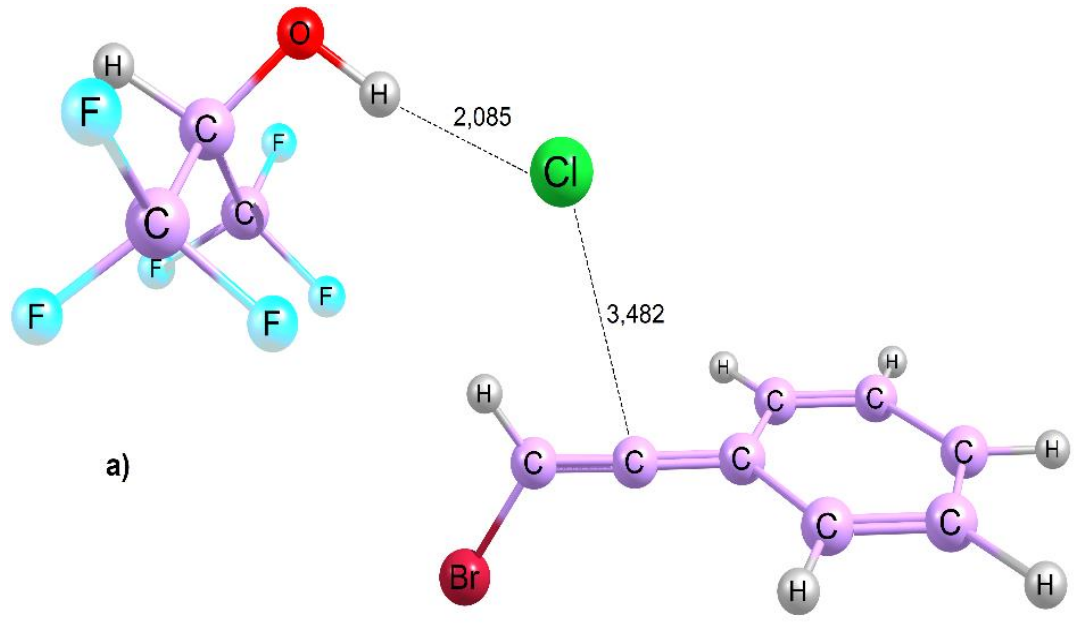

Figura 26. Exemplos de tentativas de se obter o segundo estado de transição (TSc2) com uma molécula de HFIP explícito

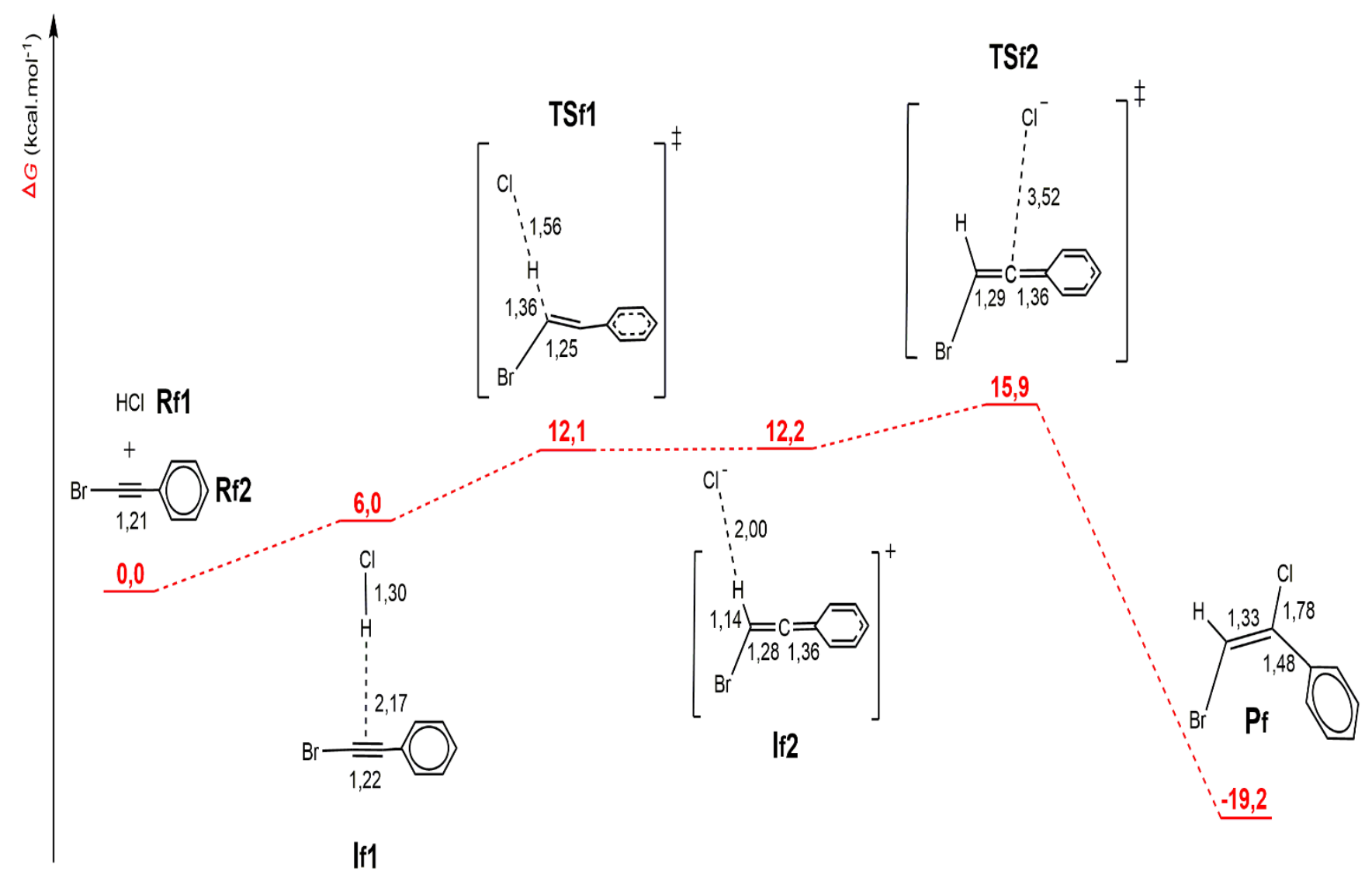

Figura 27. Perfil de energia livre da reação de hidrocloração de alquino sem catálise por ouro, com obtenção do produto syn, sob a metodologia B3LYP-D3, 6-31+G(d,p)/SDD, em ciclohexanona (SMD). As frequências imaginárias dos TSf1 e TSf2 são 833,00i $\mathrm{cm}^{-1}$ e 65,20i cm-1, respectivamente. Distâncias em Ångström e energias em kcal.mol-1 
Comparando com o perfil em água mostrado na Figura 20, as barreiras de energia permaneceram viáveis (Figura 27), porém, a constante dielétrica do solvente implícito ciclohexanona não contribuiu com a reação. Pelo contrário, não estabilizou os estados de transição (tampouco os intermediários), aumentando ligeiramente as barreiras de energia e o custo energético total - de 13,8 kcal.mol-1 em água para 15,9 kcal.mol-1 em ciclohexanona.

Sendo assim, seguiu-se para a segunda hipótese (Figuras 25 e 26). Mais uma vez, muitas tentativas foram feitas para encontrar os estados de transição TSc1/TSf1 e TSc2/TSf2 estabilizados pelo HFIP explícito (Figuras 25 e 26b), mas nenhuma foi bem-sucedida. No entanto, o estado de transição TSc2/TSf2 foi encontrado dessa maneira (Figura 26a), tanto em água, quanto em ciclohexanona, mostrando que o HFIP estabiliza tal estrutura (Figura 28). A diferença de energia livre relativa aos reagentes separados é de $17,9 \mathrm{kcal}^{\mathrm{mol}}{ }^{-1} \mathrm{em}$ ciclohexanona (frente a 15,9

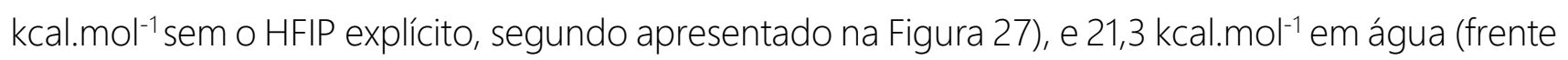
a 13,8 kcal.mol-1 sem o HFIP explícito, segundo apresentado na Figura 20).

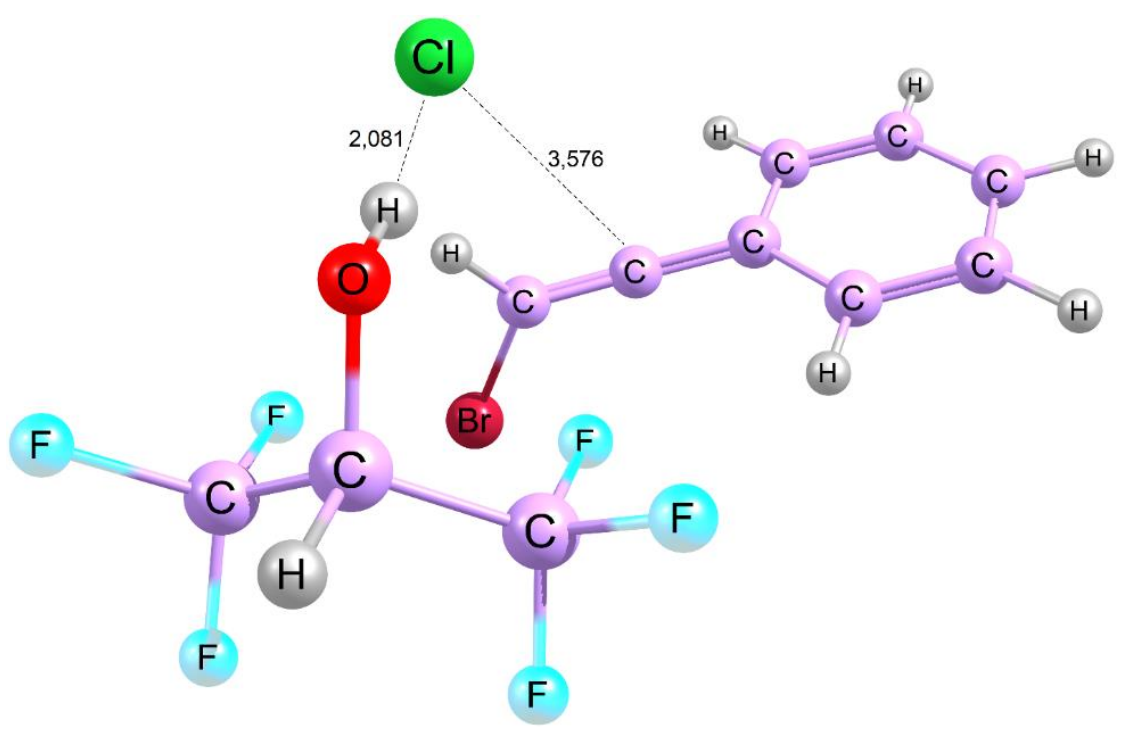

Figura 28. TSf2 $\left(43,50 \mathrm{i} \mathrm{cm}^{-1}\right)$, estabilizado por uma molécula de HFIP

Ainda com relação aos perfis apresentados nas Figuras 20 e 27, nota-se que, embora haja uma grande diferença nas constantes dielétricas da água e da ciclohexanona, as energias relativas são semelhantes, diferindo, no máximo, em $2 \mathrm{kcal} \mathrm{mol}^{-1}$. Situação similar ocorre no sistema com ouro, o que pode ser observado na Tabela 1 (seção 4.1).

Levantamos, então, duas possibilidades para explicar isso. A primeira é que, para esses sistemas, talvez não haja uma grande sensibilidade aos parâmetros considerados no modelo de solvente 
implícito SMD, o que resultaria nas energias semelhantes, apesar da grande diferença entre os solventes.

A outra possibilidade diz respeito ao uso do SMD no tipo de reação estudada, que envolve espécies carregadas. Há ressalvas na literatura indicando que o modelo (assim como os outros modelos implícitos), apesar de ser robusto e muito bem-sucedido (sobretudo ao descrever espécies neutras com a presença da base 6-31G(d)), pode apresentar falhas quando se trata da descrição de reações

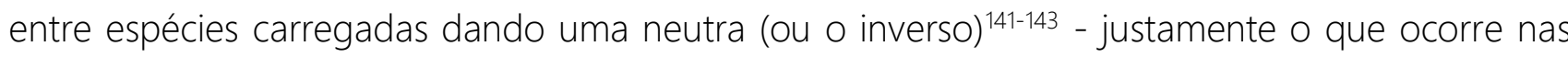
reações de estudo. Pode-se observar tal situação em todo o decorrer da reação com ouro (Figuras 14 e 15), bem como na passagem do intermediário Ic2/If2 e Id2 para os respectivos produtos (Figuras 20, 21 e 27).

Qualquer que seja o caso, abre-se então a possibilidade de as reações serem melhor descritas a partir de uma microsolvatação/solvatação explícita (ainda em conjunto com a solvatação implícita). ${ }^{142,143}$ Dessa forma, pode-se verificar a confiabilidade e adequação do modelo implícito nas reações estudadas. $O$ estado de transição da Figura 28, ao se adicionar mais moléculas de HFIP, poderia ser um dos pontos de partida em direção à microsolvatação. De maneira semelhante, o mesmo seria feito para os demais estados de transição dos sistemas.

Há ainda outra questão a ser considerada, que envolve a temperatura. Experimentalmente, a reação sem ouro foi conduzida a uma temperatura de $50^{\circ} \mathrm{C} .{ }^{65}$ Contudo, os perfis energéticos nas Figuras 20 e 27 mostram mecanismos viáveis à temperatura ambiente, sem necessidade dos $50^{\circ} \mathrm{C}$. No caso da reação com ouro, ainda que não haja descrição experimental da reação caracterizada (conforme foi exposto no início da seção 4.1), é comum o uso de temperaturas de $60,80^{\circ} \mathrm{C}$ para reações catalisadas por $\mathrm{LAu}^{+}$em água. ${ }^{137-139}$ Caso a temperatura seja utilizada para permitir que os mecanismos ocorram, a solvatação explícita poderia fornecer, então, uma descrição mais realista dos sistemas, de modo a proporcionar uma maior compatibilidade entre a temperatura usada experimentalmente e as barreiras de energia dos mecanismos. 


\subsection{Ativação do catalisador LAuCl}

As hipóteses apresentadas na Figura 6 foram testadas, em ciclohexanona como solvente implícito. A preferência desse solvente ao longo de toda esta seção se deve ao fato de o HCl se dissociar em água. Aqui, esse é um fato mais relevante do que nas seções anteriores pois, segundo mostrado na Figura 6, a molécula de $\mathrm{HCl}$ deve permanecer ligada. A base utilizada foi a 6-31G(d,p).

Para o catalisador $\mathrm{LAuCl}$ se tornar ativo, além da extensão da ligação $\mathrm{Au}-\mathrm{Cl}$, considera-se a ocorrência simultânea de algumas condições, tendo como base o que foi observado na reação com ouro catiônico (Figuras 14 e 15), de modo a propiciar um ambiente para o ataque nucleofílico:

- Distância de aproximadamente 2 A entre o átomo de ouro e a ligação tripla, e de forma que o metal se encontre ligeiramente mais próximo do carbono terminal (conforme pode ser melhor observado no TSb1, Figura 16);

- Aumento da carga parcial positiva no carbono que sofrerá o ataque nucleofílico (chamado de carbono interno e destacado em rosa nas figuras a seguir), para aproximadamente 0,3 , tendo como base o exposto na Tabela 3;

- Aumento da distância da ligação tripla do alquino, de 1,21 A para 1,23 A.

Ainda que a reação com ouro tenha sido caracterizada em água, seguindo os resultados da Tabela 1, como a diferença entre as energias relativas dos solventes não se mostrou relevante, e como nas estruturas otimizadas em água e em ciclohexanona as distâncias interatômicas são muito próximas, supõe-se que as geometrias e distâncias de interação seriam, essencialmente, as mesmas se a reação tivesse sido caracterizada em ciclohexanona. Portanto, embora haja essa mudança de solvente entre o que foi apresentado na seção 4.1 e a presente, os resultados obtidos na reação com ouro catiônico podem ser aplicados aqui para avaliar a ativação do catalisador LAuCl no solvente ciclohexanona.

De fato, como os autores sugerem, ${ }^{59}$ há um ligeiro aumento da ligação Au-Cl em B' (Figura 6)

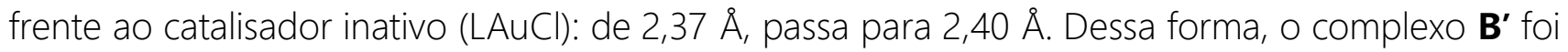
colocado interagindo com o alquino (Figura 29), para verificar o quão ativado ou não o mesmo fica. O comprimento inicial da ligação tripla no alquino isolado é 1,210 $\AA$ e, ao se aproximar do complexo B', passa a ser de 1,211 Å, com distância ao ouro entre 3 e $4 \AA$. Sendo assim, sabemos que o catalisador $\mathrm{LAUCl}$ ainda está inativo, provavelmente necessitando de moléculas de solvente explícito para ativá-lo - no caso, moléculas de HFIP. 


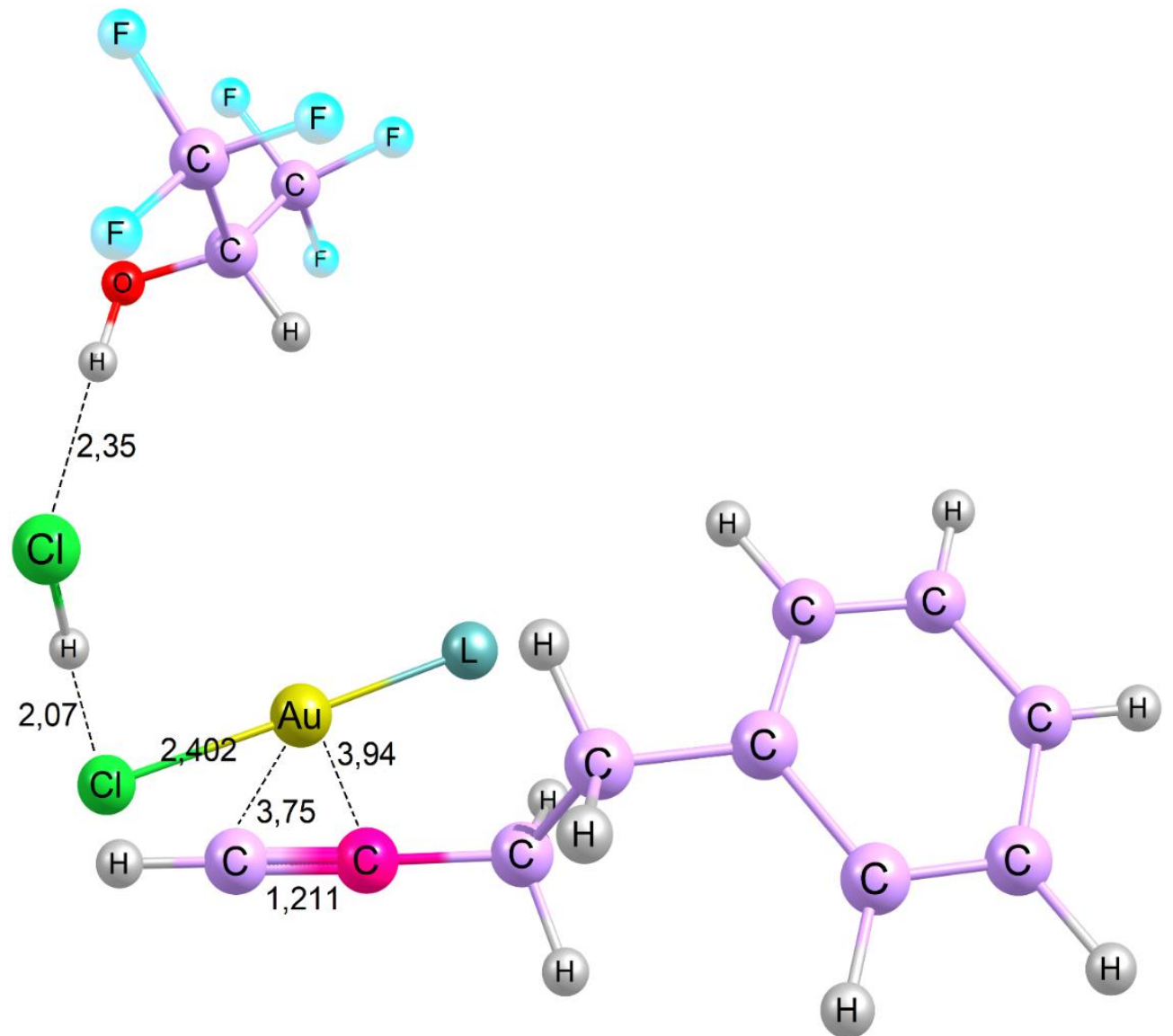

Figura 29. Complexo B' interagindo com 0 alquino, sob a metodologia B3LYP-D3, 6-31G(d,p)/SDD, em ciclohexanona (SMD). Distâncias em Ångström

Assim, testou-se colocar um HFIP interagindo com o átomo de cloro ligado ao ouro. O que ocorreu foi que esse HFIP migrou, de maneira a interagir com a ligação tripla (Figura 30): 


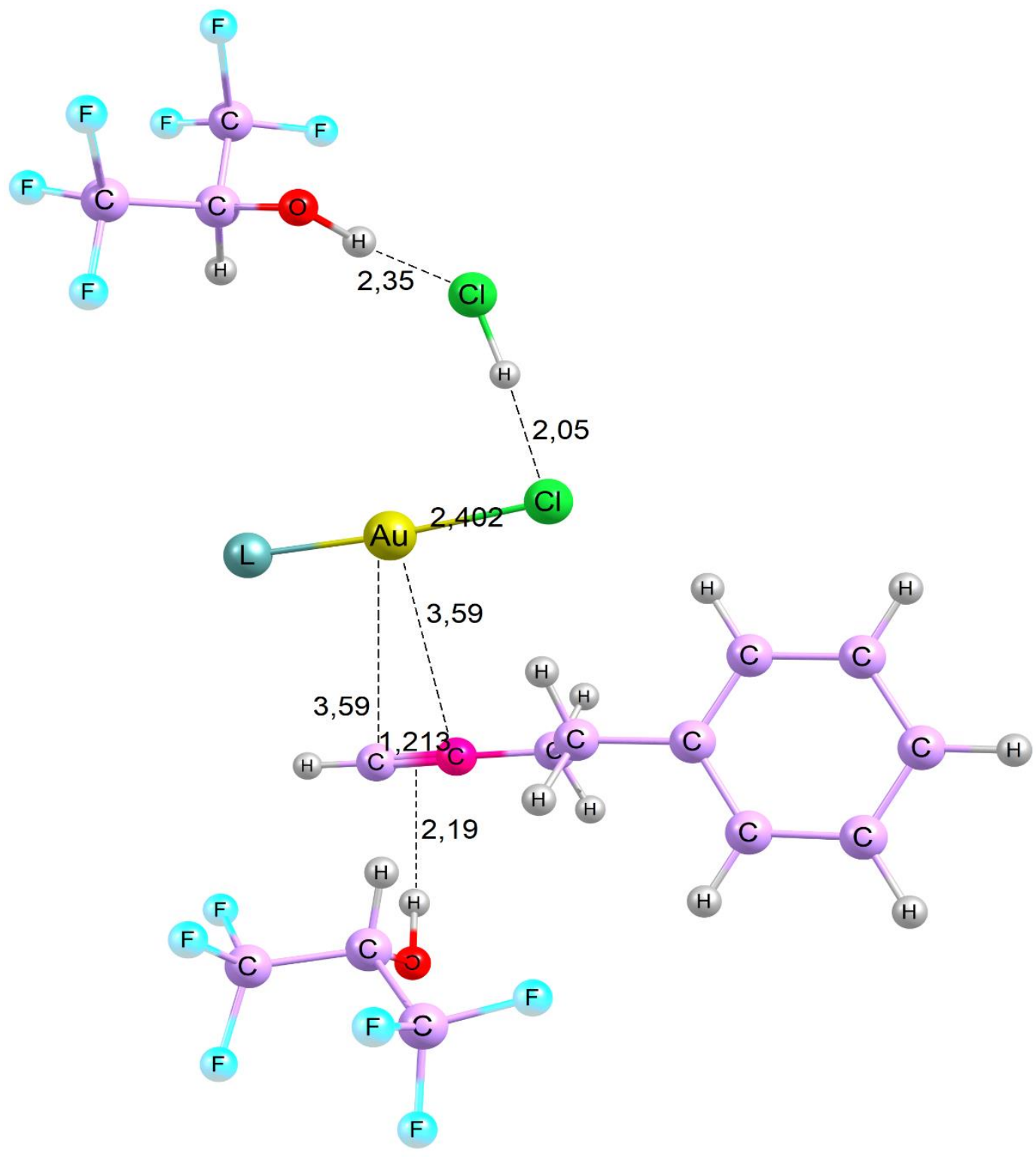

Figura 30. Complexo $\mathbf{B}^{\prime}$ com alquino, e uma molécula de HFIP explícito que interage com a insaturação, sob a metodologia B3LYP-D3, 6-31G(d,p)/SDD, em ciclohexanona (SMD). Distâncias em Ångström

Seguindo esse resultado obtido, experimentou-se introduzir mais uma molécula de HFIP no sistema, em duas diferentes posições: em rede com o primeiro HFIP (que parte da ligação tripla), hipótese exposta na Figura 31; e mais um HFIP interagindo com a ligação tripla (Figura 32). 


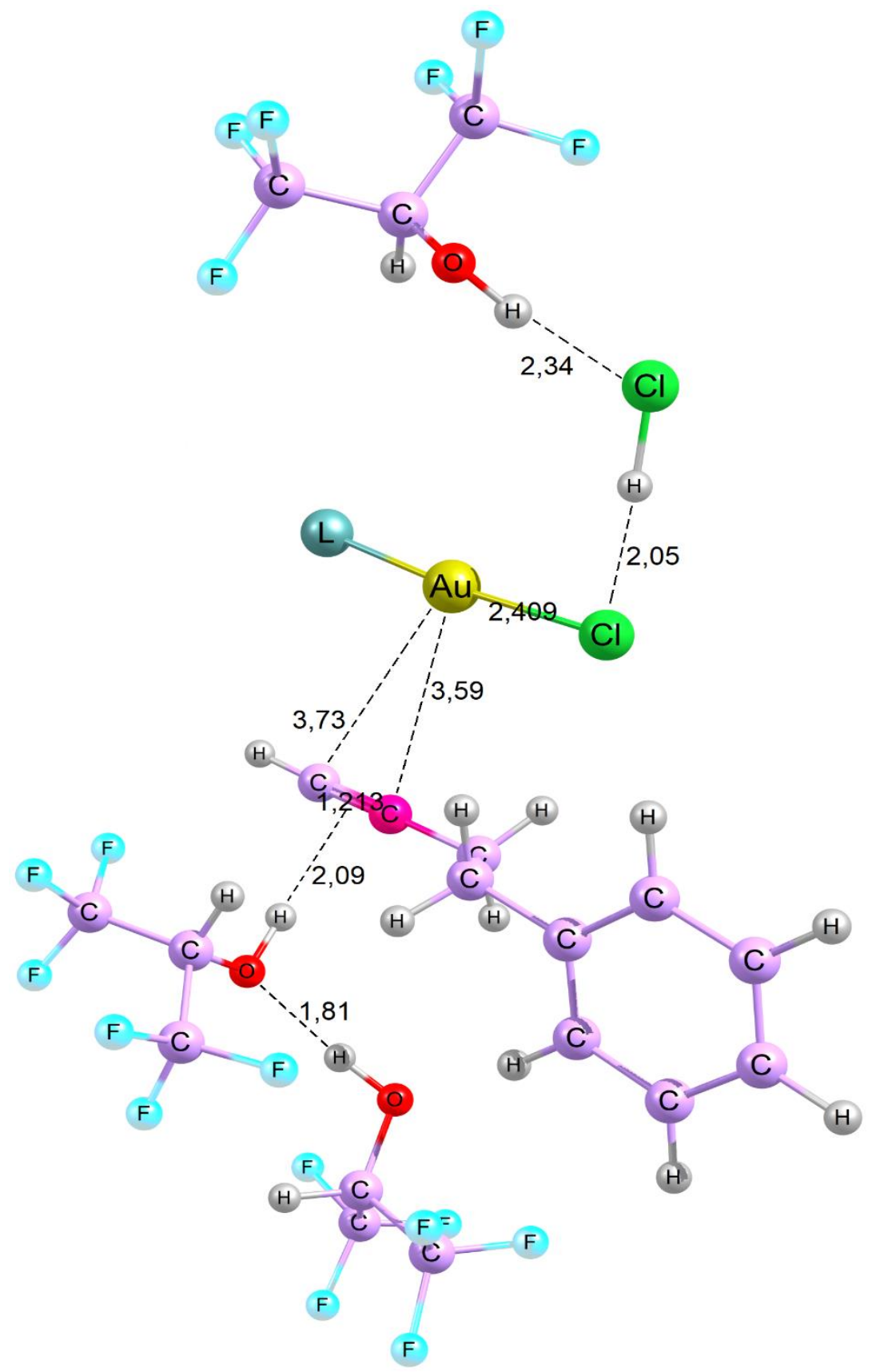

Figura 31. Complexo $\mathbf{B}^{\prime}$ com alquino, com um HFIP em rede com o que parte da ligação tripla. sob a metodologia B3LYP-D3, 6-31G(d,p)/SDD, em ciclohexanona (SMD) Distâncias em Ångström 


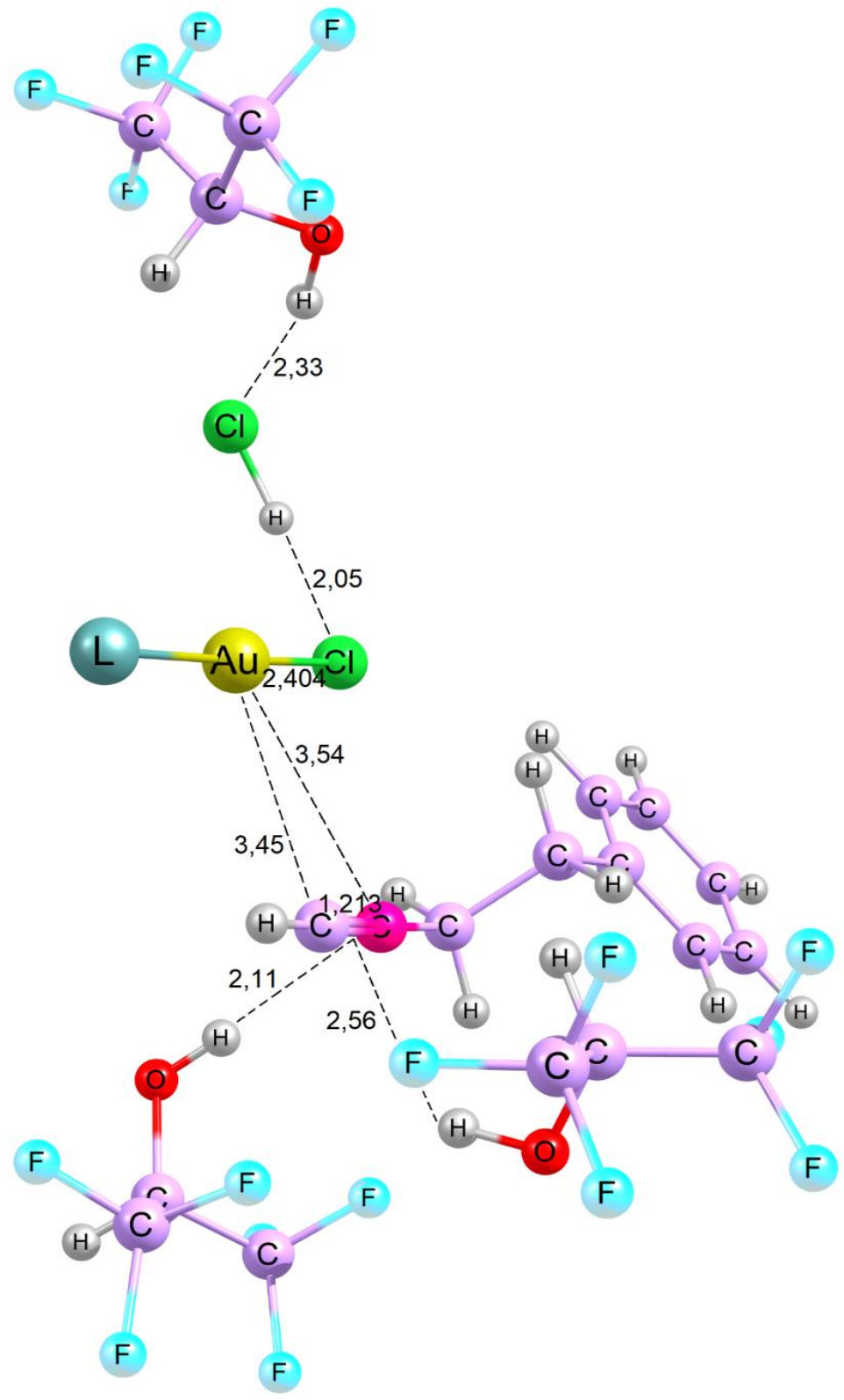

Figura 32. Complexo B' com alquino, com duas moléculas de HFIP interagindo com a insaturação, sob a metodologia B3LYP-D3, 6-31G(d,p)/SDD, em ciclohexanona (SMD). Distâncias em Ångström 
Outra alternativa foi avaliada, alterando-se o complexo A': a ligação de hidrogênio seria entre o oxigênio do HFIP, e o H do HCl, conforme explicitado na Figura 33.

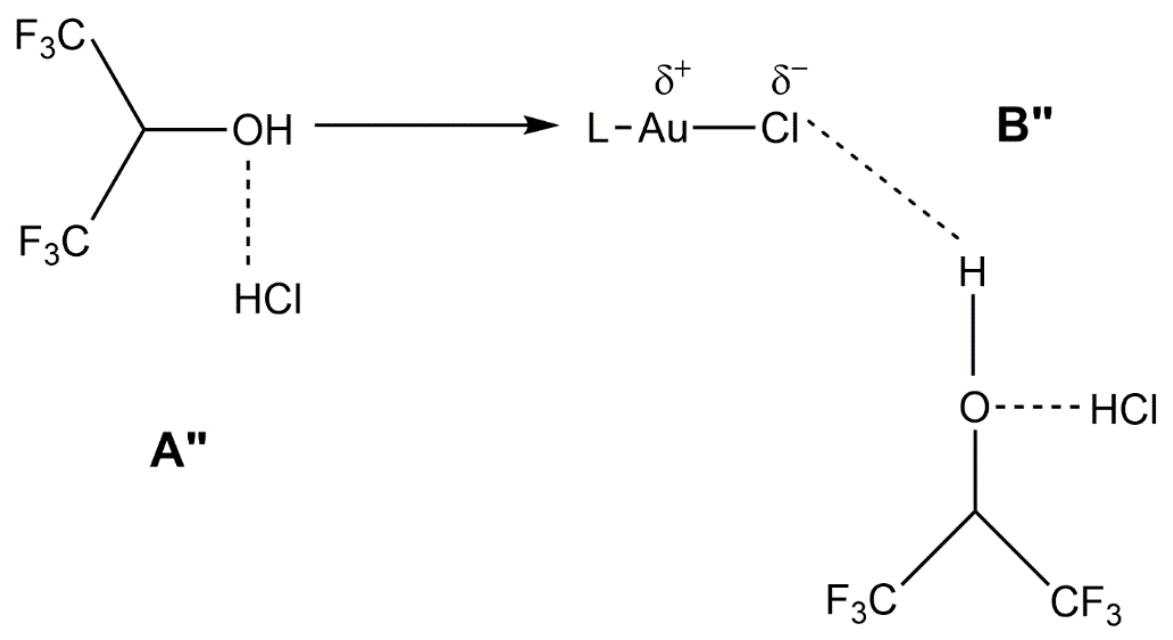

Figura 33. Alternativa à proposta apresentada na Figura 6
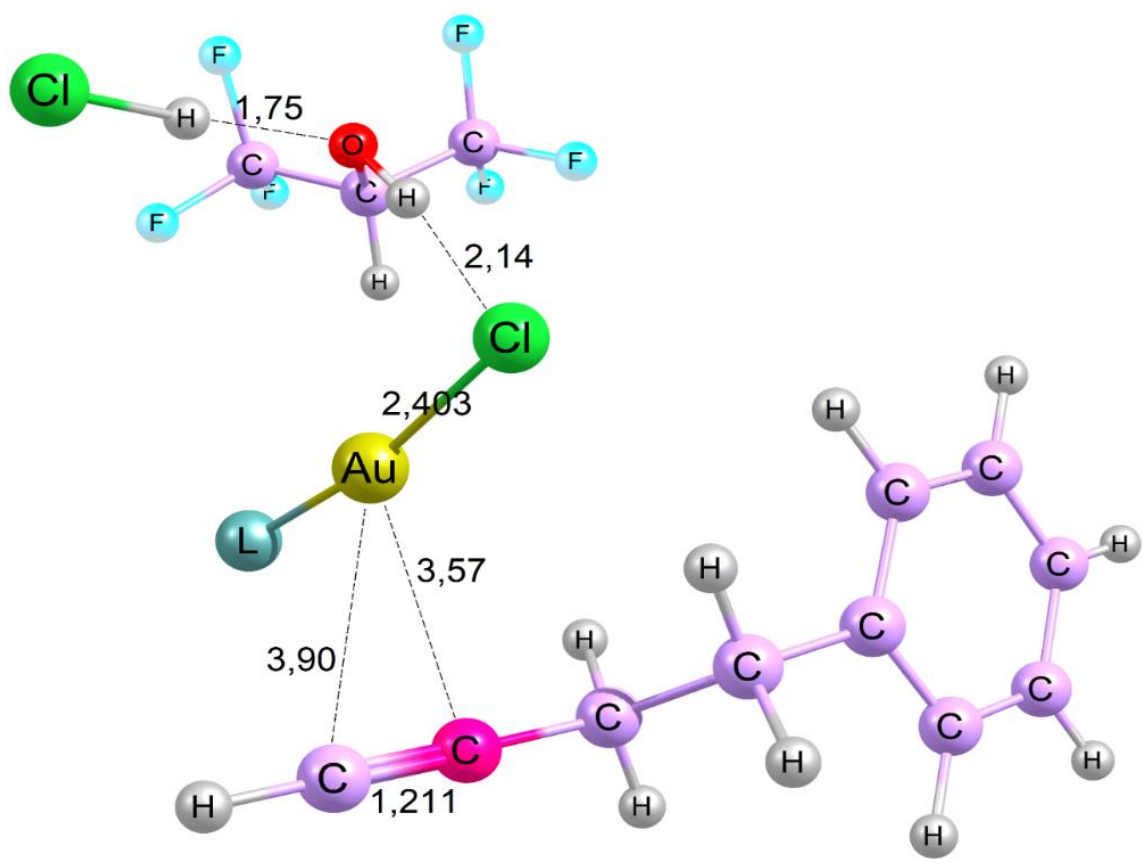

Figura 34. Complexo B" interagindo com alquino, sob a metodologia B3LYP-D3, 6-31G(d,p)/SDD, em ciclohexanona (SMD). Distâncias em Ångström

Com relação ao comprimento da ligação tripla e da ligação Au-Cl, B' (Figura 29) e B"' (Figura 34) retornaram resultados muito parecidos. Contudo, B' mostrou um resultado mais satisfatório que 
B" no diz respeito à distância do ouro aos carbonos da insaturação, já que o ouro se aproximou mais do carbono em que se ligaria (carbono terminal), no caso de ocorrer a reação de adição nucleofílica - em B', a distância foi de 3,75 A do ouro ao carbono terminal (Figura 29), enquanto em B" foi de 3,90 A (Figura 34).

A seguir, são apresentados os mesmos testes com uma e duas moléculas de HFIP explícito mostrados anteriormente com B'.

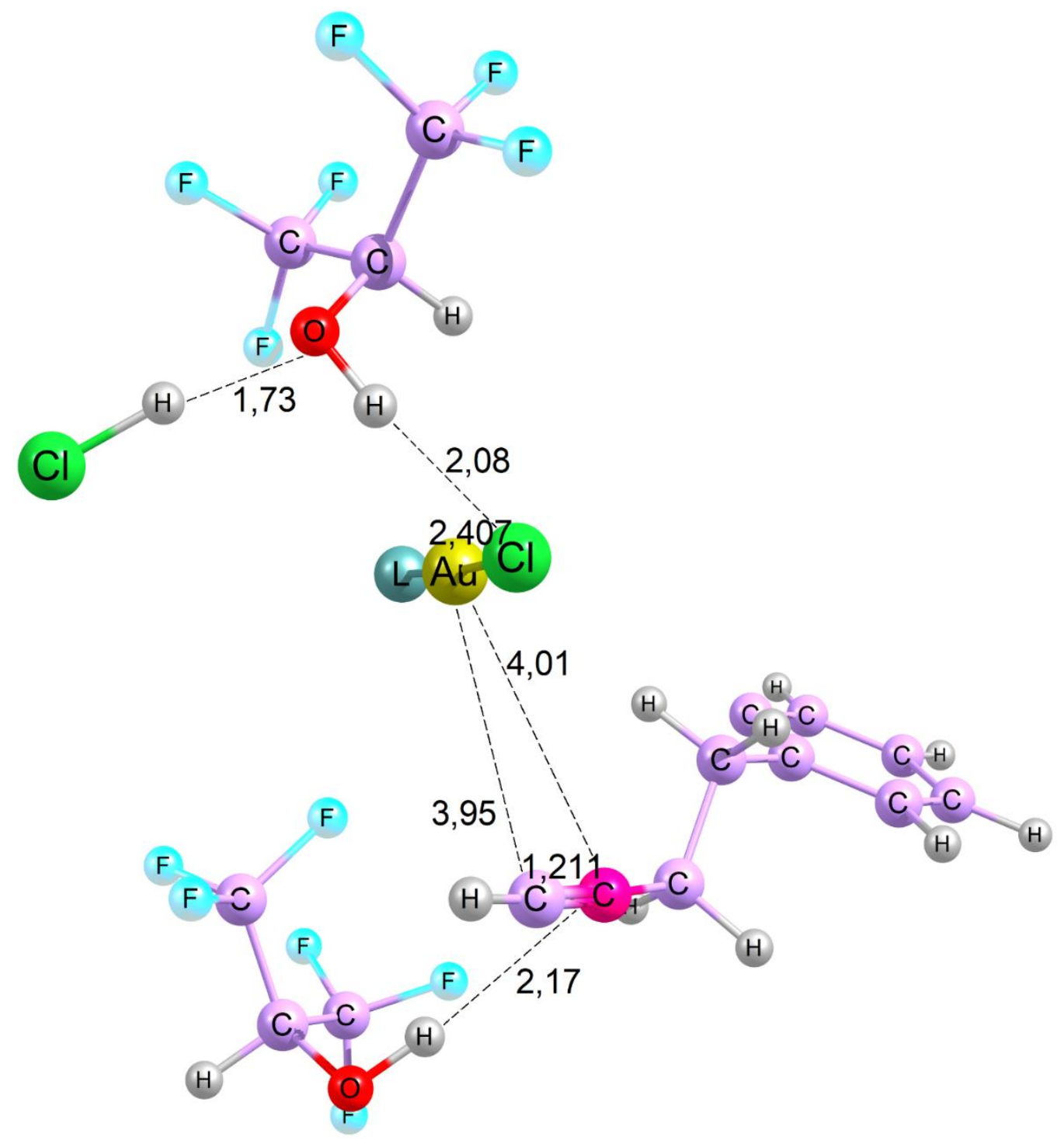

Figura 35. Complexo B" com alquino, e uma molécula de HFIP explícito que interage com a insaturação, sob a metodologia B3LYP-D3, 6-31G(d,p)/SDD, em ciclohexanona (SMD). Distâncias em Ångström 


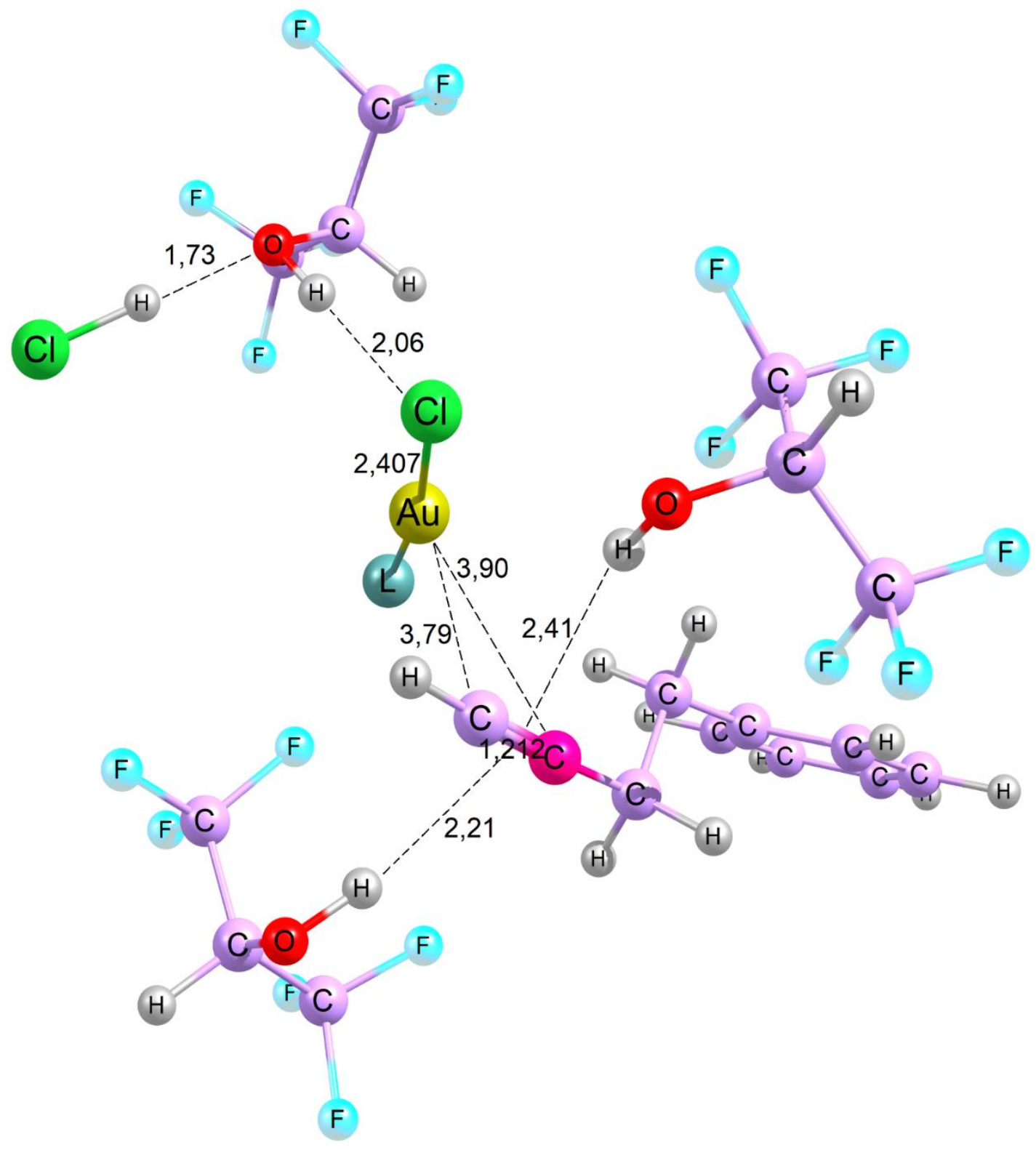

Figura 37. Complexo B" com alquino, com duas moléculas de HFIP interagindo com a insaturação, sob a metodologia B3LYP-D3, 6-31G(d,p)/SDD, em ciclohexanona (SMD). Distâncias em Ångström 
Tabela 4. Comparativo dos critérios para ativação do catalisador entre as hipóteses apresentadas

\begin{tabular}{|c|c|c|c|c|}
\hline & $\begin{array}{c}\text { Carga APT no C } \\
\text { interno }\end{array}$ & $\begin{array}{c}\text { Comprimento } \\
\text { da ligação } \\
\text { tripla }(\AA \AA)\end{array}$ & $\begin{array}{c}\text { Distância da } \\
\text { interação entre } \\
\text { Au e C terminal } \\
\text { (Å) }\end{array}$ & $\begin{array}{c}\text { Distância da } \\
\text { interação entre } \\
\text { Au e C interno } \\
\text { (A) }\end{array}$ \\
\hline $\begin{array}{l}\text { B' + alquino } \\
\text { (Figura 29) }\end{array}$ & 0,03 & 1,211 & 3,75 & 3,94 \\
\hline $\begin{array}{c}\text { B' + alquino } \\
+ \text { HFIP (Figura } \\
\text { 30) }\end{array}$ & 0,05 & 1,213 & 3,59 & 3,59 \\
\hline $\begin{array}{l}\text { B' }^{\prime}+\text { alquino } \\
+ \text { HFIP rede } \\
\text { (Figura } 31 \text { ) }\end{array}$ & 0,06 & 1,213 & 3,73 & 3,59 \\
\hline $\begin{array}{c}\text { B' + alquino } \\
\text { + HFIPs na } \\
\text { insaturação } \\
\text { (Figura 32) }\end{array}$ & 0,04 & 1,213 & 3,45 & 3,54 \\
\hline $\begin{array}{l}\text { B" + alquino } \\
\text { (Figura 34) }\end{array}$ & 0,03 & 1,211 & 3,90 & 3,57 \\
\hline $\begin{array}{c}\text { B" + alquino } \\
+ \text { HFIP (Figura } \\
\text { 35) }\end{array}$ & 0,05 & 1,211 & 3,95 & 4,01 \\
\hline $\begin{array}{c}\mathrm{B}^{\prime \prime}+\text { alquino + } \\
\text { rede de HFIP } \\
\text { (Figura } 36)\end{array}$ & 0,06 & 1,212 & 3,98 & 3,99 \\
\hline $\begin{array}{c}\text { B" + alquino + } \\
\text { HFIPs na } \\
\text { insaturação } \\
\text { (Figura 37) }\end{array}$ & 0,07 & 1,212 & 3,79 & 3,90 \\
\hline
\end{tabular}

Analisando-se os dados da Tabela 4 à luz dos critérios elencados no início dessa seção para se determinar a ativação do catalisador, como todos os valores de carga se encontram, qualitativamente, distantes de 0,3, e o comprimento da ligação tripla não se alterou de maneira 
significativa, considerou-se como sendo mais relevante a interação do ouro mais próxima do carbono terminal (em negrito na tabela). Portanto, os resultados expostos nas Figuras 32 e 37 se mostram mais alinhados com os critérios de ativação do catalisador.

Outro teste foi feito, desta vez, com os complexos $\mathbf{A}^{\prime} / \mathbf{A}^{\prime \prime}$ apenas, porém, com os HFIPs em rede, interagindo entre si (Figuras 38 e 39, respectivamente). Para tanto, levou-se em conta estudos que avaliaram a formação de clusters de HFIP. ${ }^{144,145}$ Com respeito ao cluster 1 (Figura 38), testou-se inicialmente a rede de HFIP interagindo com apenas uma molécula de $\mathrm{HCl}$. O resultado obtido foi o cluster 2, da Figura 39 - o que poderia ser um indicativo a favor do complexo B" frente ao B'. Testou-se também os dois clusters com 4 moléculas de $\mathrm{HCl}$. Contudo, as moléculas de $\mathrm{HCl}$ se afastaram das moléculas de HFIP.

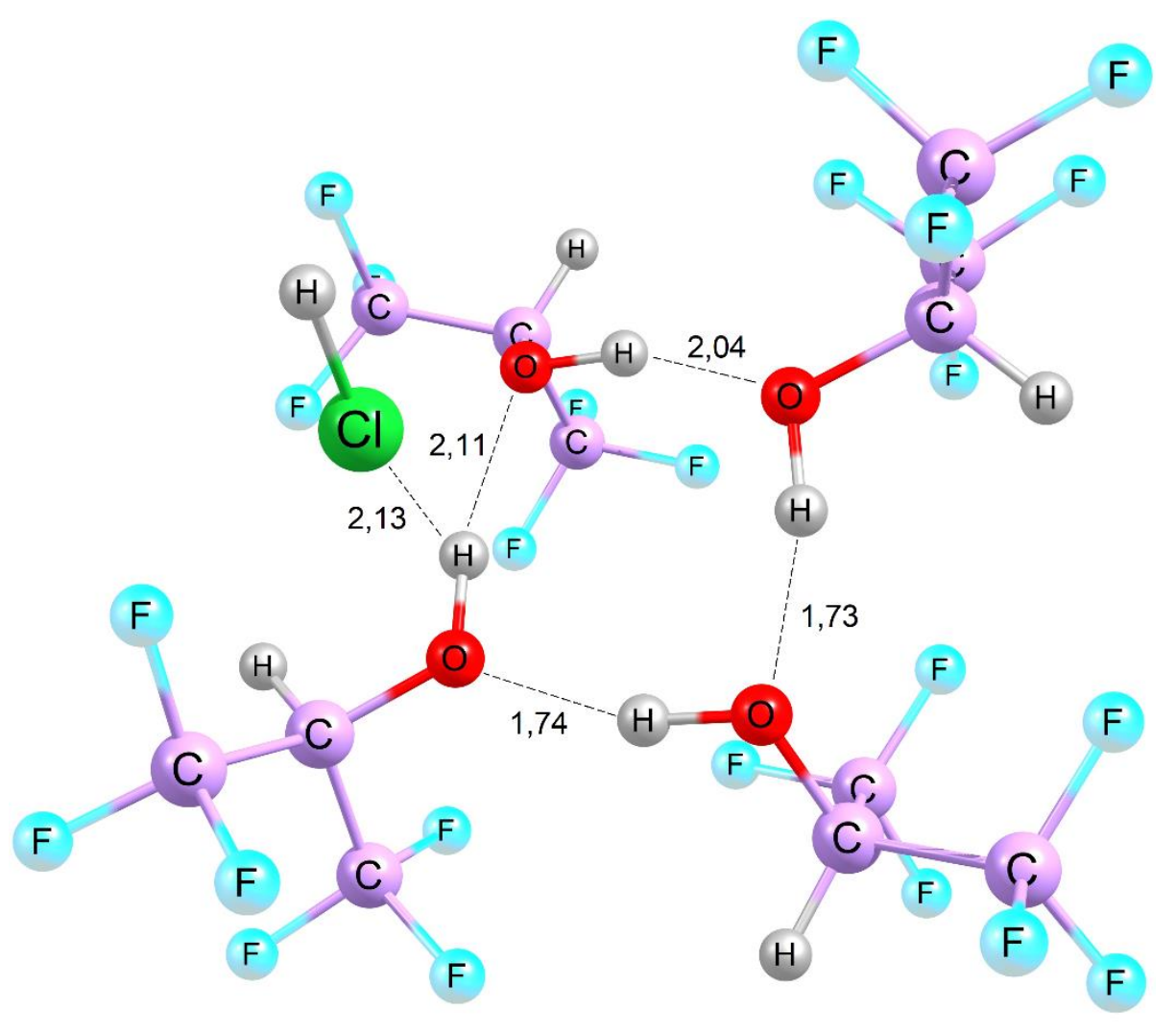

\section{Cluster 1}

Figura 38. Cluster de HFIP, com molécula de $\mathrm{HCl}$ interagindo de maneira semelhante ao complexo A', sob a metodologia B3LYP-D3, 6-31G(d,p), em ciclohexanona (SMD). Distâncias em Ångström 


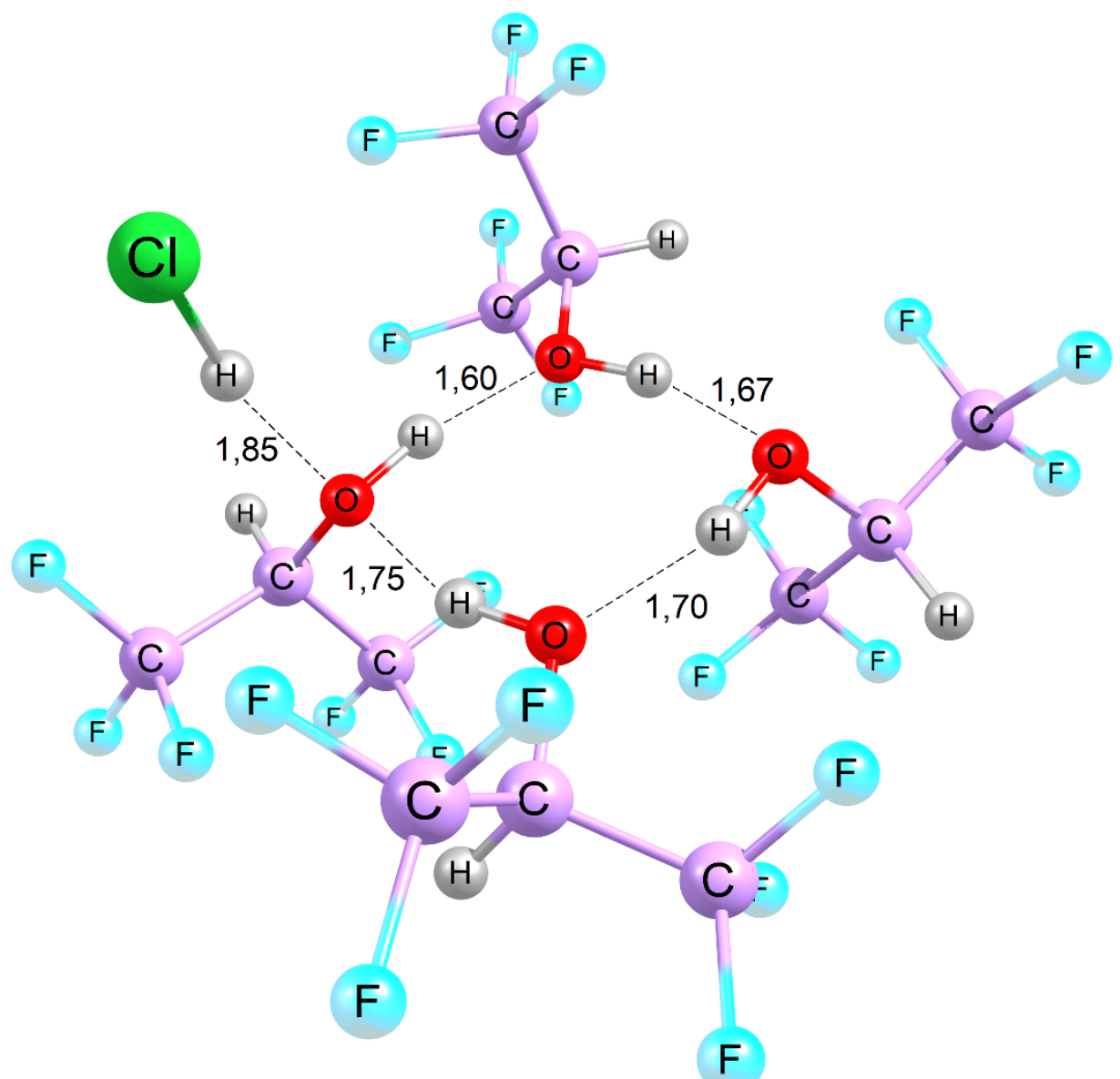

Cluster 2

Figura 39. Cluster de HFIP, com molécula de $\mathrm{HCl}$ interagindo de maneira semelhante ao complexo A", sob a metodologia B3LYP-D3, 6-31G(d,p), em ciclohexanona (SMD). Distâncias em Ångström

Já em relação ao cluster 2, feita a otimização com uma molécula de $\mathrm{HCl}$, seguiu-se para o teste com o cloro do complexo $\mathrm{LAuCl}$ interagindo com o H de uma das moléculas de HFIP do cluster, de maneira similar ao complexo B". Contudo, o catalisador inativo, LAuCl, se afastou do cluster, não estabelecendo uma clara interação com algum dos hidrogênios (distâncias entre 3 e 5 A). E, como a ligação Au-Cl não se alongou tanto quanto nos cálculos mostrados nas Figuras 29 a 32, e 34 a 37, entende-se que o HFIP em rede não seria a melhor configuração para o complexo A" (Figura 40). 


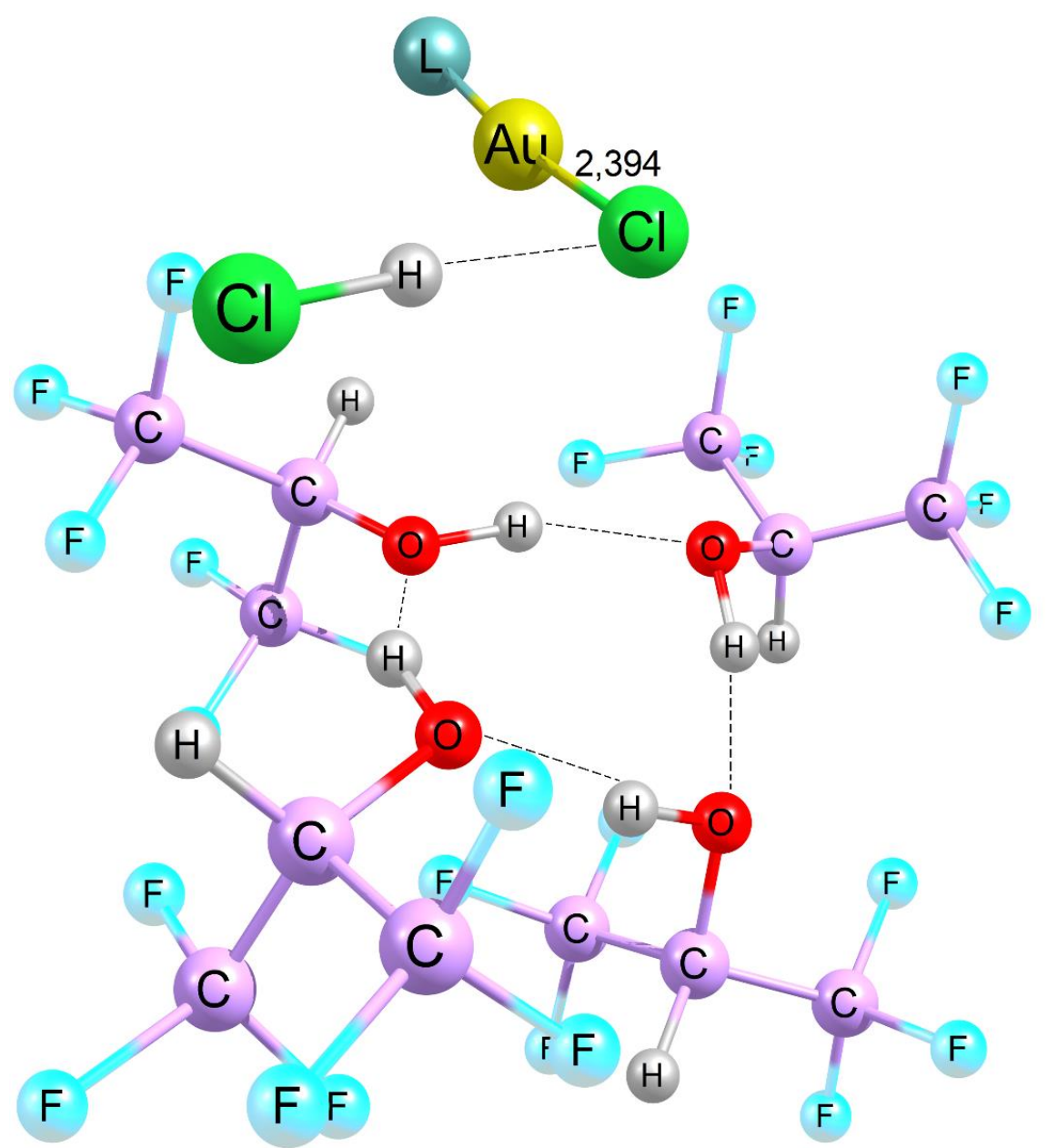

Figura 40. Cluster 2, com molécula de $\mathrm{HCl}$ e LAuCl, sob a metodologia B3LYP-D3, 6-31G(d,p)/SDD, em ciclohexanona (SMD). Distância em Ångström 


\section{Conclusões}

Todas as reações estudadas são exotérmicas e exergônicas, com mecanismos não concertados e viáveis à temperatura ambiente. Entretanto, experimentalmente, se faz uso de temperaturas maiores. ${ }^{65,137-139}$ Caso isso ocorra para viabilizar a reação - fornecer energia o bastante para superar o custo energético total -, as barreiras dos mecanismos caracterizados não condizem com as temperaturas experimentais, abrindo a possibilidade da descrição valendo-se da solvatação explícita.

Mesmo assim, os dois sistemas, com e sem ouro, cumpriram sua função, ao se mostrarem modelos capazes de demonstrar a tendência experimental da seletividade e propor a razão da regiosseletividade: ficou claro que, tendo em vista a reação com ouro catiônico, a seletividade anti é definida no primeiro estado de transição (TSa1/TSb1, com custo energético de 10,8 $\mathrm{kcal}$.mol-1 para TSb1, Figura 15) - a única posição disponível para o ataque nucleofílico do cloreto ocorrer é em oposição ao ouro, elemento de elevado raio atômico (Figura 16) -, enquanto nas duas reações competitivas sem ouro, a regiosseletividade é definida no segundo estado de transição (TSc2/TSd1), graças à presença do bromo causando o impedimento estérico, promovendo o produto syn como preferencial, que possui demanda energética aparente de $13,8 \mathrm{kcal}^{\mathrm{mol}}{ }^{-1}$ (Figura 20), frente a $16,7 \mathrm{kcal}^{\mathrm{mol}}{ }^{-1}$ do produto anti (Figura 21). Tais resultados obtidos referentes à seletividade vão de encontro ao que é observado experimentalmente. ${ }^{59,65}$

Com relação ao HFIP, há uma evidência de que tal molécula exerça diferentes papéis nos dois sistemas, com ouro e sem. Temos o indício de que, na reação sem ouro, o HFIP poderia contribuir estabilizando o cloreto no segundo estado de transição (Figura 28), ainda que não seja uma molécula necessária para viabilizar a ocorrência da reação, segundo exposto nas Figuras 20 e 27 . Já na reação catalisada por $\mathrm{LAuCl}$, além de participar da formação dos complexos $\mathbf{A}^{\prime} / \mathbf{A}^{\prime \prime}$ e $\mathbf{B}^{\prime} / \mathbf{B}^{\prime \prime}$, a atuação do HFIP se daria também por meio da interação com a ligação tripla, o que ativaria o alquino (Figuras 30, 31 e 32; 35, 36 e 37, com resultados compilados na Tabela 4), contribuindo para aumentar a distância da ligação tripla e disponibilizando os elétrons $\pi$ ao ataque eletrofílico do ouro.

Ainda na frente da ativação do catalisador (seção 4.3), o resultado obtido mais relevante foi com relação ao complexo B' e com duas moléculas de HFIP, partindo da interação com a insaturação (Figura 32), já que é a situação em que o ouro mais se aproxima do carbono terminal. Entretanto, o catalisador permanece inativo quanto ao ataque nucleofilico: o ouro deveria estar mais próximo 
da ligação tripla, cujo comprimento aumentaria ainda mais, e a carga no carbono interno deveria ser maior. Por se tratar de um modelo envolvendo um número crescente de moléculas e, portanto, de átomos (o que acarreta um aumento do custo computacional, que pode se tornar proibitivo), esse possivelmente seria um sistema descrito de maneira mais eficaz via um método híbrido, como ONIOM, ou microsolvatação.

\section{Perspectivas}

Permanecem em aberto questões a serem avaliadas, relativas aos dois sistemas, com e sem ouro. Primeiramente, os cálculos foram realizados com apenas um funcional, o B3LYP. Outro funcional muito recorrente na catálise por ouro é o M06. ${ }^{36,64,146}$ Dessa forma, seria interessante fazer o benchmark entre os dois. No sistema sem metal, o M06-2X também poderia ser utilizado, já que é da mesma família do M06, mas específico para sistemas puramente orgânicos. O uso de uma diferente base - como alguma da família de Ahlrich, classe de funções de base mais robustas frente às de Pople - também seria uma comparação pertinente. E, devido às questões mencionadas relativas à temperatura usada experimentalmente e à pequena diferença de energia entre os solventes nas reações estudadas, a inclusão de mais moléculas de solvente explícito se apresenta como uma investigação significativa no que diz respeito às barreiras de energias dos mecanismos de estudo.

Outra possibilidade a ser explorada é o uso da Teoria Quântica de Átomos em Moléculas (QTAIM, Quantum Theory of Atoms In Molecules) para avaliar o caráter das interações não covalentes na ativação do catalisador LAuCl.

Além disso, a real estrutura do catalisador ativo segue desconhecida (com muitas outras possibilidades a serem testadas - próximos estudos poderiam partir dos HFIPs interagindo com a ligação tripla, por exemplo, fazendo redes de HFIP a partir dos primeiros), bem como o mecanismo envolvendo-o. O sistema modelo da reação com ouro (Figuras 14 e 15) pode servir como base para tanto.

Por fim, tendo em vista a importância das questões ambientais atualmente, outra frente de trabalho que poderia ser considerada seria a da avaliação dos princípios da química verde nas reações 
envolvidas neste trabalho, sempre buscando formas de otimizar os processos. Por exemplo, determinação da economia de átomos e busca de solventes mais verdes.

\section{Referências}

1) Lee, J. D. Química inorgânica não tão concisa, tradução da $5^{a}$ edição inglesa; Blucher: São Paulo, 2013; páginas 207, 298, 328, 415-18, 495, 499.

2) Pyykkö, P. Relativistic effects in chemistry: More common than you thought. Annual Review of Physical Chemistry 2012, 63, 45-64.

3) Yatsimirskii, K. B. Relativistic Effects in Chemistry. Theoretical and Experimental Chemistry 1995, $31(3), 153-168$

4) Wanderley, L. J. Ouro como moeda, ouro como commodity. Revista de Economia Política e História Econômica 2015, 34, 5-46.

5) Gruber, J. B. As extensões do olhar: a arte na formação de professores Ticuna. Em Aberto 1994, $63,122-136$.

6) Gray, T. Os Elementos - Uma exploração visual dos átomos conhecidos no universo; Blucher: São Paulo, 2016; página 181.

7) https://www.suno.com.br/artigos/padrao-ouro/, acesso em 01/10/2020.

8) Gontijo, C. Os mecanismos de funcionamento do "padrão-ouro": uma visão crítica. Economia e Sociedade 2014, 23 (1), 243-280.

9) https://www.suno.com.br/artigos/fundo-de-ouro/, acesso em 01/10/2020.

10) Dorel, R.; Echavarren, A. M. Gold(I)-catalyzed activation of alkynes for the construction of molecular complexity. Chemical Reviews 2015, 115 (17), 9028-9072.

11) Hashmi, A. S. K.; Hutchings, G. J. Gold catalysis. Angewandte Chemie Internacional Edition 2006, $45,7896-7936$. 
12) Sun, K.; Kohyama, M.; Tanaka, S.; Takeda, S. Direct $\mathrm{O}_{2}$ activation on gold/metal oxide catalysts through a unique double linear O-Au-O structure. Chem CatChem 2013, 5, 2217- 2222.

13) Nijamudheen, A.; Datta, A. Gold-Catalyzed Cross-Coupling Reactions: An overview of design strategies, mechanistic studies, and applications. Chemistry - A European Journa/2020, 26, 14421487.

14) Lein, M.; Rudolph, M.; Hashmi, S. K.; Schwerdtfeger, P. Homogeneous gold catalysis: Mechanism and relativistic effects of the addition of water to propyne. Organometallics 2010, 29, 2206-2210.

15) Gorin, D. J.; Toste, F. D. Relativistic effects in homogeneous gold catalysis. Nature 2007, 446, 395-403.

16) Faza, O. N.; Rodríguez, R. A.; López, C. S. Performance of density functional theory on homogeneous gold catalysis. Theoretical Chemical Accounts 2011, 128, 647-661.

17) Hashmi, A. S. K. Homogeneous catalysis by gold. Gold Bulletin 2004, 37, 51-65.

18) Bond, G. C.; Sermon, P. A.; Webb, G.; Buchanan, D. A.; Wells, P. B. Hydrogenation over supported gold catalysts. Journal of the Chemical Society, Chemical Communications 1973, 444b-445.

19) Ito, Y.; Sawamura, M.; Hayashi, T. Catalytic asymmetric aldol reaction: Reaction of aldehydes with isocyanoacetate catalyzed by a chiral ferrocenylphosphine-gold(I) complex. Journal of the American Chemical Society 1986, 108 (20), 6405-6406.

20) Hutchings, G. J. Vapour phase hydrochlorination of acetylene: Correlation of catalytic activity of supported metal chloride catalysis. Journal of Catalysis 1985, 96, 292-295.

21) Malta, G.; Kondrat, S. A.; Freakley, S. J.; Davies, C. J.; Dawson, S.; Liu, X.; Lu, L.; Dymkowski, K.; Fernandez-Alonso, F.; Mukhopadhyay, S.; Gibson, E. K.; Wells, P. P.; Parker, S. F.; Kiely, C. J.; Hutchings, G. J. Deactivation of a single-site gold-on-carbon acetylene hydrochlorination catalyst: An X-ray absorption and inelastic neutron scattering study. ACS Catalysis 2018, 8 (9), 8493-8505.

22) Johnston, P.; Carthey, N.; Hutchings, G. J. Discovery, development, and commercialization of gold catalysts for acetylene hydrochlorination. Journal of the American Chemical Society 2015, 137, 14548-14557.

23) Nkosi, B.; Coville, N. J.; Hutchings, G. J. Reactivation of a supported gold catalyst for acetylene hydrochlorination. Journal of the Chemical Society, Chemical Communications 1988, 71-72. 
24) Nkosi, B.; Coville, N. J.; Hutchings, G. J. Vapour phase hydrochlorination of acetylene with Group VIII and 1B metal chloride catalysts. Applied Catalysis 1988, 43, 33-39.

25) Haruta, M.; Kobayashi, T.; Sano, H.; Yamada, N. Novel gold catalysis for the oxidation of carbon monoxide at a temperature far below $0^{\circ} \mathrm{C}$. Chemistry Letters 1987, 16 (2), 405-408.

26) Teles, J.; Brode, S.; Chabanas, M. Cationic gold (I) complexes: Highly efficient catalysis for the addition of alcohols to alkynes. Angewandte Chemie Internacional Edition 1998, 37, 1415-1418.

27) Nolan, S. P. Catalytic gold rush. Nature 2007, 445, 496-497.

28) Hutchings, G. J. Heterogeneous gold catalysis. ACS Central Science 2018, 4, 1095-1101.

29) Ciriminna, R.; Falletta, E.; Pina, C. D.; Teles, J. H.; Pagliaro, M. Industrial applications of gold catalysis. Angewandte Chemie Internacional Edition 2016, 55, 14210 -14217.

30) Ahmed, A.; Abdallh, M.; Al-Mashhadani, M. H.; Ahmed, D. S.; Bufaroosha, M.; Jawad, A. H.; Yousif, E. Environmental stability of poly(vinyl chloride) modified by Schiff's base under exposure to UV. Biointerface Research in Applied Chemistry 2021, 11 (5), 13465-13473.

31) Zhang, Z.; Jiang, P.; Liu, D.; Feng, S.; Zhang, P.; Wang, Y.; Fu, J.; Agus, H. Research progress of novel bio-based plasticizers and their applications in poly(vinyl chloride). Journal of Materials Science 2021, 56, 10155-10182.

32) Yu, J.; Sun, L.; Ma, C.; Qiao, Y.; Yao, H. Thermal degradation of PVC: A review. Waste Management 2016, 48, 300-314.

33) Joost, M.; Amgoune, A.; Bourissou, D. Reactivity of gold complexes towards elementary organometallic reactions. Angewandte Chemie Internacional Edition 2015, 54, 15022-15045.

34) Brocksom, T. J.; Alves, L. C.; Wulf, G. D.; Desiderá, A. L.; Oliveira, K. T. O Prêmio Nobel de Química em 2010: união direta de carbonos sp² e sp. Química Nova na Escola 2010, 32 (4), 233-239.

35) Batalha, P. N.; Sagrillo, F. S.; Gama, I. L. Acoplamento cruzado C-C: novas metodologias, aplicações e descobertas ao longo dos últimos anos. Revista Virtual de Química 2014, 6 (2), 494550.

36) Faza, O. N.; López, C. S. Computational study of gold-catalyzed homo- and cross-coupling reactions. The Journal of Organic Chemistry 2013, 78, 4929-4939.

37) Witzel, S.; Hashmi, A. S. K.; Xie, J. Light in gold catalysis. Chemical Reviews 2021, 121 (14), 88688925. 
38) Hashmi, A. S. K.; Lothschütz, C.; Döpp, R.; Rudolph, M.; Ramamurthi, T. D.; Rominger, F. Gold and Palladium Combined for Cross-Coupling. Angewandte Chemie Internacional Edition 2009, 48, 8243-8246.

39) Vollhardt, P.; Schore, N. Química Orgânica - Estrutura e Função, 6ª edição; Bookman: Porto Alegre, 2013; páginas 251, 258, 587, 588.

40) Alyabyev, S. B.; Beletskaya, I. P. Gold as a catalyst. Part I. Nucleophilic addition to the triple bond. Russian Chemical Reviews 2017, 86 (8) 689-749.

41) Shahzad, S. A.; Sajid, M. A.; Khan, Z. A.; Canseco-Gonzalez, D. Gold catalysis in organic transformations: A review. Synthetic Communications 2017, 47(8), 735-755.

42) Gao, M.; Horita, D.; Ono, Y.; Lyalin, A.; Maeda, S.; Taketsugu, T. Isomerization in gold clusters upon $\mathrm{O}_{2}$ adsorption. Journal of Physical Chemistry C2017, 121, 2661-2668.

43) Collado, A.; Gómez-Suárez, A.; Nolan, S. P. Sustainable homogeneous gold catalysis. Em Sustainable catalysis: With non-endangered metals, Part 2; North, M.; The Royal Society of Chemistry, 2016; páginas 41-90.

44) Arcadi, A. Alternative synthetic methods through new developments in catalysis by gold. Chemical Reviews 2008, 108, 3266-3325.

45) Anastas, P.; Eghbali, N. Green chemistry: Principles and practice. Chemical Society Reviews 2010, 39, 301-312.

46) Luo, L.; Luo, J.; Li, H.; Ren, F.; Zhang, Y.; Liu, A.; Li, W.; Zeng, J. Water enables mild oxidation of methane to methanol on gold single-atom catalysts. Nature Communications 2021, 12 (1218), 1-10.

47) Hashmi, A. S. K. Gold-catalyzed organic reactions. Chemical Reviews 2007, 107, 3180-3211.

48) Menezes, L. M.; Freitas, M. P. M.; Gonçalves, T. S. Biocompatibilidade dos materiais em Ortodontia: mito ou realidade? Revista Dental Press de Ortodontia e Ortopedia Facia/ 2009, 14 (2), 144-157.

49) Ott, I. On the medicinal chemistry of gold complexes as anticancer drugs. Coordination Chemistry Reviews 2009, 253, 1670-1681.

50) Clayden, J.; Greeves, N.; Warren, S. Organic Chemistry, $2^{a}$ edição; Oxford University Press Inc.: New York, 2012; página 1156.

51) Noori, T.; Dehpour, A. R.; Sureda, A.; Sobarzo-Sanchez, E.; Shirooie, S. Role of natural products for the treatment of Alzheimer's disease. European Journal of Pharmacology 2021, 898 (173974), 1-16. 
52) Sparks, T. C.; Hahn, D. R.; Garizi, N. V. Natural products, their derivatives, mimics and synthetic equivalents: Role in agrochemical discovery. Pest Management Science 2017, 73, 700-715.

53) Conte, M.; Hutchings, G. J. Hydrochlorination of Acetylene Catalyzed by Gold. In Modern gold catalyzed synthesis, $1^{a}$ edição; Hashmi, A. S. K.; Toste, F. D.; Wiley-VHC, 2012; páginas 1-26.

54) https://www.macrotrends.net/2541/platinum-prices-vs-gold-prices, acesso em 22/04/2021.

55) Echavarren, A. M.; Hashmi, A. S. K.; Toste, F. D. Gold catalysis - steadily increasing in importance. Advanced Synthesis and Catalysis 2016, 358, 1347.

56) Zhdanko, A.; Maier, M. E. The mechanism of gold(I)-catalyzed hydroalkoxylation of alkynes: An extensive experimental study. Chemistry - A European Journa/2014, 20, 1918-1930.

57) Hashmi, A. S. K.; Rudolph, M. Gold catalysis in total synthesis. Chemical Society Reviews 2008, $37,1766-1775$.

58) Schmidbaur, H.; Schier, A. Silver-free Gold(I) Catalysts for Organic Transformations. $Z$. Naturforsch. 2011, 66b, $329-350$.

59) Ebule, R.; Liang, S.; Hammond, G. B.; Xu, B. Chloride-tolerant gold(I)-catalyzed regioselective hydrochlorination of alkynes. ACS Catalysis 2017, 7 (10), 6798-6801.

60) Bistoni, G.; Belanzoni, P.; Belpassi, L.; Tarantelli,F. $\pi$ Activation of alkynes in homogeneous and heterogeneous gold catalysis. Journal of Physical Chemistry A 2016, 120, 5239-5247.

61) Hashmi, A. S. K. Homogeneous gold catalysis beyond assumptions and proposals characterized intermediates. Angewandte Chemie Internacional Edition 2010, 49, 5232 - 5241.

62) Lu, Z.; Han, J.; Hammond, G. B.; Xu, B. Revisiting the influence of silver in cationic gold catalysis: A practical guide. Organic Letters 2015, 17, 4534-4537.

63) Zhdanko, A.; Maier, M. E. Explanation of "silver effects" in gold(I)-catalyzed hydroalkoxylation of alkynes. ACS Catalysis 2015, 5, 5994-6004.

64) Fang, R.; Kirillov, A. M.; Yang, L. DFT study on the "silver effect" in gold-catalyzed hydroamination of terminal alkynyl sulfamides. Molecular Catalysis 2020, 486 (110847), 1-8.

65) Zeng, X.; Liu, S.; Hammond, G. B.; Xu, B. Hydrogen-bonding-assisted Brønsted acid and gold catalysis: Access to both $(E)$ - and $(Z)-1,2$-haloalkenes via hydrochlorination of haloalkynes. ACS Catalysis 2018, 8, 904-909.

66) Lee, C.; Yang, W.; Parr, R. G. Development of the Colle-Salvetti correlation-energy formula into a functional of the electron density. Physical Review B 1988, 37(2), 785-789. 
67) Becke, A. D. A new mixing of Hartree-Fock and local density-functional theories. The Journal of Chemical Physics 1993, 98 (2), 1372-1377.

68) Becke, A. D. Density-functional exchange energy approximation with correct asymptotic behavior. Physical Review A 1988, 38 (6), 3098-3100.

69) Becke, A. D. Density-functional thermochemistry. III. The role of exact exchange. The Journal of Chemical Physics 1993, 98 (7), 5648-5652.

70) Miehlich, B.; Savin, A.; Stoll, H.; Preuss, H. Results obtained with the correlation energy density functionals of Becke and Lee, Yang and Parr. Chemical Physics Letters 1989, 157 (3), 200-206.

71) Stephens, P. J.; Devlin, F. J.; Chabalowski, C. F.; Frisch, M. J. Ab initio calculation of vibrational absorption and circular dichroism spectra using density functional force fields. The Journal of Physical Chemistry 1994, 98 (45), 11623-11627.

72) Paton, R. S.; Maseras, F. Gold(I)-catalyzed intermolecular hydroalkoxylation of allenes: A DFT study. Organic Letters 2009, $11(11), 2237-2240$.

73) Yang, W.; Hashmi, A. S. K. Mechanistic insights into the gold chemistry of allenes. Chemical Society Reviews 2014, 43, 2941-2955.

74) Zhang, X. H.; Wang, K. T. Theoretical investigation of the mechanism of gold(I)-catalyzed hydrothiolation of alkynes and alkenes with phenthiol. RSC Advances 2015, 5, 34439-34446.

75) Krauter, C. M.; Hashmi, A. S. K.; Pernpointner, M. A new insight into gold(I)-catalyzed hydration of alkynes: Proton transfer. Chem CatChem 2010, 2, 1226 - 1230.

76) Tolbatov, I.; Coletti, C.; Marrone, A.; Re, N. Reactivity of gold(I) monocarbene complexes with protein targets: A theoretical study. International Journal of Molecular Sciences 2019, 20, 820.

77) Chaładaj, W.; Kołodziejczyk, A.; Domanski, S. Gold(I)-catalyzed conia-ene cyclization of internal $\varepsilon$-acetylenic $\beta$-ketoesters under high pressure. Chem CatChem 2017, 9, $4334-4339$.

78) Grimme, S.; Antony, J.; Ehrlich, S.; Krieg, H. A consistent and accurate ab initio parametrization of density functional dispersion correction (DFT-D) for the 94 elements H-Pu. The Journal of Chemical Physics 2010, 132, 154104-1 - 154104-19.

79) Ditchfield, R.; Hehre, W. J.; Pople, J. A. Self-consistent molecular orbital methods. IX. An extended Gaussian-type basis for molecular-orbital studies of organic molecules. The Journal of Chemical Physics 1971, 54, 724-728. 
80) Hariharan, P. C.; Pople, J. A. The influence of polarization functions on molecular orbital hydrogenation energies. Theoretica Chimica Acta 1973, 28, 213-222.

81) Hehre, W. J.; Ditchfield, R.; Pople, J. A. Self-consistent molecular orbital methods. XII. Further extensions of Gaussian-type basis sets for use in molecular orbital studies of organic molecules. The Journal of Chemical Physics 1972, 56 (5), 2257-2261.

82) Frisch, M. J.; Pople, J. A.; Binkley, J. S. Self-consistent molecular orbital methods 25. Supplementary functions for Gaussian basis sets. The Journal of Chemical Physics 1984, 80 (7), 3265-3269.

83) Andrae, D.; Haussermann, U.; Dolg, M.; Stoll, H.; Preuss, H. Energy-adjusted ab initio pseudopotentials for the second and third row transition elements. Theoretica Chimica Acta 1990, $77,123-141$.

84) Frisch, M. J. et al. Gaussian 09, Revision D.01. Gaussian, Inc., Wallingford CT, 2013.

85) Schaftenaar, G.; Noordik, J. H. Molden: a pre- and post-processing program for molecular and electronic structures. Journal of Computer-Aided Molecular Design_2000, 14, 123-134.

86) Chemcraft - graphical software for visualization of quantum chemistry computations. Disponível em https://www.chemcraftprog.com, acesso em 19/05/2021.

87) Cioslowski, J. A new population analysis based on atomic polar tensors. Journal of the American Chemical Society 1989, $111(2), 8333-8336$.

88) http://www.chemspider.com/Chemical-Structure.2015971.html, acesso em 19/05/2021.

89) http://www.chemspider.com/Chemical-Structure.14248016.html, acesso em 19/05/2021.

90) Marenich, A. V.; Cramer, C. J.; Truhlar, D. G. Universal solvation model based on solute electron density and on a continuum model of the solvent defined by the bulk dielectric constant and atomic surface tensions. The Journal of Physical Chemistry B 2009, 113, 6378-6396.

91) Colomer, I.; Chamberlain, A. E. R.; Haughey, M. B.; Donohoe, T. J. Hexafluoroisopropanol as a highly versatile solvent. Nature Reviews Chemistry 2017, 1, 1-12.

92) http://gaussian.com/scrf/?tabid=7, acesso em 19/05/2021.

93) Einstein, A. A brief outline of the development of the Theory of Relativity. Nature 1921, 106, 782-784. 
94) Kotz, J. C.; Treichel, P. M.; Weaver, G. C. Química geral e reações químicas, tradução da $6^{a}$ edição norte-americana, volume 1; Cengage Learning: São Paulo, 2012; páginas 55, 266, 267, 271, 273 e 275.

95) Atkins, P.; de Paula, J.; Friedman, R. Quanta, matter and change: A molecular approach to physical chemistry. W. H. Freeman and Company: Nova lorque, 2009; páginas 30, 41, 57, 59, 74, $99,138,224,682$.

96) McQuarrie, D. A. Quantum Chemistry. $2^{a}$ edição; University Science Books: Califórnia, 2008; páginas 4, 8, 12, 16, 26, 86, 101, 110, 145, 170, 321, 331, 346, 350, 359, 381, 382, 444, 464, 500, 626, $627,653$.

97) Russel, J. B. Química geral. McGraw-Hill: São Paulo, 1982; páginas 132-136, 159, 160.

98) Griffiths, D. J. Mecânica Quântica. 2ª edição; Pearson Education do Brasil: São Paulo, 2011; páginas 1, 17-19,130, 131, 220, 271.

99) Norrby, L. J. Why is mercury liquid? Journal of Chemical Education 1991, 68 (2), 110-113.

100) Dirac, P. A. M. Theory of electrons and positrons. Nobel Lecture, 1933. NobelPrize.org. Nobel $\begin{array}{lllll}\text { Prize } & \text { Outreach } & \text { AB } & 21 . & \text { Disponivel }\end{array}$ https://www.nobelprize.org/prizes/physics/1933/dirac/lecture/, acesso em 22/06/2021.

101) Schwerdtfeger, P. Relativistic effects in properties of gold. Heteroatom Chemistry 2002, 13 (6), 578-584.

102) Bartlett, N. Relativistic effects and the chemistry of gold. Gold Bulletin 1998, 31 (1), 22-25.

103) Junior, F. R.; Ferraro, N. G.; Soares, P. A. T. Os fundamentos da física. Volume 2; Moderna: São Paulo, 2007; páginas 221, 222.

104) Burrows, A.; Holman, J.; Parsons, A.; Pilling, G.; Price, G. Química3: introdução à química inorgânica, orgânica e físico-química. Volume 3; GEN/LTC: Rio de Janeiro, 2012; páginas 401, 402. 105) Cramer, C. J. Essentials of computational chemistry: Theories and models. $2^{a}$ edição; John Wiley \& Sons, Ltd: West Sussex, 2004; páginas 6, 112, 132, 133, 166, 249, 252-254, 257-259, 266, 267, 271, 534.

106) Lowe, J. P. Quantum Chemistry. 2ª edição; Academic Press: San Diego, 1993; páginas 193, 357. 
107) Corminboeuf, C. Scalar relativistic correction to nucleus-independent chemical shifts of coinage-metal compounds: How does the pseudopotential approximation perform? Chemical Physics Letters 2006, 418, 437-441.

108) Bagno, A.; Bonchio, M. Effective core potential DFT calculations of nuclear shielding as a tool for the prediction and assignment of the tungsten chemicalshift in mono- and polynuclear complexes. Chemical Physics Letters 2000, 317, 123-128.

109) Levine, I. N. Physical chemistry. Edição internacional para estudantes; McGraw-Hill Kogakusha: Tóquio, 1978; páginas 574, 579, 581, 601, 729, 764.

110) Cremer Jr., J. T. The Klein-Gordon and Dirac equations. Em Neutron and X-ray optics. Elsevier, 2013, páginas 813-888.

111) Chamizo, F. Dirac equation, spin and fine structure Hamiltonian. 2019. Disponível em http://matematicas.uam.es/ fernando.chamizo/physics/files/fine_structure.pdf. Acesso em 14/09/2021.

112) Boeyens, J. C. A. Understanding electron spin. Journal of Chemical Education 1995, 72 (5), $412-$ 415.

113) Autschbach, J. Perspective: Relativistic effects. The Journal of Chemical Physics 2012, 136, 150902.

114) Kutzelnigg, W. Solved and unsolved problems in relativistic quantum chemistry. Chemical Physics 2012, 395, 16-34.

115) Arfken, G. B.; Weber, H. J.; Harris, F. E. Mathematical Methods for Physicists - A Comprehensive Guide. $7^{a}$ edição; Elsevier: Waltham, 2013, páginas 111 e 112.

116) de Faria, E.; de Melo, W. Relativity, the Lorentz group, and Dirac's equation. Em Mathematical Aspects of Quantum Field Theory. Cambridge University Press, 2010, páginas 51-64.

117) Serway, R. A.; Jewett Jr., J. W. Princípios de Física - Mecânica Clássica. Tradução da $3^{a}$ edição norte-americana; Thomson: São Paulo, 2004; página 295.

118) Parpia, F. A.; Mohanty, A. K.; Clementi, E. Relativistic calculations for atoms: self-consistent treatment of Breit interaction and nuclear volume effect. Journal of Physics B: Atomic, Molecular and Optical Physics 1992, 25 (1), 1-16.

119) Tang, L. Y.; Tang, Y. B.; Shi, T. Y.; Mitroy, J. Solution of the Dirac Coulomb equation for heliumlike ions in the Poet-Temkin model. The Journal of Chemical Physics 2013, 139, 134112-1 - 1341128. 
120) Kim, Y. K. Relativistic self-consistent-field theory for closed-shell atoms. Physical Review 1967, $154(1), 17-39$.

121) Plante, D. R.; Johnson, W. R.; Sapirstein, J. Relativistic all-order many-body calculations of the $n=1$ and $n=2$ states of heliumlike ions. Physical Review A 1994, 49 (5), 3519-3530.

122) http://open-inorganic-chemistry.digitalscholarship.utsc.utoronto.ca/node/39, acesso em 26/09/2021.

123) Lewars, E. G. Computational Chemistry: Introduction to the theory and applications of molecular and quantum mechanics. $2^{a}$ edição; Springer, 2011; páginas 1-5, 16-18, 21-23, 28, 29, 31, 33, 101, 255, 445, 446, 460 e 461.

124) Trzesniak, D. R. F. Modelagem quântica de inibidores enzimáticos. São Paulo, 2002; páginas 3-2 a $3-5$.

125) Zhao, Z.; Gong, J. Uncertainties in theoretical description of well-defined heterogeneous catalysts; Em Studies in Surface Science and Catalysis, Volume 177; Elsevier, 2017; páginas 541-565.

126) Kumar, A. A brief introduction to Thomas-Fermi model in partial differential equations. 2012. Disponível em ThomasFermi.pdf (mcgill.ca). Acesso em 20/06/2021.

127) Geerlings, P.; De Proft, F.; Langenaeker, W. Conceptual Density Functional Theory. Chemical Reviews 2003, 103, 1793-1873.

128) Colle, R.; Salvetti, O. Approximate calculation of the correlation energy for the closed shells. Theoretica chimica acta 1975, 37, 329-334.

129) Perdew, J. P.; Ruzsinszky, A.; Constantin, L. A.; Sun, J.; Csonka, G. I. Some fundamental issues in ground-state Density Functional Theory: A guide for the perplexed. Journal of Chemical Theory and Computation 2009, 5 (4), 902-908.

130) Howard, A.; Rorres, C. Álgebra linear com aplicações. 8a edição; Bookman: Porto Alegre, 2001; página 240.

131) Pliego Jr., J. R. Modelos contínuos do solvente: fundamentos. Química Nova 2006, 29 (3), 535 542.

132) Pliego Jr., J. R. The role of nonelectrostatic solvation to chemical reactions in liquid phase. Journal of Brazilian Chemical Society 2005, 16 (2), 227-231.

133) Grimme, S. Density functional theory with London dispersion corrections. WIREs Computational Molecular Science 2011, 1 (2), 211-228. 
134) Timakov, A. A.; Prusakov, V. N.; Drobyshevskii, Y. V. Gold heptafluoride. Doklady Akademii Nauk SSSR 1986, 291, 125-128.

135) Himmel, D.; Riedel, S. After 20 years, theoretical evidence that "AuF7" is actually AuF5. $F_{2}$. Inorganic Chemistry 2007, 46, 5338-5342.

136) Kumar, M.; Hammond, G. B.; Xu, B. Cationic gold catalyst poisoning and reactivation. Organic Letters 2014, 16, 3452-3455.

137) Yao, X.; Li, C. Water-triggered and gold(I)-catalyzed cascade addition/cyclization of terminal alkynes with ortho-alkynylaryl aldehyde. Organic Letters 2006, 8 (9), 1953-1955.

138) Czégéni, C. E.; Papp, G.; Kathó, Á.; Joó, F. Water-soluble gold(I)-NHC complexes of sulfonated IMes and SIMes and their catalytic activity in hydration of alkynes. Journal of Molecular Catalysis A: Chemica/ 2011, 340, 1-8.

139) González-Liste, P. J.; García-Garrido, S. E.; Cadierno, V. Gold(I)-catalyzed addition of carboxylic acids tointernal alkynes in aqueous medium. Organic and Biomolecular Chemistry 2017, 15, 16701679.

140) Kozuch, S.; Shaik, S. How to conceptualize catalytic cycles? The energetic span model. Accounts of Chemical Research 2011, 44 (2), 101-110.

141) D’Alessandro, E. V.; Pliego Jr., J. R. Solvent selection for chemical reactions: Automated computational screening of solvents using the SMD model. Química Nova 2018, 41 (6), 628-633.

142) Herbert, J. M. Dielectric continuum methods for quantum chemistry. WIREs Computational Molecular Science 2021, e1519, 11 (4), 1-73.

143) Pliego Jr., J. R.; Riveros, J. M. Hybrid discrete-continuum solvation methods. WIRES Computational Molecular Science 2020, e1440, 10 (2), 1-25.

144) Berkessel, A; Adrio, J. A. Dramatic acceleration of olefin epoxidation in fluorinated alcohols: Activation of hydrogen peroxide by multiple H-bond networks. Journal of the American Chemical Society 2006, 128 (41), 13412- 13420.

145) Berkessel, A.; Adrio, J. A.; Hüttenhain, D.; Neudörfl, J. M. Unveiling the "Booster Effect" of fluorinated alcohol solvents: Aggregation-induced conformational changes and cooperatively enhanced H-bonding. Journal of the American Chemical Society 2006, 128 (26), 8421-8426.

146) Sun, Q.; Hong, P.; Wei, D.; Wu, A.; Tan, K.; Lu, X. Chemoselectivity in gold(I)-catalyzed propargyl ester reactions: Insights from DFT calculations. Frontiers in Chemistry 2019, 7, 1-9. 